Check for updates

Cite this: Nat. Prod. Rep., 2018, 35, 575

\title{
Regulation of antibiotic production in Actinobacteria: new perspectives from the post-genomic era
}

\author{
Helga U. van der Heul, (D) a Bohdan L. Bilyk, (D) ${ }^{\mathrm{b}}$ Kenneth J. McDowall, \\ Ryan F. Seipke (D) b and Gilles P. van Wezel (D) *a
}

\author{
Covering: 2000 to 2018
}

The antimicrobial activity of many of their natural products has brought prominence to the Streptomycetaceae, a family of Gram-positive bacteria that inhabit both soil and aquatic sediments. In the natural environment, antimicrobial compounds are likely to limit the growth of competitors, thereby offering a selective advantage to the producer, in particular when nutrients become limited and the developmental programme leading to spores commences. The study of the control of this secondary metabolism continues to offer insights into its integration with a complex lifecycle that takes multiple cues from the environment and primary metabolism. Such information can then be harnessed to devise laboratory screening conditions to discover compounds with new or improved clinical value. Here we provide an update of the review we published in NPR in 2011. Besides providing the essential background, we focus on recent developments in our understanding of the underlying regulatory networks, ecological triggers of natural product biosynthesis, contributions from comparative genomics and approaches to awaken the biosynthesis of otherwise silent or cryptic natural products. In addition, we highlight recent discoveries on the control of antibiotic production in other Actinobacteria, which have gained considerable attention since the start of the genomics revolution. New technologies that have the potential to produce a step change in our understanding of the regulation of secondary metabolism are also described.

DOI: $10.1039 / c 8 n p 00012 c$ rsc.li/npr

8. Morphological developmental control of antibiotic production

1. Introduction

2. Transcriptional regulation by cluster-situated regulators

2.1. Pathway-specific regulation: streptomycin and actinorhodin as paradigms

2.2. Cross-regulation of disparate BGCs by cluster-situated regulators

3. The impact of phosphate availability on secondary metabolism

4. Regulation of secondary metabolism by nitrogen

5. Control of antibiotic production by the carbon source

5.1. Carbon catabolite repression and the control of antibiotic production

5.2. New insights into the nutrient-sensory DasR system

5.3. Competition between AtrA, Rok7B7 and DasR and connections to CCR

6. Connections between phosphate, nitrogen and carbon metabolism

7. The impact of metals on secondary metabolism

${ }^{a}$ Leiden University, Leiden Institute of Chemistry, 2300 RA Leiden, Netherlands. E-mail: g.wezel@biology.leidenuniv.nl

${ }^{b}$ Faculty of Biological Sciences, Astbury Centre for Structural Molecular Biology, University of Leeds, Leeds, LS2 9JT, UK

9. Autoregulators and the control of antibiotic production

9.1. The gamma-butyrolactone regulatory system in $S$. coelicolor and $S$. avermitilis

9.2. GBL-receptors and antibiotic production in other streptomycetes

10. EMERGING themes in the control of antibiotic production in Actinobacteria

10.1. Control of glycopeptide biosynthesis

10.2. Control of glycopeptide resistance

10.3. $\sigma$-Factor/anti- $\sigma$-factor systems and the control of antibiotic biosynthesis

10.4. Regulation of antibiotic production in Salinispora

10.5. Regulation of rifamycin biosynthesis in Amycolatopsis mediterranei

10.6. GBL-receptors and antibiotic production in Actinobacteria other than Streptomyces

11. Outlook

12. Conflicts of interest

13. Acknowledgements

14. References 


\section{Introduction}

Streptomyces species are renowned for their ability to produce a multitude of bioactive secondary metabolites, some of which have been co-opted clinically as a source of antibacterial, anticancer, antifungal, antiparasitic and immunosuppressive agents. ${ }^{1-5}$ The secondary metabolites produced by this taxon offer a chemical diversity that greatly exceeds that of libraries of compounds synthesized chemically and have been pre-selected through millions of years of evolution to interact effectively with biological targets. With the development of numerous approaches for counter selecting compounds with activities that have been previously characterised and in the case of antibiotics might have been rendered ineffective by the emergence of resistance, natural products are being revisited as a potential source of new pharmaceuticals. ${ }^{6,7}$

The biological role of antibiotics has been a topic of some debate. Whilst antibiotics in the natural habitat are typically regarded as weapons, in the same way as they are used in the clinic, ${ }^{8-10}$ it has been argued that at least some could function

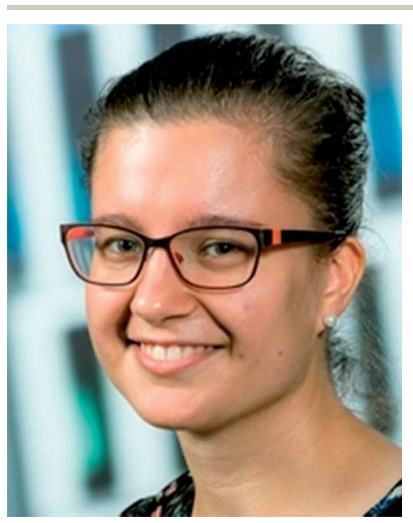

Helga van der Heul, MSc, received her $B S c$ from the Rotterdam University of Applied Sciences, The Netherlands, in 2012 and her MSc in Biology from Leiden University, The Netherlands, in 2014. In the same year she started a position as researcher in the Molecular Biotechnology group led by Prof. Gilles van Wezel. Currently she is a 3rd year PhD student in the same lab, working on the regulation and biosynthesis of natural products in Streptomyces.

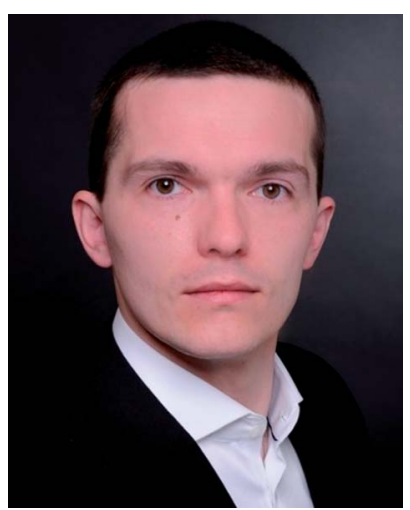

Bohdan Bilyk, PhD, received his $B S c$ and $M S c$ in Biochemistry from Lviv University in 2008. $\mathrm{He}$ then moved to the University of Freiburg, Germany, where he held a DAAD Fellowship for one year. In 2010, he moved to the Helmholtz Institute of Pharmaceutical Research Saarland to begin his PhD thesis under the supervision of Prof. Andriy Luzhetskyy, which he finished in 2014. In the same year he started to work as a research associate at PharmBioTec GmbH on a joint project with Sanofi. In 2016, he joined Dr Seipke's laboratory in the Faculty of Biological Sciences at the University of Leeds. He is currently studying the regulation and biosynthesis of microbial natural products. primarily in cell communication and signalling: ${ }^{11-13}$ The latter view was based largely on the believe that compounds with antibiotic activity are unlikely to reach concentrations in the soil that block growth, as defined by the minimal inhibitory concentration (MIC). However, selection for resistance occurs even at concentrations far below the MIC and antibioticsensitive strains are demonstrably disadvantaged in competing for growth. ${ }^{\mathbf{1 4 - 1 6}}$

The majority of the antibiotics that are used in the clinic are produced by Actinobacteria, which are high $\mathrm{G}+\mathrm{C}$, Grampositive bacteria. Of the Actinobacteria, perhaps the most prolific antibiotic producers are members of the genus Streptomyces, which belong to the family Streptomycetaceae..$^{2,17,18}$

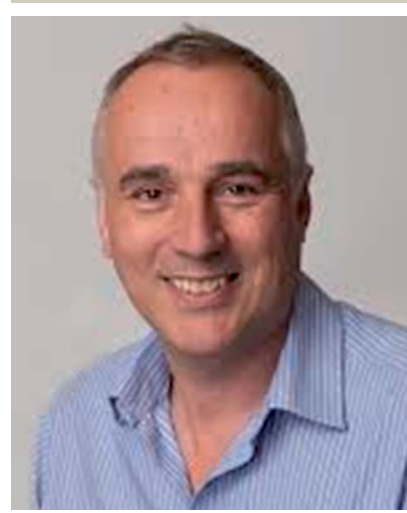

Kenneth J. McDowall is a member of the Astbury Centre for Structural Molecular Biology at the University of Leeds. He graduated with a B.Sc. (Hons) in microbiology from the University of Edinburgh (1987); undertook graduate research in the laboratory of Prof. Iain S. Hunter (then at the University of Glasgow), exploring the regulation of oxytetracycline production in $S$. rimosus and obtaining a Ph.D. in genetics in 1991; and was a postdoctoral researcher in the laboratory of Prof. Stanley N. Cohen at Stanford University, where his interests expanded to include post-transcriptional gene control. In 1996, he was awarded a Royal Society University Research Fellowship and returned to the UK. His current research employs a blend on molecular and 'omics approaches to understand and manipulate gene expression in a range of model bacterial species. He also has a strong interest in student education and currently manages this area for the Faculty of Biological Sciences.

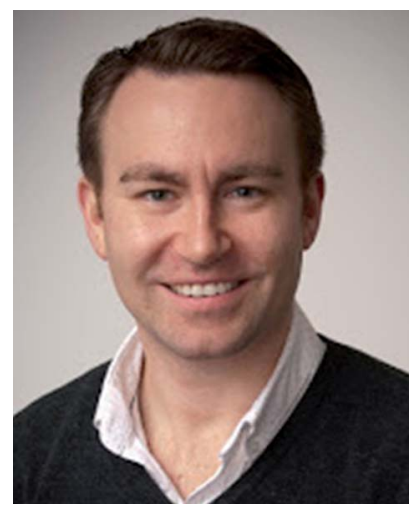

Ryan Seipke, PhD, was awarded his BA in biology from Adrian College in 2003 and his PhD in microbiology from Cornell University in 2008. He then moved to the University of East Anglia to conduct postdoctoral research and in 2013 was appointed to his current post of Assistant Professor in Bacteriology in the Faculty of Biological Sciences at the University of Leeds. His research interests focus on the regulation, biosynthesis and bioengineering of microbial natural products. 
Streptomycetes are found in environments with varying nutrient supply, and metabolise a variety of carbon, nitrogen and phosphate sources. To respond appropriately to the challenges imposed by the environment, the genome of the model streptomycete $S$. coelicolor harbours a staggering 700 regulatory genes. ${ }^{\mathbf{1 9}}$ Streptomycetes have a multicellular life cycle, which culminates in sporulation. The reader is referred elsewhere for details of this process. $^{20-24}$ In brief, streptomycetes grow as non-motile, vegetative hyphae to produce a network of interwoven filaments called vegetative mycelium. When reproduction is required, for example at the time when nutrients run out, the vegetative mycelium acts as a substrate for newly formed aerial hyphae that eventually differentiate into chains of unigenomic exospores.

Genes required for the transition from vegetative to aerial growth are typically referred to as bld genes, referring to their bald phenotype, due to their failure to produce the fluffy white aerial hyphae. ${ }^{25}$ Mutants that produce aerial hyphae but no spores are referred to as whi mutants, for their white phenotype caused by the lack of the grey spore pigment. ${ }^{26}$ Many of the bld and whi mutants that had been isolated in the 1970s by phenotypic screening have later been identified by genetic complementation experiments, and they have been instrumental in providing better insights into the regulatory cascades that control morphological differentiation. For details we refer the reader to excellent reviews elsewhere.,.$^{2,23,27-30}$

Production of bioactive compounds is typically linked to the developmental lifecycle, and antibiotics are presumably produced to safeguard the nutrient supply during developmental growth. ${ }^{31-33}$ Streptomycetes produce an arsenal of degradative enzymes (e.g. glycosyl hydrolases, lipases and proteases), which combined with the production of antibiotics

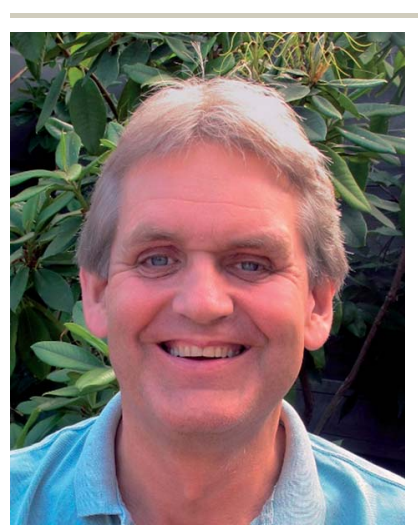

Gilles van Wezel is Professor of Molecular Biotechnology at the Institute of Biology, Leiden University. He is also distinguished professor at the Netherlands Ecology Institute (NIOOKNAW) in Wageningen. He studied Chemistry at the Free University in Amsterdam and obtained his PhD in the lab of Prof. Leendert Bosch at Leiden University in 1994, on the control of protein biosynthesis. He did his postdoc at the John Innes Centre in Norwich with Prof. Mervyn Bibb, on the control of sugar metabolism. He obtained a fellowship from the Netherlands Royal Academy for Arts and Sciences (KNAW) in 2000 and co-founded the Biotech company Mycobics BV in 2001. He obtained a full professorship in 2010. In 2011 his lab developed the practical Antibiotica Gezocht! (Wanted: Antibiotics!), to allow high school pupils to identify antibiotics produced by Actinobacteria in the classroom. His current research focuses on the biology of Actinobacteria and on approaches to discover novel antibiotics and anticancer compounds that should find their way to the clinic. and the ability to form desiccation-resistant exospores has facilitated their success in a multitude of soil environments and sediments including those of marine and freshwater ecosystems. The competitive attributes possessed by streptomycetes have not gone unutilised by higher organisms. For instance, it has become clear that many insects, animals and plants engage in protective symbioses with antibiotic-producing Streptomyces species (reviewed in ref. 34 and 35). However, not all interactions between streptomycetes and higher organisms are beneficial - a minority of species produce a cellulose synthase inhibitor called thaxtomin and a coronafacic acid-like phytotoxin, which lead to the development of scab diseases on potato and other tap-root crops. ${ }^{36,37}$

Over the past 50 years, $S$. coelicolor has been the major model for the study of antibiotic production and its control. Early on it was apparent that this strain produced numerous natural products, including actinorhodin $\left(\mathrm{Act}^{38}\right)$, undecylprodigiosin $\left(\operatorname{Red}^{39}\right)$, the calcium-dependent antibiotic $\left(\mathrm{Cda}^{\mathbf{4}}\right)$ and plasmid-encoded methylenomycin $\left(\mathrm{Mmy}^{\mathbf{4 1}}\right)$. The genes that encode the machinery for the production of these respective antibiotics are clustered together in 'biosynthetic gene clusters' (BGCs), which typically also harbour resistance gene(s) and one or more transcriptional regulators that control biosynthesis. Sequencing of the S. coelicolor genome was a landmark event that revealed an unexpected potential for the production of hitherto unidentified or cryptic natural products, ${ }^{19}$ with more than 20 BGCs specifying a diverse range of secondary metabolites. ${ }^{\mathbf{4 2 , 4 3}}$ One of these is a so-called cryptic polyketide antibiotic (later named coelimycin), which is only produced under specific growth conditions. ${ }^{\mathbf{4 4 , 4 5}}$ Sequencing of other model Actinobacteria revealed a similar picture, with some species harbouring more than 50 different BGCs. ${ }^{46-51}$ Thus, the potential of Actinobacteria as producers of bioactive molecules was found to be much greater than was initially thought. This prompted the sequencing and analysis of the genomes of a large array of species to identify novel BGCs (reviewed in ref. 52-55) plus the development of approaches to induce the production of natural products under laboratory conditions. ${ }^{1,56-59}$ The identification of BGCs is now relatively routine using bioinformatics tools, such as antiSMASH, ${ }^{60}$ CLUSEAN $^{61}$ and PRISM. ${ }^{62}$ Available also are tools for the identification of BGCs corresponding to specific classes of natural product, e.g. NRPSPredictor for nonribosomal peptides, ${ }^{63}$ BAGEL for bacteriocins and lantibiotics $^{64}$ and SEARCHPKS for polyketides. ${ }^{65}$ For a comprehensive overview of the available bioinformatic tools for genome mining we refer the reader to excellent reviews elsewhere. ${ }^{66,67}$

This review is intended to be an update to our comprehensive review on the same subject published in this journal in $2011 .^{33}$ The broad subject is covered, but in the interest of limiting duplicated content, the reader is often referred to our previous review. Here, the focus lies on recent insights into the regulation of natural product biosynthesis in streptomycetes, based on the literature from the period of 2011-2017. The article focuses on both pleotropic and cluster-situated regulators, highlighting recent discoveries. We thereby give specific attention to the control of antibiotic production in other Actinobacteria. We also provide an update on our understanding of the links between primary and secondary metabolism and 
ecological triggers that stimulate natural product biosynthesis, and outline methodology that could be used to activate silent or cryptic natural product biosynthetic pathways.

\section{Transcriptional regulation by cluster-situated regulators}

Over the last several decades, investigations into the regulation of the antibiotics produced by S. coelicolor (Act, Red, Cda, Mmy and coelimycin) and that of streptomycin biosynthesis by $S$. griseus have established key aspects of the regulation of secondary metabolism in Streptomyces. For details we refer to reviews elsewhere. ${ }^{31-33}$ The regulation of secondary metabolism is complex and frequently involves pleotropic global regulators that either directly activate or repress biosynthetic genes or do so via cluster-situated repressors or activators. A plethora of regulatory proteins is involved in the control of antibiotic production, across a broad range of regulator families. And crossregulation results in a highly complex regulatory network. This is necessary to correctly interpret the environmental signals and translate them into appropriate transcriptional responses, so as to time the production of natural products, often closely connect to development. The different families of transcriptional regulators known to be involved in the control of antibiotic production, and some well-studied examples, are provided in Table 1.

The regulation of the BGCs for actinorhodin (Act; controlled by ActII-ORF4), undecylprodigiosin (Red, controlled by RedD) and calcium-dependent antibiotic (Cda, controlled by CdaR) of S. coelicolor and for streptomycin (Str, controlled by StrR) are the most well-studied examples of cluster-situated regulators (CSRs). ActII-ORF4, CdaR and RedD belong to the SARP family of Streptomyces antibiotic regulatory proteins, ${ }^{68}$ while StrR unusually belongs to the family of ParB-Spo0J proteins, most of which are involved in DNA segregation and sporulation. ${ }^{69}$ All available evidence supports the conclusion that the cellular level of a cluster-situated regulator dictates the level of transcription of its cognate BGC, which correlates closely with the level of production of the corresponding natural product. ${ }^{70,71}$ Indeed, the timing of Red production fully depends on the promoter that drives the transcription of $\operatorname{red} D$, allowing its use as a transcriptional reporter system. ${ }^{72}$ Thus, the ultimate factor deciding whether or not a BGC is expressed is its $\operatorname{CSR}(\mathrm{s})$. While ActII-ORF4 and StrR act as single CSRs within their respective BGCs, production of RedD is in turn controlled by RedZ, ${ }^{73,74}$ which is related to the response regulators (RR) of prokaryotic two-component systems (TCS) but 'orphaned', i.e. not genetically linked to a histidine kinase ${ }^{75}$ It is becoming increasingly clear that the presence of multiple CSRs is more often the rule than the exception with each regulator effecting control of a subsets of genes or contributing to a hierarchical cascade. The latter is exemplified by the BGCs specifying polyene antifungal compounds such as amphotericin, nystatin, natamycin (pimaricin) and candicidin. ${ }^{76-79}$ It has been assumed and, in some cases, shown that many regulators are responsive to small molecule signals. Regulators responsive to autoregulatory molecules such as $\gamma$-butyrolactones are well known, ${ }^{80,81}$ and feedback control by biosynthetic intermediates over production or export has been demonstrated for jadomycin, Act and simocyclinone biosynthesis. ${ }^{82-84}$ However, the identity of the ligands/signals perceived by both pleotropic and CSRs is a major question within the field, and if answered could lead to a revolution in chemical genetic tools for the stimulation of natural product biosynthesis, and thus drug discovery.

\subsection{Pathway-specific regulation: streptomycin and actinorhodin as paradigms}

The first complete regulatory pathway leading to activation of a BGC was described for Str in S. griseus. ${ }^{85}$ Transcription of StrR, which as mentioned above is the corresponding CSR, is activated by the pleiotropic regulator AdpA (A-factor-dependent protein) $;{ }^{86}$ whose transcription depends on the accumulation of the $\gamma$-butyrolactone 2-isocapryloyl-3R-hydroxymethyl- $\gamma$ butyrolactone, better known as A-factor. The hormone-like compound binds to ArpA ${ }^{87}$ which acts as a repressor of adpA transcription..$^{88}$ AdpA also activates morphological differentiation, and thus plays a key role in the coordination of chemical and morphological differentiation. ${ }^{89,90}$ A-Factor is synthesized by the enzyme AfsA. ${ }^{91}$ The role of A-factor in the control of antibiotic biosynthesis is further discussed in Section 9.

The transcription of $s t r R$ is subject to multi-level control, and in particular by the pleiotropic regulator AtrA, ${ }^{92,93}$ which has an orthologue in S. coelicolor that activates transcription of act IIORF4, the CSR within the act cluster. ${ }^{94}$ Binding of AtrA in vivo within the vicinity of the actII-ORF4 promoter has recently been confirmed by chromatin immunoprecipitation in combination with DNA sequencing (ChIP-seq) (McDowall et al., unpubl. data). Compared to what is known about strR, the control of actII-ORF4 is complex with many transcription factors reported to control its expression directly. Numerous direct and indirect regulators have been identified..$^{32,33}$ Some of the most recent examples are summarized in Table 2. For some of these transcription factors, binding has been demonstrated in vivo by ChIP-based approaches. In addition to AtrA, these include DasR, ${ }^{95}$ a member of the GntR family that controls the uptake and metabolism of $N$-acetylglucosamine (GlcNAc) and the degradation of chitin to GlcNAc, ${ }^{96,97}$ AbsA2, ${ }^{98}$ the response regulator of the AbsA TCS, which negatively controls antibiotic production in S. coelicolor, ${ }^{99,100} \mathrm{AbrC} 3,{ }^{101}$ a response regulator of a TCS that is atypical in having two histidine kinases, ${ }^{102}$ and Crp ${ }^{103}$ the cyclic AMP receptor protein, which is perhaps best known for mediating carbon catabolite repression of the lac operon in $E$. coli ${ }^{104}$ controls diverse cellular processes in many bacteria, ${ }^{105}$ and is a key regulator of secondary metabolism as well as spore germination and colony development in S. coelicolor. ${ }^{106}$ In addition to direct regulation, the expression of actIIORF4 is dependent on relA, ${ }^{107}$ which is required for induction of the stringent response. The stringent response enables bacteria to survive sustained periods of nutrient deprivation by enhancing the transcription of numerous genes required to survive stress, while lessening transcription of genes, such as those specifying stable RNAs, whose products are required in significantly reduced amounts during periods of slowed 
Table 1 Major families of regulators involved in the control of antibiotic production. Representative examples and their host and target are indicated

\begin{tabular}{|c|c|c|c|c|c|}
\hline Family $^{d}$ & Example & Host $^{a}$ & Control $^{b}$ & Target $\mathrm{BGC}^{c}$, comment & Reference \\
\hline \multirow[t]{3}{*}{ SARP } & $\begin{array}{l}\text { ActII-ORF } 4, \\
\text { RedD, CdaR }\end{array}$ & S. coelicolor & $(+)$ & Act, Red, Cda, respectively & 68 \\
\hline & AfsR & S. coelicolor & $(+)$ & Activates transcription of AfsS & 138 \\
\hline & FarR3/Far4 & S. lavendulae & $(+,-)$ & Indigoidine, nucleoside and D-cycloserine & 299 \\
\hline StrR & StrR & S. griseus & $(+)$ & Streptomycin & 391 \\
\hline \multirow[t]{2}{*}{ (ParB-Spo0J) } & Tei15* & Actinoplanes teichomyceticus & $(+)$ & Teicoplanin & 332 and 335 \\
\hline & Dbv4 & Nonomuraea sp. ATCC39727 & $(+)$ & A40926 & 330 and 336 \\
\hline \multirow[t]{3}{*}{ LAL } & FscRI & S. albus & $(+)$ & Candicidin and antimycin & 121 \\
\hline & Aver & S. avermitilis & $(+,-)$ & Avermectin and oligomycin & 392 \\
\hline & Dbv3 & Nonomuraea sp. ATCC39727 & $(+)$ & A40926 & 330 \\
\hline \multirow[t]{3}{*}{ TetR } & AtrA & S. griseus & $(+)$ & Global regulator & 92 \\
\hline & ArpA & S. griseus & $(-)$ & GBL receptor, repressor of $a d p A$ & 86 \\
\hline & ScbR & S. coelicolor & $(+,-)$ & GBL receptor & 143 \\
\hline AraC/Xyls & AdpA & S. griseus & & Activates StrR expression & 90 \\
\hline GntR & DasR & S. coelicolor & $(+,-)$ & $\begin{array}{l}\text { Global regulator of antibiotic production; } \\
\text { effector molecule is } N \text {-acetylglucosamine }\end{array}$ & 95 and 194 \\
\hline $\begin{array}{l}\text { c-AMP receptor } \\
\text { protein }\end{array}$ & Crp & S. coelicolor & $(+)$ & $\begin{array}{l}\text { Regulator coordinating development, } \\
\text { primary and secondary metabolism }\end{array}$ & 103 \\
\hline \multirow[t]{2}{*}{ Orphan RR } & RedZ & S. coelicolor & $(+)$ & Red & 73 \\
\hline & $\mathrm{GlnR}$ & S. coelicolor & $(+)$ & Act and Red & 145 and 151 \\
\hline \multirow[t]{5}{*}{ TCS } & AbsA1/AbsA2 & S. coelicolor & $(-)$ & Act, Red, Cda & 98 \\
\hline & AfsQ1/2 & S. coelicolor & $(+)$ & Act, Red, Cda; responds to nitrogen & 111 \\
\hline & PhoRP & S. coelicolor & $(+,-)$ & Act; global regulator & 129 and 230 \\
\hline & DraR/K & S. coelicolor & $(+,-)$ & $\begin{array}{l}\text { Act, Red, coelimycin, responds to high } \\
\text { concentrations of nitrogen }\end{array}$ & 113 \\
\hline & OsdR/K & S. coelicolor & $(+)$ & Act, responds to oxygen level & 112 \\
\hline ROK & Rok7B7 & S. coelicolor & $(+,-)$ & Act, Red, Cda; CCR & 209 and 210 \\
\hline \multirow[t]{2}{*}{$\sigma$ Factor } & MibX/MibW & Microbispora corallina & $(+)$ & Microbisporicin & 350 and 352 \\
\hline & AntA & S. albus & $(+)$ & Antimycin & 359 \\
\hline BldB & BldB & S. coelicolor & $(+)$ & Antibiotic production, development and CCR & $187-189$ \\
\hline tRNA & BldA & Streptomyces species & & $\begin{array}{l}\text { Leucine-tRNA for UAA codon. Translational } \\
\text { control of antibiotic production } \\
\text { and morphogenesis }\end{array}$ & 393 \\
\hline XRE & MmyB & S. coelicolor & $(+)$ & Methylenomycin B; controlled by furans & 286 and 394 \\
\hline $\begin{array}{l}\text { Wbl (WhiB-like } \\
\text { protein) }\end{array}$ & WblA & S. coelicolor & $(-)$ & $\begin{array}{l}\text { Pleiotropic regulator of antibiotic } \\
\text { production and development }\end{array}$ & 395 \\
\hline LacI & AcrC & Actinoplanes sp. SE50/110 & $(-)$ & Acarbose & 396 \\
\hline $\mathrm{LmbU}$ & & S. lincolnensis & $(+,-)$ & Lincomycin & 397 and 398 \\
\hline Lrp/AsnC & SCO3361 & S. coelicolor & $(+)$ & Act; control by amino acids & 399 \\
\hline NsdA & NsdA & S. coelicolor & $(-)$ & Act, Cda, Mmy & 400 \\
\hline IclR & NdgR & S. coelicolor & - & Act; dependent on amino acids & 401 \\
\hline MarR & DptR3 & S. roseosporus & + & Daptomycin & 402 \\
\hline
\end{tabular}

${ }^{a}$ Streptomyces abbreviated with ' $S .{ }^{\prime} .{ }^{b}$ Activation indicated by + , repression by.$-{ }^{c}$ Act, actinorhodin; Cda, calcium-dependent antibiotic; Red, prodiginines; Mmy, methylenomycin. ${ }^{d}$ LAL, large ATP-binding regulators of the LuxR family (in the text mentioned as LuxR); XRE, xenobiotic response element.

growth. ${ }^{108,109}$ Whilst the signals transduced by Crp and the stringent response are well described, the signals sensed or transduced by most of the transcription factors that bind the actII-ORF4 promoter remain to be elucidated. An exception is DasR, which is a receptor for glucosamine-6-phosphate (GlcN$6 \mathrm{P}$ ), an intermediate in GlcNAc metabolism, and derivatives. ${ }^{97}$ The binding of GlcN-6P by DasR reduces its affinity for DNA, which de-represses the expression of genes that facilitate the degradation of chitin to GlcNAc and its uptake and metabolism. ${ }^{96,97}$ Links between DasR and AtrA are described later in this review (Section 5.3).

In addition to AraC and AbsA, several other TCSs regulate secondary metabolism in $S$. coelicolor and other
Actinobacteria. ${ }^{110-113}$ TCSs are the major signal-transduction systems of bacteria and enable them to monitor and adapt to environmental changes. ${ }^{11,115}$ Streptomycetes harbour a large number of TCSs, which likely reflects the changing and variable nature of their natural habitats. ${ }^{19,110,116}$ The PhoRP TCS system is ubiquitous in bacteria and senses phosphate and regulates its assimilation. PhoRP plays a major role in the control of antibiotic production in streptomycetes. ${ }^{117-119}$ Similar has been found for the AfsQ1/2 TCS, which controls the biosynthesis of Act, Red and Cda in response to nitrogen limitation ${ }^{111}$ via what appears to be direct interaction with the promoter regions of actII-ORF4, redZ (which activates redD) and $c d a R$, respectively. The AfsQ1/2 TCS is closely related to CseBC, which responds to 
Table 2 Recently discovered transcriptional regulators that control antibiotic production in S. coelicolor. Orthologues also studied in S. avermitilis or S. venezuelae are indicated

\begin{tabular}{|c|c|c|c|}
\hline Gene & $\mathrm{ID}^{a}$ & Function(s) of the regulator(s) ${ }^{b}$ & Ref. \\
\hline \multicolumn{4}{|c|}{ Regulators known to directly control antibiotic BGCs } \\
\hline mtraB & SCO3013/2; SVEN2756/5 & TCS; MtrA activates actII-ORF4 and redZ and links their production to development & 403 \\
\hline & SCO3361 & Lrp/AsnC family positive regulator for Act production. Binds to actII-ORF4 (EMSA) & 399 \\
\hline crp & SCO3571 & Regulator of primary and secondary metabolism; activates actII-ORF4, $c d a R$ and $c p k A$ (Chip-seq) & 103 \\
\hline abrC1C2C3 & SCO4596 & $\begin{array}{l}\text { Atypical TCS with two kinase (C1 and C2); response regulator AbrC3 is a transcriptional } \\
\text { activator of actII-ORF4 (ChIP-chip); impacts Red production }\end{array}$ & 101 \\
\hline \multirow[t]{2}{*}{$\operatorname{lex} A$} & SCO5803 & Global regulator of the DNA damage response; repressor of actII-ORF4 (EMSA) & 404 \\
\hline & SCO6256 & $\begin{array}{l}\text { GntR family regulator of antibiotic production. Direct activator of } c d a R \text { and indirect } \\
\text { repressor of Act production (EMSA) }\end{array}$ & 405 \\
\hline $\operatorname{scbR2}$ & SCO6286 & $\begin{array}{l}\text { Activator of } a c t \mathrm{II}-\mathrm{ORF} 4, \mathrm{redD}, \mathrm{red} Z \text { and } c d a R \text {, repressor of } c p k O \text { and SCO6268 } \\
\text { (cpk cluster) (Chip-seq, EMSA) }\end{array}$ & 143 \\
\hline \multirow[t]{2}{*}{ abra1A2 } & SCO1744/5 & TCS; represses Act, Red and Cda production and morphological differentiation & 237 \\
\hline & SCO2140 & $\begin{array}{l}\text { Lrp/AsnC family protein. Indirectly regulates ACT and CDA production or cooperate } \\
\text { with other transcriptional regulators involved in production of these antibiotics (EMSA) }\end{array}$ & 407 \\
\hline aor1 & SCO2281 & $\begin{array}{l}\text { Orphan response regulator; upregulates Act, Red and Cda production and downregulates } \\
\operatorname{sig} B \text {, thus linking antibiotic production to osmotic stress response }\end{array}$ & 408 \\
\hline $\operatorname{stg} R$ & SCO2964 & $\begin{array}{l}\text { LTTR; negative regulator for Act and Red production trough upregulation of actII-ORF4 } \\
\text { and redZ, respectively. Exact regulatory cascade remains unknown }\end{array}$ & 409 \\
\hline $\operatorname{sig} T$ & SCO3892 & ECF sigma factor; required for normal Act production under nitrogen limitation & 358 \\
\hline CIAABCDEF & SCO4126-SCO4131 & Operon for membrane proteins; affects differentiation and causes increased production of Act & 410 \\
\hline phou & SCO4228 & Activates Act and Red production. Exact regulatory cascade unknown & 411 \\
\hline
\end{tabular}

cell-envelope stress. $^{75}$ Recently, it was shown that the DraRK TCS, which responds to high concentrations of nitrogen, ${ }^{\mathbf{1 1 3}}$ and the OsdRK TCS, which is oxygen-responsive, are similar in function to the system controlling dormancy in mycobacteria, ${ }^{\mathbf{1 1 2 , 1 2 0}}$ and are both required for Act production. Interestingly, in the absence of a functional DraRK system the production of Cpk and Red increases. ${ }^{113}$ The AbsA system has been exploited to improve the chance of success during screening of streptomycetes for new antibiotics by overexpression of the $S$. coelicolor homologue in other streptomycetes; this led among others to the induction of pulvomycin production in $S$. flavopersicus. Cross-talk between the different regulatory networks is discussed in Sections 5 and 6.

\subsection{Cross-regulation of disparate BGCs by cluster-situated regulators}

It is well established that a CSR usually binds to promoter sequence(s) and either activates or represses genes only within its cognate BGC. For examples see Tables 1 and 2. However, this is not strictly true for all CSRs. Recently, the PAS-LuxR family cluster-situated regulator within the candicidin BGC was shown to not only activate 16 out of the 21 genes in the gene cluster, but also to be required for expression of the antimycin BGC. ${ }^{\text {79,121 }}$ Thus, antimycin and candicidin biosynthesis are co-ordinately controlled by FscRI in S. albus. ${ }^{\mathbf{1 2 1}}$ A similar observation was made in $S$. avermitilis, where PteF, a member of PAS-LuxR family and cluster-situated activator of the filipin BGC, was proposed to cross-regulate the production of oligomycin. ${ }^{122}$ Thus, evidence is accumulating, at least for PAS-LuxR family regulators, that they may not in fact simply be CSRs but act more broadly to co-ordinately control the biosynthesis of multiple compounds. This is likely rooted in the flexible inverted repeat the family of regulators appears to bind to both in vitro and in vivo. ${ }^{121,123}$ It is an obvious and attractive hypothesis that production of secondary metabolites with antimicrobial properties or subsets thereof should be coordinated, so as to maximise any synergistic activity and minimise the development of resistance to the agents produced.

\section{The impact of phosphate availability on secondary metabolism}

The impact of phosphate availability on bacterial physiology and gene expression in particular has been intensely studied in 
Streptomyces species and other bacteria. ${ }^{\mathbf{1 2 4 - 1 2 7}}$ Expression of a suite of genes involved in phosphate management termed the pho regulon is controlled by the PhoRP TCS. ${ }^{116,128,129}$ During phosphate starvation, the membrane-bound sensor kinase, PhoR, undergoes autophosphorylation and transfers its phosphate group to the response regulator, $\mathrm{PhoP}^{\mathbf{1 1 9 , 1 3 0}}$ (Fig. 1). The phosphorylated form of PhoP (PhoP-P) binds to a well conserved DNA motif called a PHO box and can either activate or repress expression of genes within the pho regulon. ${ }^{118}$ During growth in phosphate replete conditions, PhoR is prevented from phosphorylating PhoP via physical interaction with the phosphate-specific transport (Pst) system, a high-affinity phosphate transport system whose production is activated by PhoR. ${ }^{118,131,132}$ This interaction creates a regulatory loop in which the Pst system is produced at a low level during conditions of phosphate sufficiency. When phosphate levels drop, PhoR is released and phosphorylates PhoP, which then activates transcription of genes within the Pst system and the other genes within the pho regulon. ${ }^{118}$ The precise signal that frees PhoR to phosphorylate PhoP is unknown, but it is known that the switch is reversible.

It has been known for some 15 years that deletion of phoP can lead to earlier and increased production of antibiotics. ${ }^{\mathbf{1 1 9}}$ This phenomenon was covered in our previous review ${ }^{33}$ and for $S$. coelicolor was rooted in destabilization of a negative regulatory loop involving the AfsKRS system. ${ }^{\mathbf{1 3 3 , 1 3 4}}$ AfsR is a transcription factor related to SARPs that when phosphorylated by AfsK activates transcription of the gene encoding AfsS, a small sigma factor-like protein required for antibiotic biosynthesis in $S$. coelicolor. ${ }^{\mathbf{1 3 5 - 1 3 8}}$ In the proposed regulatory loop, PhoP represses the production of AfsS and AfsR represses the production of PhoRP and the Pts system. ${ }^{\mathbf{1 3 5}}$ However, recently PhoP was shown to in fact be an activator of afs $S$ transcription in experiments using a full panel of $p h o P$, afsR and afsR/phoP mutants and a suite of synthetic promoters engineered to prevent AfsR binding but not PhoP binding. ${ }^{139}$ In a revised model, PhoP hinders higher activation of afs $S$ transcription by AfsR by outcompeting AfsR for binding to the afsS promoter (Fig. 1). ${ }^{\mathbf{1 3 5 , 1 3 9}}$

A series of ChIP-Chip experiments were conducted with $S$. coelicolor, which provided genome-wide insight into the role of PhoPR in controlling secondary metabolism. ${ }^{\mathbf{1 4 0}}$ These revealed that PhoP serves as a master regulator of secondary metabolism during phosphate starvation, whereby it transiently represses pleotropic activators of antibiotic production and regulators of morphological development, namely bldA, which specifies the leucine tRNA corresponding to the rare UUA codon, and $s c b A R$, which encodes the $\gamma$-butyrolactone regulatory system of $S$. coelicolor that positively influence morphological development, and Act and Red biosynthesis. ${ }^{\mathbf{1 4 1 , 1 4 2}}$ Interestingly, the ScbAR system also indirectly controls the gene expression of $s c b R 2$ whose gene product activates afsK expression, ${ }^{\mathbf{1 4 3}}$ which is the cognate sensor kinase responsible for activating the global regulator of secondary metabolism, AfsR (mentioned above). Thus, although PhoP activates expression of afs $S$, it also indirectly represses transcription of afsK, which means AfsR remains unphosphorylated and inactive (Fig. 1).

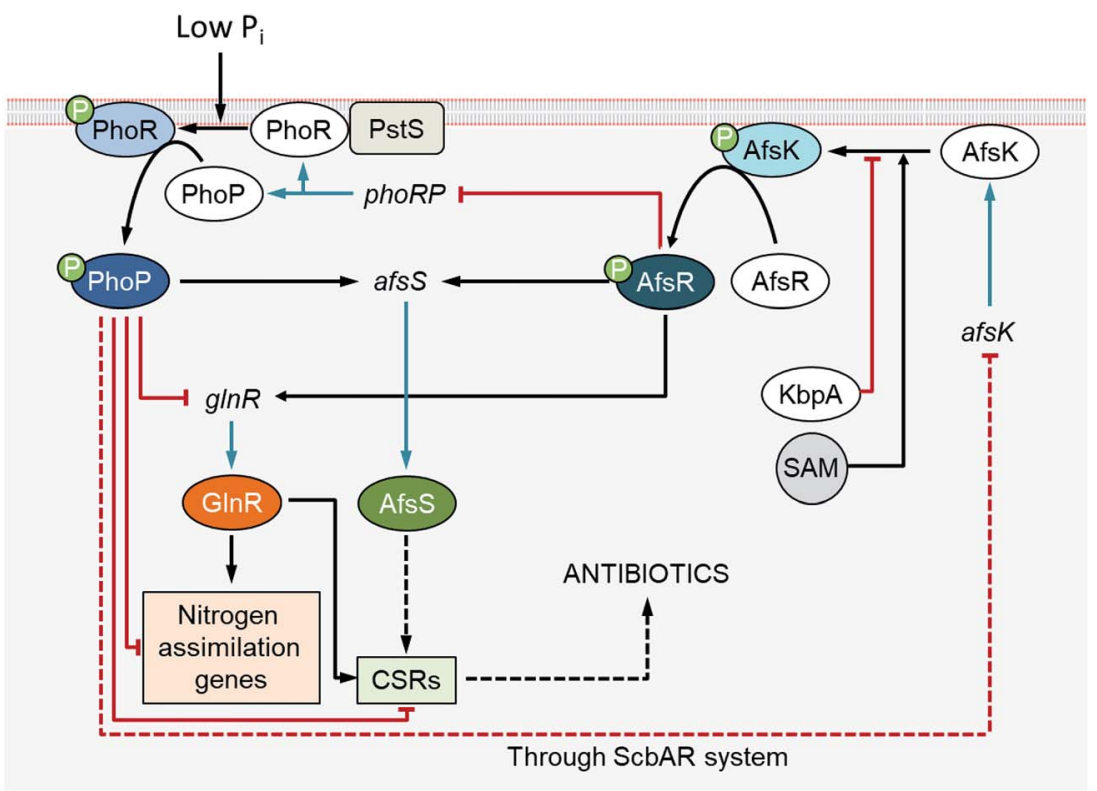

Fig. 1 The PhoRP and AfsKRS systems and their interplay in regulation of nitrogen metabolism and antibiotic production. Black arrows indicate activation and red bars indicate repression, cyan arrows indicate expression of genes. During growth under phosphate deplete conditions, the global regulator PhoP is activated by the membrane-bound sensor kinase, PhoR. Activated PhoP acts directly upon BGCs by modulating expression of CSRs or other transcription factors, such as glnR, which controls expression of nitrogen metabolism genes and afsS, part of AfsKRS regulatory system. PhoP may directly inhibit expression of nitrogen assimilation genes and has an indirect negative impact (through ScbAR system) on expression of afsK. KbpA and S-adenosyl-L-methionine (SAM) can also modulate the activity of AfsK. The membrane associated kinase, AfsK, in turn, activates AfsR. AfsR interacts with the PhoP in several ways: it can directly repress expression of the phoRP regulon, compete for activation of afs $S$ or as activator of $g \ln R$ expression can upregulate expression of the genes responsible for nitrogen assimilation. 
Although there are only a handful of example thus far, it is clear that in addition to controlling pleotropic regulators, PhoP can also act directly upon BGCs. For example, in $S$. coelicolor, PhoP negatively regulates the biosynthesis of Cda by repressing the $c d a R$ gene. ${ }^{\mathbf{1 4 0}}$ Interestingly, the inverse seems to be the case for the BGC specifying coelimycin where there are three PHO boxes within the DNA sequence of two structural genes and expression of the gene cluster appears to be PhoP-dependent. ${ }^{\mathbf{1 4 0}}$ Direct regulation of biosynthetic pathways by $\mathrm{PhoP}$ is not a peculiarity of $S$. coelicolor, as PhoP was recently shown to negatively regulate avermectin biosynthesis by repressing the expression of aveR, which encodes a clustersituated activator. ${ }^{143}$

\section{Regulation of secondary metabolism by nitrogen}

The uptake and incorporation of nitrogen is essential for anabolism of amino acids, nucleic acids and peptidoglycan, among other important macromolecules. S. coelicolor can utilise diverse nitrogen sources including ammonia, nitrate, nitrite, urea, amino sugars and amino acids. ${ }^{144-146}$ Assimilation of nitrogen results in the production of glutamate and glutamine, which act as the primary nitrogen donors within the cell. ${ }^{147}$ Like other bacteria, Streptomyces species possess a sophisticated regulatory system that enables adaptation to nitrogen availability. Many studies have indicated that the source of nitrogen can influence the production of secondary metabolites. The production of most of the secondary metabolites is reduced by nitrogen sources that are favourable for growth. ${ }^{\mathbf{1 4 8 , 1 4 9}}$ This is presumably because utilization of a high-quality nitrogen source (e.g. ammonium) causes more of the available carbon to be consumed for growth and generation of biomass and thus ultimately less carbon is available for secondary metabolism when starvation occurs. Although the above has been known for a long time, the underpinning molecular detail has taken longer to elucidate. The global regulator controlling nitrogen metabolism is GlnR, which is an orphan response regulator without a cognate sensor kinase (Fig. 1). ${ }^{\mathbf{1 4 5 , 1 5 0}}$ Deletion of $g \ln R$ in $S$. coelicolor blocks production of Act and Red. ${ }^{151}$ GlnR-mediated regulation of Act and Red production was assumed to be indirect until a recent study demonstrated otherwise. In vitro DNA binding and DNaseI footprinting studies showed that GlnR binds the promoter sequence of CSRs within these BGCs (actII-ORF4 and redZ, respectively), implying that GlnR regulation is direct. ${ }^{152}$ In the same study, direct regulation of CSRs of avermectin and oligomycin biosynthesis (aveR and olmRI/ $R I I$, respectively) by GlnR in $S$. avermitilis was also demonstrated; thus, direct regulation of a subset of natural product BGCs by GlnR is likely to be universal. ${ }^{\mathbf{1 5 2}}$ Several studies have recently been conducted that have enhanced the understanding of nitrogen metabolism and its interconnectedness with phosphate and carbon utilization. These connections and their implications for secondary metabolism are further discussed in Section 6.

\section{Control of antibiotic production by the carbon source}

\subsection{Carbon catabolite repression and the control of antibiotic production}

In the natural environment, the availability of high-energy carbon sources, for instance, glucose, promotes vegetative growth and suppresses morphological and chemical differentiation. ${ }^{153,154}$ Examples of antibiotics whose production is repressed by glucose include Act in $S$. coelicolor, ${ }^{\mathbf{1 5 5 , 1 5 6}}$ chloramphenicol in S. venezuelae, ${ }^{157}$ Str in $S$. griseus, ${ }^{\mathbf{1 5 8}}$ and erythromycin in Saccharopolyspora erythraea. ${ }^{159,160}$ Like in most bacteria, carbon utilization by streptomycetes is controlled by carbon catabolite repression (CCR), which ensures that high-energy carbon sources such as glucose, fructose or TCA cycle intermediates are utilized preferentially over energetically less favourable ones, such as lactose, glycerol or mannitol. The best studied system is CCR by glucose, which is often referred to as glucose repression. ${ }^{\mathbf{1 6 1 - 1 6 4}}$

In most bacteria, glucose is transported through the phosphoenolpyruvate-dependent phosphotransferase system or PTS. The PTS encompasses Enzyme I (EI) and phosphocarrier protein HPr in combination with carbohydrate-specific transport complexes called Enzyme II (EII), which confer substrate specificity. ${ }^{165,166}$ As a result, the PTS typically plays a key role in glucose repression. ${ }^{104,167,168}$ However, in Streptomyces species, deletion of either of the genes $p t s H$, ptsI or crr for HPr, EI and EIIA, respectively, has no influence on CCR, but instead leads to a block in morphological differentiation, with mutants failing to produce aerial hyphae and/or spores on a reference medium such as R2YE agar. ${ }^{97,169}$ This sporulation defect is surprising and may be associated with lack of iron and/or copper in this medium, accompanied by a reduced production of the siderophore, desferrioxamine. ${ }^{\mathbf{1 7 0 - 1 7 2}}$ This link between carbon availability, iron homeostasis and morphological differentiation has not yet been resolved. The limited role of the PTS in CCR may be explained by the fact that in streptomycetes, glucose is internalized via the GlcP permease, which belongs to the major facilitator subfamily of transporters. ${ }^{\mathbf{1 7 3 - 1 7 5}}$ For a summary of central carbon metabolism and CCR, see Fig. 2.

It was recognized many decades ago that randomly generated mutants lacking CCR are invariably mutated in the gene glkA, which encodes a glucose kinase. ${ }^{\mathbf{1 7 6 , 1 7 7}}$ Indeed, a targeted deletion of glkA in a clean genetic background was pleiotropically defective for CCR. ${ }^{178-180}$ The activity of Glk is mediated by as of yet unknown mechanism. ${ }^{181}$ Its role in catabolite repression may be co-ordinately controlled with a number of other proteins. These include SCO2127, a protein of unknown function, which is encoded by the gene upstream of $g l k A^{182,183}$ and regulatory proteins that control the transcriptional network of genes that mediate CCR, such as the global regulators Rok7B7 and DasR (see below). Another interesting protein is the phosphoinositide phosphatase, SblA. ${ }^{\mathbf{1 8 4}}$ Deletion of sblA in Streptomyces lividans leads to relief of CCR, with accelerated growth and development in the presence of glucose on some media. ${ }^{\mathbf{1 8 5}}$ These phenotypes correlated with reduced glucose uptake by 


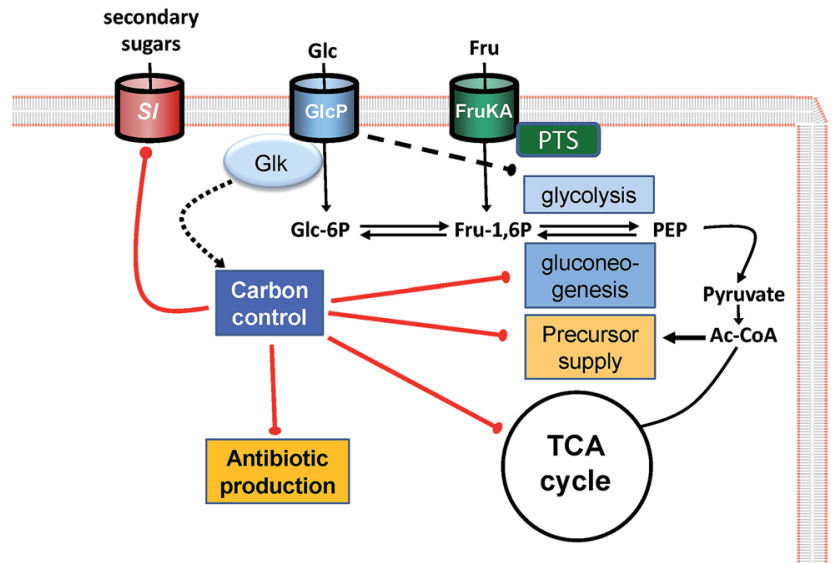

Fig. 2 CCR and the control of antibiotic production. Glucose repression is shown for primary and secondary metabolism. Black arrows indicate activation, red lines repression. Glucose kinase (Glk) is activated post-translationally in a glucose transport-dependent manner (van Wezel et al., 2007). Glc, glucose; Fru, fructose, secondary sugars (energetically less favorable sugars, such as lactose, mannitol and glycerol). SI, substrate induction. Note that glucose is transported by an MFS transporter and not by the PTS in Streptomyces.

the mutant and may therefore affect the activity of GlcP. The cleavage of phosphoinositides by SblA is apparently required to resume growth in transition phase, although the mechanism has not been elucidated. ${ }^{185}$

Studies with $S$. peucetius suggested the existence of an integral regulatory system that responds to glucose transport and metabolism, which probably elicits CCR. ${ }^{154}$ Indeed, addition to growth media of either of the glycolytic intermediates fructose 1,6-biphosphate and phosphoenolpyruvate results in glucose repression of daunorubicin and doxorubicin biosynthesis in
S. peucetius. ${ }^{186}$ This connects to observations that the activity of GlkA depends on interaction with the glucose permease GlcP in S. coelicolor. ${ }^{181}$

Many antibiotics show growth phase-dependent control. As a consequence, developmental mutants that are blocked in an early phase of the life cycle - in particular bld mutants - typically fail to produce antibiotics. A well-studied case is represented by mutants that lack the developmental gene, $b l d B$, as these are not only disturbed in development and antibiotic production, but are also defective in CCR. ${ }^{187,188}$ This links the pathways that regulate carbon utilization and morphological differentiation. BldB is a member of a family of DNA-binding proteins that are only found in Actinobacteria. The family is widespread in streptomycetes, with several paralogues in $S$. coelicolor, including AbaA and WhiJ, which play a role in the control of antibiotic synthesis and development, respectively. ${ }^{189}$ Identification of the BldB regulon and the way its activity is modulated will likely offer important new insights into the growth phasedependent control of antibiotic production and the role of CCR in this process.

\subsection{New insights into the nutrient-sensory DasR system}

In streptomycetes, the PTS plays a major role as the first step in a global antibiotic sensory system revolving around the nutrient sensory protein, DasR, which is conserved in streptomycetes and many other Actinobacteria. DasR is a GntR-family repressor with a pleiotropic role in the regulation of primary and secondary metabolism and of development. For details, we refer to reviews elsewhere. ${ }^{33,190}$ Here we summarise the key elements of the regulon and highlight recent insights (Fig. 3). The core regulon of DasR in all Gram-positive bacteria revolves around the genes for aminosugar transport ( $\mathrm{pts}$ ) and metabolism ( $\mathrm{nag}$ )

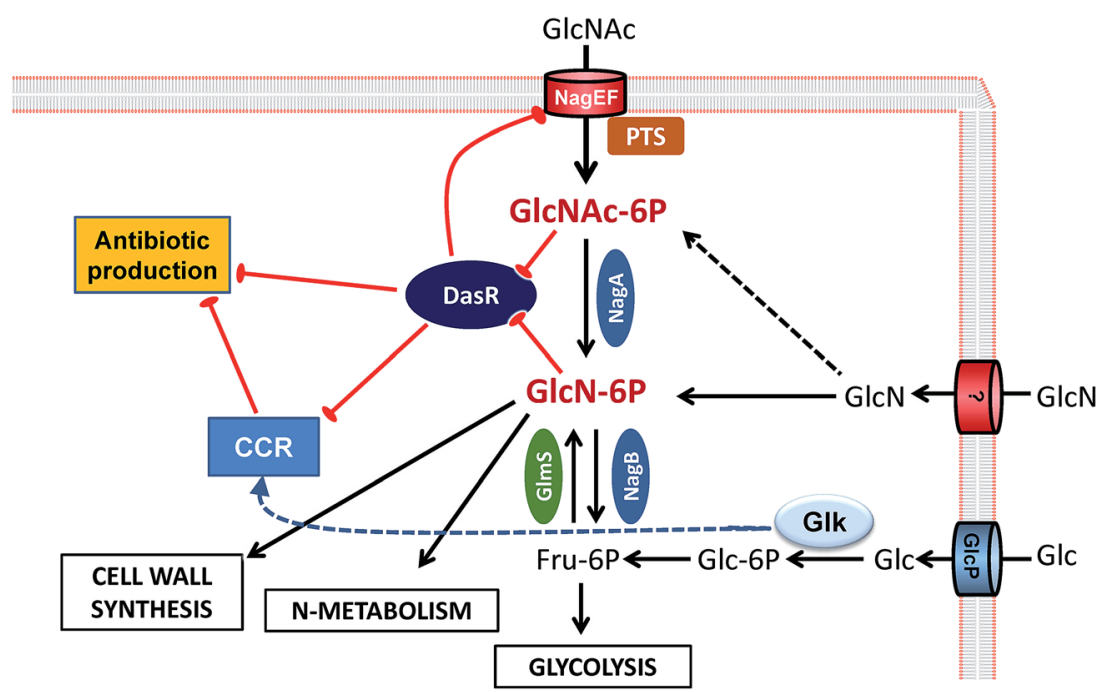

Fig. 3 The DasR regulatory network. The primary metabolism of S. coelicolor is shown for N-acetylglucosamine (GlcNAc), glucose (Glc) and glucosamine (GlcN). Glucosamine 6-phosphate (GlcN-6P) is a central metabolite that stands at the crossroads of aminosugar metabolism, glycolysis, nitrogen metabolism and cell wall synthesis. GlcN-6P and GlcNAc-6P are ligands that modulate the DNA-binding activity of DasR. DasR is a global repressor of specialised metabolism. Internalised glucose is phosphorylated by glucose kinase (Glk), which is key to carbon catabolite repression in S. coelicolor. In turn, DasR suppresses CCR by downregulating Glk expression. The broken lines represent known routes that have not yet been fully characterised. 
and in streptomycetes also the genes for the chitinolytic system (chi). Originally identified as the repressor of the chitobiose transporter DasABC, ${ }^{\mathbf{1 9 1}, \mathbf{1 9 2}}$ it was soon recognized that DasR also controls many genes involved in antibiotic production. Comprehensive analysis of the DasR regulon of $S$. coelicolor showed that it acts as a direct and very global transcriptional repressor of antibiotic production by binding to the promoter regions of the CSRs for all known chromosomally located antibiotic BGCs in $S$. coelicolor. ${ }^{95,97,193,194}$ DasR also represses siderophore biosynthesis via control of the iron-homeostasis regulator $d m d R 1 .{ }^{170,195} \mathrm{~A}$ similar pleiotropic role of DasR has also been reported in the erythromycin producer S. erythraea, ${ }^{196,197}$ but is not typical of all streptomycetes.

The DNA-binding activity of DasR is modulated by ligands derived from GlcNAc or glucosamine (GlcN), in particular GlcNAc-6P and GlcN-6P, and the crystal structure of DasR and its orthologue NagR of Bacillus subtilis in complex with these ligands have been elucidated. ${ }^{\mathbf{1 9 8 , 1 9 9}}$ GlcN-6P stands at the crossroads of carbon and nitrogen metabolism and cell-wall synthesis, and by acting as an effector of the DasR-dependent antibiotic control system, it plays a major role in the connection between primary and secondary metabolism (Fig. 3). The DNA-binding activity of DasR depends on environmental conditions. High concentrations of GlcNAc under famine conditions (e.g. on minimal media) result in inactivation of DasR, and thus derepression of its targets, leading to enhanced antibiotic production and development. Conversely, on rich media, GlcNAc represses antibiotic and development, leading to a complete developmental block..$^{\mathbf{9 7 , 1 9 4 , 2 0 0}}$ This phenomenon is known as feast or famine; under conditions of nutritional richness, aminosugars are perceived as derived from chitin, signalling plenty of nutrients, while under poor growth conditions (famine) it is perceived as coming from autolytic degradation of the cell wall and hence cell death. The latter elicits development and antibiotic production. Besides the phosphorylated aminosugars GlcN-6P and GlcNAc-6P, other metabolites may also modulate the DNA-binding activity of DasR. These include high concentrations of phosphate (organic or inorganic), which were shown to enhance the binding of DasR to its recognition sites. ${ }^{95,201}$ Thus, the affinity of DasR for its recognition sites (and with that the expression of its regulon, including many BGCs for natural products) depends on the metabolic status of the cell. Interestingly, high concentrations of phosphate (either organic or inorganic) enhance binding of DasR to its recognition site in vitro, which reinforces the PhoP-mediated repression of antibiotic production by phosphate. ${ }^{95,201}$

Full genome-scale identification of the DasR binding sites in vivo using ChIP-chip analysis corroborated the identity of canonical DasR binding sites or dre (DasR-responsive elements), but also revealed so-called class II sites, which do not conform to the known consensus sequence..$^{95}$ These sites are not found by the regulon prediction algorithm PREDetector. ${ }^{202}$ Binding of DasR to class II sites may require a corepressor, which has not yet been identified. The ChIP-Chip analysis also showed that the binding profile of DasR changes dramatically over time, with only small overlap in the binding profiles between 24 (vegetative growth) and 54 hours (morphological differentiation and antibiotic production). Thus, the DasR regulon is a highly complex system, which is influenced by metabolic status and most likely also by other regulatory proteins. Taken together, the metabolic status of the cell determines the selectivity of DasR for its recognition sites and thus the expression of its regulon, which includes many secondary metabolite BGCs.

\subsection{Competition between AtrA, Rok7B7 and DasR and connections to CCR}

Until the discovery of DasR, it was unclear how global carbon control was related to the control of specific carbon utilization regulons and antibiotic biosynthetic genes. Deletion of the genes for either GylR or MalR relieves both CCR and substrate induction of glycerol and maltose utilization, respectively, and hence gives constitutive expression even in the absence of inducer, while over-expression results in hyperrepression..$^{\mathbf{2 0 3 , 2 0 4}}$ This suggests that a global regulatory system for carbon utilization does not exist in $S$. coelicolor. In most bacteria, global carbon control depends on the cAMP receptor protein (CRP). Streptomycetes do have a cAMP receptor protein, but in contrast to other bacteria, it does not seem to play a role in CCR. Instead, CRP plays a role in the control of germination, and crp null mutants show prolongued dormancy. ${ }^{106}$ Importantly, genomewide DNA binding studies and transcriptional analysis revealed that CRP also globally controls antibiotic BGCs in $S$. coelicolor (ref. 103; see also Section 6).

There is also growing evidence that besides DasR, the TetRfamily regulator AtrA plays a role in carbon utilization (Fig. 4). Very recent ChIP-seq experiments (McDowall et al., unpubl. data) have confirmed that AtrA binds upstream of nagE2, which encodes a known permease for the uptake of GlcNAc. ${ }^{205}$ Similar to what was found for actII-ORF4, this binding appears to activate transcription as disruption of atrA results in reduced levels of nagE2 transcript (Nothaft et al., 2010). This led to the suggestion that AtrA may increase Act production indirectly through enhanced GlcNAc-induced inactivation of DasR as well as directly through activation of actII-ORF4 transcription (Nothaft et al., 2010). The control of DasR activity by AtrA via cellular levels of GlcNAc may extend beyond nagE2 as recent ChIP-seq also identified AtrA binding to recognisable motifs upstream of SCO0481, which encodes a protein that binds chitin (a rich source of GlcNAc), and crr (SCO1390), for the global PTS component EIIA, that is required for GlcNAc transport. The role of AtrA in carbon utilisation almost certainly extends beyond GlcNAc metabolism (Fig. 4). ChIP-seq also identified AtrA binding to sites upstream of $g y l R$ (SCO1658) and glpk2 (SCO0509), which encodes a glycerol kinase outside the $g y l$ operon. Control of morphological differentiation by AtrA is explained at least in part by transcriptional control of $s s g R$ (Fig. 4), ${ }^{206}$ the transcriptional activator of the gene encoding SsgA, which is involved in cell division and sporulation. ${ }^{207,208}$ Disruption of atrA suggests it activates transcription of $s s g R,{ }^{206}$ and direct binding of AtrA within the upstream regulatory region of $s s g R$ was confirmed by ChIP-seq (McDowall et al., unpubl. data). 


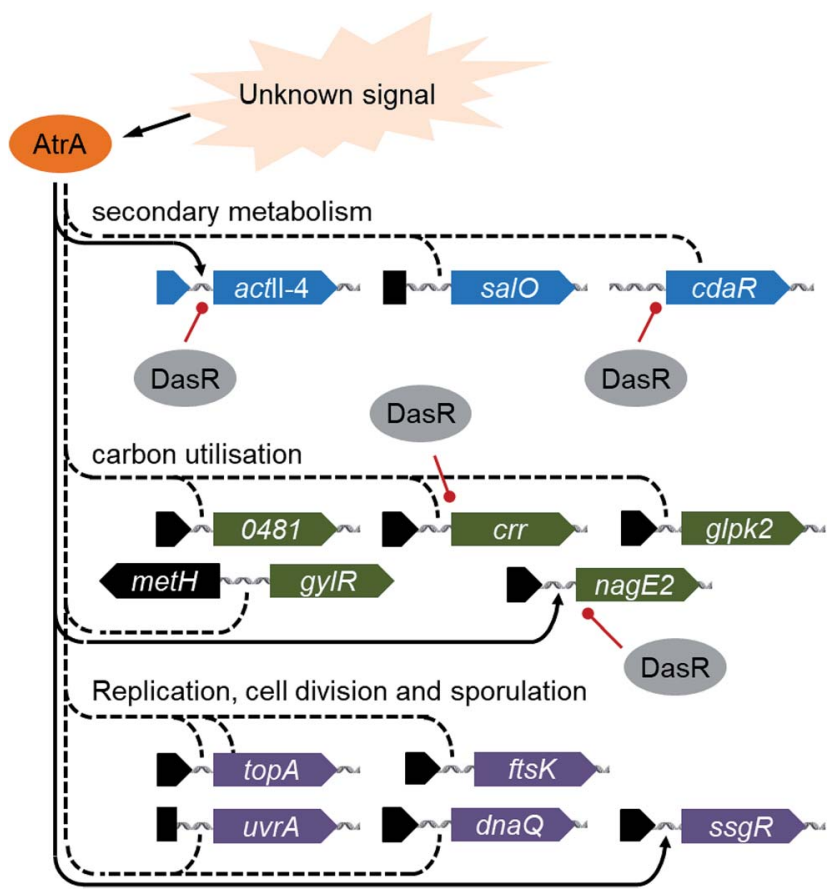

Fig. 4 Schematic illustration of a selection of genes corresponding to sites of AtrA binding in S. coelicolor. Black and red solid black lines with arrow heads represent previously described interactions associated with activation by AtrA and repression by DasR, respectively. The broken lines represent interactions identified by chromatin immunoprecipitation but not yet characterized AtrA binds to upstream regions of genes encoding CSRs (actll-ORF4, cdaR of S. coelicolor and salO of S. albus; the latter encodes the CSR for salinomycin biosynthesis). The activator AtrA and the repressor DasR compete for binding to the upstream regions of actll-ORF4 and $c d a R$ and upstream regions of genes that are involved in the uptake of GlcNAc (crr and nagE2). In addition AtrA binds to an upstream region of SCO0481, which encodes a protein that binds chitin, a rich source of $\mathrm{GlcNac}$. The positive control of AtrA on GlcNac uptake suggest that AtrA increases Act production indirectly through enhanced GlcNAc-induced inactivation of DasR as well as directly through activation of actll-ORF4 transcription. AtrA also binds to upstream regions of genes involved in glycerol catabolism (gylR and glpk2 (SCO1658)). The binding of AtrA to the upstream region of genes involved in DNA replication (topA, DNA topoisomerase 1, uvrA, dnaQ) cell division and sporulation (ssgR and $f t s K$ ) explains the role of AtrA in the control of morphological development.

The ROK-family protein, Rok7B7 takes up an interesting position in the regulatory network as it connects the control of antibiotic production and carbon catabolite repression. ${ }^{209}$ Mutants lacking rok $7 B 7$ are delayed in their developmental programme and are pleiotropically disturbed in terms of antibiotic production, perhaps as a consequence of a yet unexplained change in CCR. Rok7B7 activates the transcription of actII-ORF4 (and hence Act production) and represses the biosynthesis of Red and Cda, although its binding site has so far not been identified. ${ }^{209,210}$ Aside from actII-ORF4, Rok7B7 also activates the GlcNAc pts gene, nagE2, which means it counteracts the activity of DasR in a manner very similar to AtrA.

The signals that are required for activation of AtrA and Rok7B7 are unknown. Since AtrA is a TetR-regulator it is suggested that this protein is regulated in an allosteric manner by a ligand to exert its effect on secondary metabolism. In S. globisporus, AtrA is inhibited by the binding of heptaene, a biosynthetic intermediate of lidamycin whose biosynthesis is controlled by AtrA via activation of its CSR. ${ }^{211}$ As part of this work, it was also reported that the DNA-binding activity of $S$. coelicolor AtrA is regulated by Act. ${ }^{211}$ Whilst this finding was shown with different preparations of Act, the specificity of this effect needs to be evaluated further. To our knowledge, in all streptomycetes atrA is co-located with a divergent AtrA-target gene (SCO4119 in S. coelicolor) that encodes NADH dehydrogenase. ${ }^{212}$ There is interest in identifying the substrate of SCO4119 as at least some members of the TetR family interact with ligands that are structurally identical or related to the substrates of proteins encoded by genes divergent to their own. ${ }^{213}$ As ChIPchip experiments failed to show binding of ROK7B7 to genomic DNA under standard growth conditions on minimal media, it was proposed that the regulator requires a co-factor or ligand to facilitate its DNA binding activity. The control of - and gene synteny with - the xylose transport operon $x y l E F G$ by Rok7B7 hints at C5-sugars as candidate ligands for this regulator. ${ }^{209}$

Interestingly, there is an intricate link between Rok7B7, DasR and CCR, which in turn has important implications for the control of antibiotic production. Proteomic comparison of $S$. coelicolor and a glkA null mutant showed that glucose activates the expression of Rok7B7 in a Glk-independent manner, ${ }^{214}$ which was later confirmed by transcriptomic analysis. ${ }^{215}$ In turn, DasR and Rok7B7 repress the expression of glkA and thus CCR, ${ }^{95,209}$ while conversely, Glk represses Rok7B7. ${ }^{214}$ Deletion of rok $7 B 7$ results in a loss of CCR, which directly implicates Rok7B7 in CCR. ${ }^{214,215}$ It is unlikely however that $g l k A$ is a member of the rok7B7 regulon, as glkA transcription is constitutive, and its activity is post-translationally controlled. ${ }^{\mathbf{1 8 1 , 2 1 5}}$

In summary for this chapter, there are multiple regulatory networks that connect carbon control to the control of antibiotic production. Understanding carbon source-dependent control of antibiotic production is important from the perspective of both the design of growth media for yield optimization and for screening of new bioactive molecules. Despite the wealth of literature, it is still unclear how Glk exerts CCR, and we expect that more regulatory proteins that play a role in this important process will be discovered. It is becoming clear that there is a strong connection to the regulons of DasR, Rok7B7 and AtrA. Future research will need to elucidate precisely how this multi-layer control network is governed. Finding the ligands for AtrA and Rok7B7 would be one of the major steps to take.

\section{Connections between phosphate, nitrogen and carbon metabolism}

Carbon, nitrogen and phosphate are essential components for the basic building blocks of all cellular life. It is reasonable to assume that acquisition and utilization of these elements would be coordinately controlled. Although widely accepted, molecular characterization of this interconnectivity has only emerged recently, with the important discovery that GlnR, DasR and CRP 
jointly regulate three genes for citrate synthesis in the erythromycin producer $S$. erythraea. ${ }^{\mathbf{2 1 6}}$ CRP controls early processes during growth in Streptomyces species ${ }^{\mathbf{1 0 6 , 2 1 7}}$ and acts as a global regulator of Act, Cda and Red production, perhaps by coordinating precursor flux. ${ }^{103}$ Indeed, 8 out of 22 secondary metabolic clusters on within the $S$. coelicolor genome harbour Crp binding sites, suggesting a pleiotropic role in control of antibiotic production. Further evidence for the connection between $\mathrm{C}$ - and $\mathrm{N}$-metabolism via GlnR came from elegant experiments showing that several $\mathrm{ABC}$ transporter systems are under direct control of GlnR in S. erythraea, affecting growth on maltose, mannitol, mannose, sorbitol and trehalose. ${ }^{218}$ Recent data show that in $S$. coelicolor, GlnR is activated by glucose, ${ }^{215}$ while GlnR directly activates transcription of a putative carbohydrate transport operon agl3EFG. ${ }^{219}$ Taken together, these data suggest direct linkage between carbon and nitrogen metabolism, albeit perhaps only when certain carbon sources are available.

The understanding of links between nitrogen and phosphate metabolism in S. coelicolor is better developed. PhoP and GlnR control antibiotic production in response to the availability of phosphate and nitrogen sources, respectively. ${ }^{135,220}$ Similar to the competitive activation of afs $S$ by AfsR and PhoP described in Section 3, these two regulators bind to overlapping regions within the $g \ln R$ promoter, but unlike the afs $S$ story, PhoP represses $g \ln R$ transcription while only AfsR promotes it $^{\mathbf{1 3 9}}$ (Fig. 1). When phosphate is plentiful, PhoP is inactive and thus AfsR (dependent on the growth phase) activates transcription of $g \ln R$, but when phosphate is in short supply, PhoP is phosphorylated by PhoR and represses the expression of $g \ln R$ (Fig. 1). ${ }^{220}$ In addition, PhoP also directly represses transcription of genes within the GlnR regulon, namely two glutamine synthetases $(g \ln A$ and $g \ln I I)$ and the promoter for the $a m t B-g \ln K$ $g \ln D$ operon, which encodes an ammonium transporter and putative nitrogen sensing/regulatory proteins. ${ }^{221}$ Uptake/ utilization of nitrogen is presumably superfluous if insufficient phosphate is available, hence the PhoP-mediated repression of genes involved in these processes. Thus, PhoP-mediated control of nitrogen metabolism may help balancing the cellular $\mathrm{P} / \mathrm{N}$ equilibrium.

Connection between phosphate and carbon metabolism is less well studied, but one link may be governed via the PhoPcontrolled enzyme PPK (polyphosphate kinase), which affects antibiotic production in response to the level of inorganic phosphate (Pi). ${ }^{127,222}$ PPK is involved in maintaining the cellular energy balance by regenerating ATP from ADP and polyphosphates and $p p k$ mutants show enhanced Act production under Pi-limited growth conditions. ${ }^{\mathbf{1 2 7}}$ This was recently explained by increased degradation of triacylglycerols (TAGs), resulting in accumulation of the polyketide precursor acetylCoA. ${ }^{223}$ Additionally, phospho-sugars inhibit antibiotic production in streptomycetes. This effect is mediated by the phosphate- rather than of the glyco-moiety, as the inactivation of $p h o P$ or $p p k$ prevents or enhances, respectively, their utilization as nutrient sources and their inhibitory effect on antibiotic production. ${ }^{224}$

Thus, it is becoming evident that the conventional understanding of the PhoRP, AfsR and GlnR as the elements of the linear transduction systems regulating primary and secondary metabolism have been revised significantly over the last several years. Recent discoveries made it possible to understand, at least partially, the cross-talk occurring between regulators for phosphate and nitrogen metabolism, and to a lesser extent carbon metabolism in streptomycetes. It is a reasonable expectation to predict that established methods for assessing DNA binding in vivo (i.e. ChIP-seq) ${ }^{225}$ in combination with new strategies for robustly mutagenizing and identifying mutants (i.e. Tn-Seq) ${ }^{226}$ will enhance the ability to probe these regulons and their cross regulation.

\section{The impact of metals on secondary metabolism}

Iron is an essential metal that plays important roles in DNA replication, protein synthesis and respiration. Iron is relatively unavailable in the soil due to the low solubility of the $\mathrm{Fe}^{3+}$ ion under aerobic conditions at neutral pH. Production of ironchelating compounds called siderophores is the most common way that bacteria circumvent this problem. ${ }^{227}$ Moreover, some bacteria have developed systems that allow them to utilize siderophores synthesised by neighbouring microorganisms. ${ }^{171,228,229}$ The primary impact of iron deficiency in Streptomyces and other bacteria, is the stimulation of siderophore production. All Streptomyces species examined thus far appear to harbour a BGC for desferrioxamine, which has been proposed to be part of the 'core' secondary metabolome of the genus, ${ }^{230}$ while other streptomycetes produce additional siderophores; S. coelicolor and S. scabies produce coelichelin and pyochelin, respectively, for example. ${ }^{231,232}$ Production of desferrioxamine is normally repressed by the DmdR1 protein, which becomes derepressed in the absence of iron. ${ }^{233-235}$ The $d m d R 1$ gene is unusual in that its DNA sequence encodes a second gene $(\mathrm{adm})$ using the anti-sense strand of DNA. ${ }^{236}$ Deletion of the $d m d R 1$-amd locus in $S$. coelicolor abolished sporulation and the production of Act and Red. ${ }^{233}$ Subsequent experimentation whereby either $d m d R 1$ or amd were individually mutated by a point mutation revealed that inactivation of $d m d R 1$ had no impact on Act and Red production where as these compounds were overproduced when only amd was mutated. ${ }^{236}$ Another link between iron availability and secondary metabolism in $S$. coelicolor is that iron de-represses the pleiotropic TCS, AbrA1/ A2, which negatively regulates Act and Red production, although the mechanism has not yet been resolved. ${ }^{237}$

Zinc is an important transition metal required as a cofactor for many enzymes and regulatory proteins important for normal bacteria physiology. However, the intracellular free level of this element should be maintained within a narrow range due to its potential toxicity. ${ }^{238,239}$ Its uptake in streptomycetes as well as in other bacteria is regulated by Zur, a zinc-responsive transcriptional regulator. ${ }^{\mathbf{2 4 0 , 2 4 1}}$ Interestingly, there is a Zur-binding site within the BGC for the metal chelator, coelibactin and adjacent to this is a binding site for another zinc-sensitive regulator, AbsC; together these regulators repress coelibactin biosynthesis. ${ }^{242}$ Interestingly, AbsC also seems to be required for the 
production of Act and Red when $S$. coelicolor is cultivated under the specific conditions of zinc limitation and inactivation of zur and $a b s C$ genes block sporulation. Binding of AtrA upstream of the promoter for $z u r^{243}$ has been identified both biochemically and by ChIP-seq (McDowall et al., unpubl. data) suggesting yet another layer of regulation that potential facilitates integration with primary metabolism as well as secondary metabolism and morphological development. More detailed study of these regulators is necessary in order to fully illuminate their regulons and the nature in which they overlap and interconnect with other metal acquisition systems. Amycolatopsis japonicum produces the biodegradable ethylenediame-tetra acetate (EDTA) isomer $[S, S]$-EDDS, whose gene cluster was elucidated. ${ }^{244}$ Trace amounts of zinc in the culture media inhibit the production of $[S, S]$-EDDS, which led to the proposal that the molecule is required for zinc uptake. The synthesis of the zincophore is repressed by the zinc regulator Zur. ${ }^{244}$

Recently, the impact of rare earth elements (REEs) on secondary metabolism was explored. Supplementation of culture medium with scandium or lanthanum stimulated the production Act by $S$. coelicolor, Str by $S$. griseus and actinomycin by $S$. antibioticus. ${ }^{245}$ Although precise mechanistic detail is lacking, scandium stimulation of Act production is dependent on the ppGpp synthetase, RelA and is mediated by upregulation of actII-ORF4. ${ }^{245}$ Interestingly, scandium was also able to rescue the ability of $S$. lividans to produce Act, a compound that the species does not normally produce despite harbouring a nearly identical gene cluster. ${ }^{245}$ Quantitative RT-PCR and HPLC analyses showed that in addition to Act, scandium supplementation stimulated the expression of eight other BGCs in S. coelicolor. ${ }^{246}$ Stimulation of secondary metabolism by REEs is not restricted to Actinobacteria - scandium was recently shown to elicit the production of amylase and bacilysin in B. subtilis. ${ }^{247}$ Thus, REEs represent a relatively unexplored method for activating the expression of silent or weakly expressed BGCs and future studies should be aimed at understanding the molecular mechanism(s) by which this occurs.

\section{Morphological developmental control of antibiotic production}

As mentioned in the introduction to this review, the production of antibiotics (and other secondary metabolites) is temporally correlated to the onset of development of Streptomyces colonies. ${ }^{31,33}$ A model of the linkage between the control of antibiotic production and development is presented in Fig. 5. A likely explanation is that the colony is particularly vulnerable to competitors when it is undergoing programmed cell death (PCD), and antibiotics are produced to protect the colony and the nutrients released during PCD. Until recently, the occurrence of PCD in bacteria has been a subject to major debate, but it is becoming

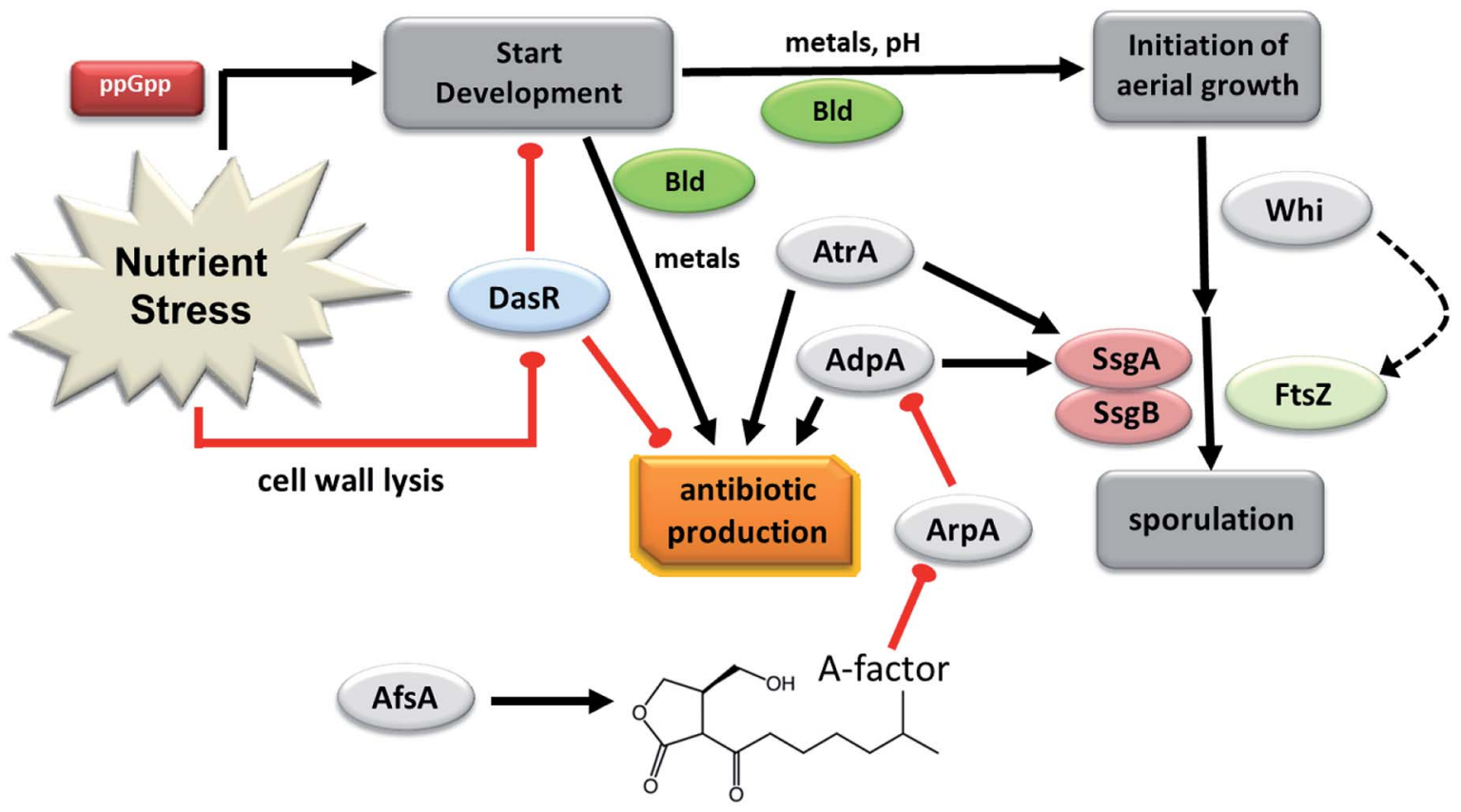

Fig. 5 Initiation of development and antibiotic production. The developmental programme starts with nutrient stress and growth cessation, followed by the accumulation of ppGpp. The autolytic dismantling of the cell wall (PCD) releases cell wall-derived metabolites that inhibit the activity of the nutrient sensory DasR. The onset of antibiotic production correlates temporally to the transition from vegetative to aerial growth, and is controlled by multiple pathway-specific and global regulators. Shown here are three key pleiotropic regulators, namely the antibiotic repressor DasR which responds to phosphorylated aminosugars likely derived from PCD, the activator AtrA (signal unknown) and AdpA, which responds to the accumulation of A-factor (synthesized by AfsA). Bld proteins and environmental signals control the procession towards aerial growth and antibiotic production. Whi proteins control aerial growth. Eventually, FtsZ accumulates and localizes to septum sites in an SsgABdependent manner. Solid black arrows represent major transitions in development. The arrow indicates the FtsZ accumulation checkpoint controlled by the Whi proteins. Red lines indicate repression. 
increasingly clear that PCD plays a major role the life cycle of multicellular bacteria, ${ }^{22,248-250}$ and in that of streptomycetes in particular. ${ }^{251,252}$ A direct link between PCD and antibiotic production was demonstrated with the discovery that GlcNAc, which together with $\mathrm{N}$-acetylmuramic acid forms the peptidoglycan strands, acts as an elicitor of antibiotic production via metabolic inactivation of the global antibiotic repressor DasR. ${ }^{\mathbf{1 9 4 , 2 5 3}}$ For details we refer to Section 5. Interestingly, production of prodiginines, which have anticancer activity by degrading the DNA, may play a direct role in triggering PCD in S. coelicolor, and mutants that fail to produce prodiginines have strongly reduced PCD, whereby vegetative growth is prolongued..$^{254}$

As a consequence of the growth phase-dependent control of antibiotic production, developmental mutants that are blocked in an early phase of the life cycle - in particular bld mutants typically fail to produce antibiotics. As mentioned in Section 5.1, mutants of the developmental gene $b l d B$ are not only disturbed in development and antibiotic production, but are also defective in CCR. ${ }^{187,188}$ This links the pathways that regulate carbon utilization and morphological differentiation. BldB is a member of a family of DNA-binding proteins that are only found in Actinobacteria. The family is widespread in streptomycetes, with several paralogues in $S$. coelicolor, including AbaA and WhiJ, which play a role in the control of antibiotic synthesis and development, respectively. ${ }^{189}$ Identification of the BldB regulon and the way its activity is modulated will likely offer important new insights into the growth phase-dependent control of antibiotic production and the role of CCR in this process.

BldD is a small DNA-binding protein that is required for development and antibiotic production (Fig. 5). ${ }^{255}$ BldD is related to $\operatorname{SinR}$, a master regulator of the transition from the motile to a sessile state in Bacillus subtilis, and hence associated with the control of biofilm formation. ${ }^{256,257}$ The BldD regulon encompasses over 150 transcriptional units, many of which are involved in the control of development. ${ }^{258}$ One of its targets is $b l d A$, which at least in part explains the requirement of BldD for antibiotic production. BldD binds to DNA as a homodimer, and dimerization is dependent on the binding of a tetramer of the signalling molecule cyclic-di-GMP. ${ }^{259}$ This is another interesting example of small molecule-based control of antibiotic production in Streptomyces.

Other bld mutants also fail to produce antibiotics, but the phenotype of these mutants is not independent of the growth medium (Fig. 5). In fact, bldA, bldC, bldG, bldH (adpA), bldJ and $b l d K$ mutants produce spores on non-repressing carbon sources such as mannitol or glycerol, but not on media containing glucose. Interestingly, mutation of $g l k A$ restores antibiotic production and morphological development to bldA mutants, ${ }^{33}$ while $b l d J$ and $b l d K$ mutants are rescued by supplementing the colonies with iron. The latter is due to their failure to produce the siderophore desferrioxamine. ${ }^{\mathbf{1 7 0}}$ In fact, most bld mutants are affected in desferrioxamine biosynthesis, with strongly reduced production of the siderophore in bldA, bldJ, and ptsH mutants, and overproduction in $b l d F, b l d K, \mathrm{crr}$ and ptsI mutants. ${ }^{\mathbf{1 7 0}}$

An infamous example of translational control of development and antibiotic production is BldA, the tRNA that recognizes the rare UUA codon for leucine. Mutants of $S$. coelicolor defective in bldA have a bald phenotype and fail to produce antibiotics. ${ }^{\mathbf{2 6 0}, 261}$ The latter is a direct consequence of the presence of UUA codons in the mRNA of the genes for ActII-ORF4 and RedZ. ${ }^{73,74}$ The presence of TTA codons in BGCs for specialized metabolites - and in particular in genes encoding CSRs - is more a rule than an exception, which provides strong phylogenetic evidence for the fact that control of antibiotic production by BldA has evolved with a purpose. ${ }^{262}$

Mutants that are blocked in sporulation (so-called whi mutants) generally are not affected in antibiotic production. This is most likely because the decisions to switch on secondary metabolism made at an earlier stage in the life cycle. The exception is $s s g A$, whose transcription does not depend on any of the 'classical' whi genes. ${ }^{207}$ SsgA activates sporulation-specific cell division by controlling the localization of its paralogue $\mathrm{SsgB}$, which in turn recruits FtsZ to initiate sporulation-specific cell division (Fig. 5). ${ }^{263}$ In contrast to most developmental control proteins, SsgA and SsgB lack DNA-binding domains. The SsgA-like proteins are unique to sporulating Actinobacteria, and most likely function as chaperones that recruit multicomponent complexes. ${ }^{264,265}$ Over-expression of $s s g A$ results in overproduction of prodiginines (Red), while Act production is blocked. ${ }^{266,267}$ The most likely explanation is that SsgA blocks S. coelicolor development at a stage corresponding to early aerial growth, where Red production has been switched on, while Act production has not yet been initiated. SsgA and SsgB probably represent another important link in the coordination of secondary metabolite production with vegetative growth. ${ }^{268}$

WblA is a member of the WhiB-like proteins, and 11 paralogues are encoded by the $S$. coelicolor chromosome. ${ }^{269}$ The Wbl proteins are small iron-sulphur proteins that are unique to Actinobacteria. Disruption of $w b l A$ has a highly pleiotropic effect on overall gene expression in $S$. coelicolor and prevents development while strongly increasing antibiotic production in this organism. ${ }^{269}$ Conversely, overproduction of WblA pleiotropically represses the biosynthesis of Act, Red and Cda in S. coelicolor and of anthracyclines in $S$. peucetius. ${ }^{270}$ Deleting $w b l A$ also results in enhanced production of specialized metabolites in other streptomycetes, such as Streptomyces ansochromogenes, Streptomyces glaucescens, Streptomyces roseosporus and Streptomyces sp. C4412 as well as in Pseudonocardia,,$^{271-276}$ and should therefore be considered as a general approach to achieve enhanced production of cryptic antibiotics in a given strain. It is yet unclear how WblA controls antibiotic production.

\section{Autoregulators and the control of antibiotic production}

Bacteria communicate with each other through production of small extracellular molecules, called bacterial hormones or autoregulators. After the discovery of the gamma-butyrolactone A-factor (2-isocapryloyl-3R-hydroxymethyl- $\gamma$-butyrolactone), produced by $S$. griseus, many more bacterial hormones have been identified, such as GBLs similar to A-factor, furans, gammabutenolides and PI-factor. In general, these signalling molecules are active in nanomolar concentrations and diffuse readily 
from one actinomycete to another, thereby affecting development and antibiotic production. GBL production is most likely not species-specific, as different species can produce the same GBL, suggesting extensive interspecies communication and 'eavesdropping'. Antibiotics may also function as signalling molecules, thereby induce antibiotic activity and/or resistance, and again in a more general fashion, affecting a broad range of hosts. Thus, the usage of bacterial hormones or antibiotics is an important factor in the discovery of novel antibiotics, as well as co-culturing micro-organisms (recently reviewed in ref. 277).

\subsection{The gamma-butyrolactone regulatory system in S. coelicolor and $S$. avermitilis}

Enzymes responsible for the synthesis of gamma-butyrolactones (GBLs) in streptomycetes are identifiable through their homology to the A-factor synthetase AfsA of $S$. griseus. ${ }^{91}$ The orthologue of AfsA of $S$. coelicolor is encoded by $s c b A$ (SCO6266) within the $c p k$ gene cluster responsible for the production of the yellow compound coelimycin $\mathrm{P} 1 .^{278} \mathrm{ScbA}$ is required for the production of the GBLs of $S$. coelicolor. This strain produces 8 different GBLs (SCB1-8). The structure of these molecules have recently been solved after they were overproduced in the super host M1152. ${ }^{279}$ Deletion of $s c b A$ resulted in the overproduction of Act and Red biosynthesis and reduced $c p k$ expression ${ }^{280}$ divergent to $s c b A$ lies $s c b R$ (SCO6265), which encodes a transcription factor that appears to activate transcription of $s c b A$ as well as a repressor of its own transcription and that of cpkO (kasO), which encodes the CSR of the coelimycin BGC cluster, provided GBL is not bound by ScbR. ${ }^{\mathbf{1 4 1 , 1 4 2}}$ It also positively regulates CdaR, the CSR of the Cda BGC. Deletion of $s c b R$ resulted in reduced Act, Red and Cda production and increased coelimycin P1 production. ${ }^{\mathbf{1 4 3}}$ The regulation of $s c b A$ is complex, with no fewer than five $s c b R$ paralogues in $S$. coelicolor, ${ }^{277}$ one of which $s c b R 2$ (SCO6286) is also encoded within the coelimycin BGC. ${ }^{281}$ The reader is referred to our previous review for more details. ${ }^{33}$

ScbR2 is highly similar to ScbR, but unlike ScbR it is not able to bind GBLs, and is hence considered a pseudo gammabutyrolactone receptor. ${ }^{278,282}$ Instead it binds the endogenous antibiotics Act and Red and the exogenous antibiotic jadomycin $\mathrm{B}$ and related angucyclines. ${ }^{278,283}$ Interestingly, addition of nonendogenous jadomycin B from $S$. venezuelae releases ScbR2 from the promoters of redD and $a d p A$ in $S$. coelicolor, leading to accelerated Red production and morphological differentiation. ScbR2 probably has a greater effect on secondary metabolism than ScbR. Deletion of $s c b R 2$ abolishes Act, Red and Cda production and induces coelimycin production. ${ }^{281,283}$ Like ScbR, $\mathrm{ScbR} 2$ directly represses $c p k O .^{278} \mathrm{ScbR} 2$ is also a repressor of $s c b A$, and acts both directly and indirectly on antibiotic production. ${ }^{282}$ ChIP-seq showed that ScbR and ScbR2 have many shared targets genes related to primary and secondary metabolism. ${ }^{\mathbf{1 4 3 , 2 8 4}}$ Both directly act on afs $K$ and on genes involved in malonyl-CoA synthesis and hence precursor supply for polyketide natural products. Interestingly, the TetR-like proteins ScbR and ScbR2 can also bind as heterodimers, and coimmunoprecipitation of ScbR2 and ScbR revealed that only the ScbR-ScbR2 heterodimer can control SCO5158, which encodes an uncharacterized protein. ${ }^{285}$ Such heterodimer formation is not unique, and was previously proposed for the gene products of $m m f R$ and $m m y R$ of the methylenomycin BGC. ${ }^{286}$

$S$. avermitilis contains three GBL-like receptors encoded by genes that are located in a single locus, namely aveR1, aveR2 and aveR3. This locus also contains the genes aco and cyp17 required for avenolide biosynthesis. The bacterial hormone avenolide increases avermectin production in a dose-dependent manner when added in nanomolar concentrations to an aco deletion mutant. ${ }^{287}$ The AveR1 protein was identified as its cognate receptor. ${ }^{288}$ Deletion of aveR1 or addition of avenolide did not influence avermectin production, but increased avenolide production. An explanation for the latter might be that the threshold that is required for avermectin production has already been reached at the start of growth. This led to the suggestion that AveR1 acts as a repressor in the early stages of growth. ${ }^{289}$ AverR1 represses its own transcription and that of $a c o .^{289}$

AveR2 is a pseudo GBL-receptor that represses the transcription of aveR, encoding the positive CSR of the ave cluster. ${ }^{290}$ Additionally, AveR2 represses aco and cyp17, and controls genes involved in primary metabolism, ribosomal protein synthesis and stress responses. Such an extended regulon is reminiscent of ScbR2 (see above), and it is important to note that both regulators can bind endogenous and exogenous antibiotics. Indeed, the affinity of AveR2 for DNA is influenced by avermectins and also by the exogenous antibiotics jadomycin B and by aminoglycosides. Thus, we note that such pseudo-GBL receptors should be considered as important pleiotropic regulators. ${ }^{290}$

AveR3 shows similarity to autoregulator receptors and activates aveR transcription of the avermectin BGC, and indirectly also filipin biosynthesis. ${ }^{291,292}$ Interestingly, deletion of aveR3 resulted in the discovery of the cryptic natural product, phthoxazolin A, a cellulose synthesis inhibitor that shows activity against plant pathogenic oomycetes. The fact that GBL-mediated regulatory systems control cryptic genes in both $S$. coelicolor and $S$. avermitilis makes them candidate targets for drug discovery.

\subsection{GBL-receptors and antibiotic production in other streptomycetes}

The examples of $S$. coelicolor and $S$. avermitilis suggest that the presence of genes for GBLs and their receptor proteins may serve as beacons for cryptic BGCs. Similarly, the BGCs for the angucyclines jadomycin B (from $S$. venezuelae) and auricin (from $S$. aureofaciens) also contain genes for GBL synthases and their cognate receptors. ${ }^{293,294}$ The gene jadR3 harboured within the jadomycin B BGC encodes a putative GBL receptor located upstream of the GBL synthase genes jadW123. The product of this GBL synthase system is SVB1, which is identical to the GBL SCB3, produced by $S$. coelicolor. In $S$. venezuelae, only JadW2 is required for jadomycin production. ${ }^{294}$ Nevertheless, deletion of jadW1 abolishes both jadomycin $\mathrm{B}$ and chloramphenicol production under conditions that are known to be favourable for production of these antibiotics. ${ }^{295} \mathrm{JadR} 3$ is an autorepressor and also represses jadW1 transcription, and thereby represses jadomycin B production. ${ }^{294}$ The auricin BGC of $S$. aureofaciens is controlled by the GBL synthase SagA and its cognate receptor 
SagR, and again the genes encoding these proteins are located directly next to the biosynthetic genes. Deletion of $s a g R$ results in early but reduced auricin production, while deletion of sagA abolishes auricin production, establishing their key role in controlling auricin biosynthesis. In contrast to other GBL receptor proteins, SagR does not auto-regulate its own transcription, but instead $s a g R$ and $s a g A$ are repressed by the CSR Aur1R. ${ }^{293}$

Further on the theme, the production of indigoidine (a bluepigmented compound), of nucleoside antibiotics (showdomycin and minimycin) and of D-cycloserine by $S$. lavendulae FRI-5 is controlled by the bacterial hormone IM-2 and its cognate receptor FarA. ${ }^{\mathbf{2 9 6 , 2 9 7}}$ Supplementation of culture media with IM-2 enhances production of indigoidine, but abolishes production of D-cycloserine. ${ }^{296}$ FarA inhibits its own expression and activates the expression of FarX, the protein required for IM-2 biosynthesis. The genes encoding FarA and FarX are located on a regulatory island spanning $12.1 \mathrm{~kb} .^{298}$ This island contains the genes farA-E, farR1-5 and far $X .^{298}$ FarA negatively regulates its own expression and the expression of farR1 (which encodes an orphan response regulator), farR2 (for a pseudo-GBL receptor), farR4 (for a SARP regulator), ${ }^{299} \operatorname{farB}$ (for a structural protein). ${ }^{298}$ Since farR3 and farR4 can be transcribed both as monocistronic and bicistronic mRNA, it appears that farR3 is also a target of FarA. ${ }^{299}$ FarR2 is a pseudo-GBL receptor that positively regulates the production of indigoidine, but negatively regulates the expression of the far regulatory genes in the regulatory island, including the expression of $\operatorname{far} X .^{\mathbf{3 0 0}}$ Similarly, FarR3 positively regulates the production of indigoidine, ${ }^{299}$ but in both cases the control is most likely indirect. ${ }^{300,301}$ The SARP regulator FarR4 represses IM2 biosynthesis. ${ }^{299}$ Which offers a unique example of a SARP regulator that acts at the front instead of the end of a regulatory cascade. ${ }^{299}$

The complex regulatory network of the "pristinamycin supercluster" of $S$. pristinaespiralis is also under the control of a GBL-receptor. Pristinamycin is a mixture of two compounds, including the cyclohexane depsipeptide pristinamycin I (PI) and the poly-unsaturated macrolactone pristinamycin II (PII) that are produced in a $30: 70$ ratio. The mixture of pristinamycin is significantly more active against pathogenic bacteria than PI and PII separately. ${ }^{302}$ PI is synthesized by non-ribosomal peptide synthetases (NRPS) and PII by hybrid polyketide synthases (PKS)/ NRPS. ${ }^{303}$ The genes required for PI and PII production are not arranged in a single BGC, but are heterogeneously divided over a $210 \mathrm{~kb}$ genomic region whereby the biosynthetic genes are interspersed by a cryptic BGC. ${ }^{303}$ These characteristics of the BGC and the fact that the cluster contains seven genes encoding CSRs makes the regulation of pristinamycin biosynthesis very complex. $^{304}$ These CSRs include the GBL-receptor SpbR, two TetR-like regulators (PapR3 and PapR5), three SARP regulators (PapRI, PapR2, PapR4) and a response regulator (PapR6). ${ }^{\mathbf{3 0 3 , 3 0 4}}$ The regulatory cascade starts with the release of SpbR from the DNA when its ligand reaches a critical concentration. ${ }^{304}$ The pristinamycin BGC is under the direct control of the SARP regulators PapR1, PapR2 and the response regulator PapR6. ${ }^{\mathbf{3 0 4}}$ PapR2 is most likely the master regulator of the pristinamycin BGC, as this is the only regulator that is fully required for pristinamycin biosynthesis. ${ }^{304}$ The regulatory genes that directly control the pristinamycin BGC are repressed by the TetRregulator PapR5. ${ }^{\mathbf{3 0 4 , 3 0 5}}$ PapR5 shows similarity to pseudo-GBL receptors, suggesting that perhaps pristinamycin and/or biosynthetic intermediates act as ligands for PapR5 and may thereby control the level of pristinamycin. ${ }^{304}$ Similar as to other regulatory networks, the GBL-receptor is not the first regulator in the regulatory cascade, since $\mathrm{SpbR}$ is positively regulated by an AtrA (SSDG_00466) regulator outside the BGC. AtrA in turn positively controls the transcription of PapR5. ${ }^{305}$ Thus, the pristinamycin BGC is subject to complex and multi-level control, several elements of which deserve further investigation, so as to unravel the full regulatory network.

\section{EMERGING themes in the control of antibiotic production in Actinobacteria}

Besides the usual suspects, less well-studied genera of Actinobacteria (often referred to as rare Actinobacteria) also produce a wide range of natural products, and insights into their molecular regulation is important from the perspective of drug discovery and production improvement. Culture collections housed by biotechnology companies and research institutes possess several rare Actinobacteria, including Micromonosporaceae, Streptosporangiae, Pseudonocardiaceae, Nocardiaceae, and Thermomonosporaceae, and many other rare and unclassified species that have yet to be explored. ${ }^{306-309}$ In recent years, interest in strains isolated from marine environments and other ecological niches such as plants and insects has grown because they offer a rich new microbial source for NP discovery. ${ }^{35,310,311}$ The regulation of natural product biosynthesis by rare Actinobacteria is poorly characterised, because many of them are genetically intractable and limited genetic tools are available. As the cell wall structure between Actinobacteria often varies and is different from that of streptomycetes, preparation of protoplasts (and regeneration) typically requires different methods. ${ }^{312}$ A protocol to prepare protoplasts of Planobispora rosea, the producer of the thiazolyl peptide antibiotic GE2270 that targets elongation factor $\mathrm{EF}^{-\mathrm{Tu}^{313}}$ was applied to different rare Actinobacteria. ${ }^{312}$ This protocol demonstrated the applicability of both lysozyme and mutanolysin (from S. globisporus) to produce protoplasts from these industrially important strains. ${ }^{\mathbf{3 1 2}}$ Other issues that need to be solved for genetic manipulation of rare Actinobacteria include identification of suitable origins of replication for plasmids, ${ }^{\mathbf{3 1 4}}$ the methylation pattern of the $\mathrm{DNA}^{315,316}$ and the use of specific promoters for expression..$^{317,318}$ Many of these technical difficulties can in principle be circumvented by the use of expression of a BGC in a heterologous host. Expression of the BGC for GE2270 of P. rosea in $S$. coelicolor M1146 allowed the study of its regulation. ${ }^{319}$ Deletion of $p b t R$, encoding a TetR-family regulator, abolished the production of GE2270. Similarly, the BGC for taromycin A from Saccharomonospora sp. CNQ490 was also expressed in $S$. coelicolor M1146 to allow its genetic manipulation. Deletion of tar20, encoding a LuxR regulator of the taromycin BGC, increased the 
production of the compound in the heterologous strain. ${ }^{\mathbf{3 2 0}}$ Heterologous expression of a BGC may often be suitable to study the function of CSRs within a BGC, but for understanding of the global regulatory network and the ecological responses that control the BGC of interest, it is necessary to study the BGC in its natural host. In a number of Actinobacteria, the molecular regulation of antibiotic production has been studied. Especially in strains that produce clinically important antibiotics, such as glycopeptide producers. It appears that the rare Actinobacteria that have been studied indeed contain similar regulators as Streptomyces and therefore we expect that most of the control mechanisms of antibiotic production are similar. Below the control of antibiotic production in a number of Actinobacteria is discussed and compared to that of Streptomyces.

\subsection{Control of glycopeptide biosynthesis}

The glycopeptide antibiotics vancomycin and teicoplanin are important last line of defence antibiotics that are used to treat infections associated with multi-drug resistant Gram-positive bacteria. ${ }^{321,322}$ Their target is the peptidoglycan precursor lipid II, thereby inhibiting synthesis of the bacterial cell wall. ${ }^{323}$ Vancomycin is produced by Amycolatopsis orientalis and teicoplanin by Actinoplanes teichomyceticus. ${ }^{324,325}$ Other well-studied members include the precursor of dalbavancin, A40926 produced by Nonomuraea sp. ATCC39727,,26 balhimycin produced by Amycolatopsis balhimycina, ${ }^{327}$ and the sugarless glycopeptide A47934 produced by $S$. toyocaensis. ${ }^{328}$ A comparison of the BGCs for these compounds (tei for teicoplanin, bal for balhimycin and $d b v$ for A40926) and their control is presented in Fig. 6. Members of the glycopeptides share a heptapeptide core, which is synthesized by non-ribosomal peptide synthetases (NRPS), with further modifications such as crosslinking, methylation, halogenation glycosylation or attachment of sulphur groups. ${ }^{322,329}$ Glycopeptides bind to the D-alanyl-D-alanine (D-ala-D-ala) terminus of the growing lipid attached peptidoglycan chain on the outside of the cytoplasmic membrane and thereby prevent the binding of transpeptidases that create the cross-links between the polysaccharides, required for cell wall integrity. ${ }^{323}$
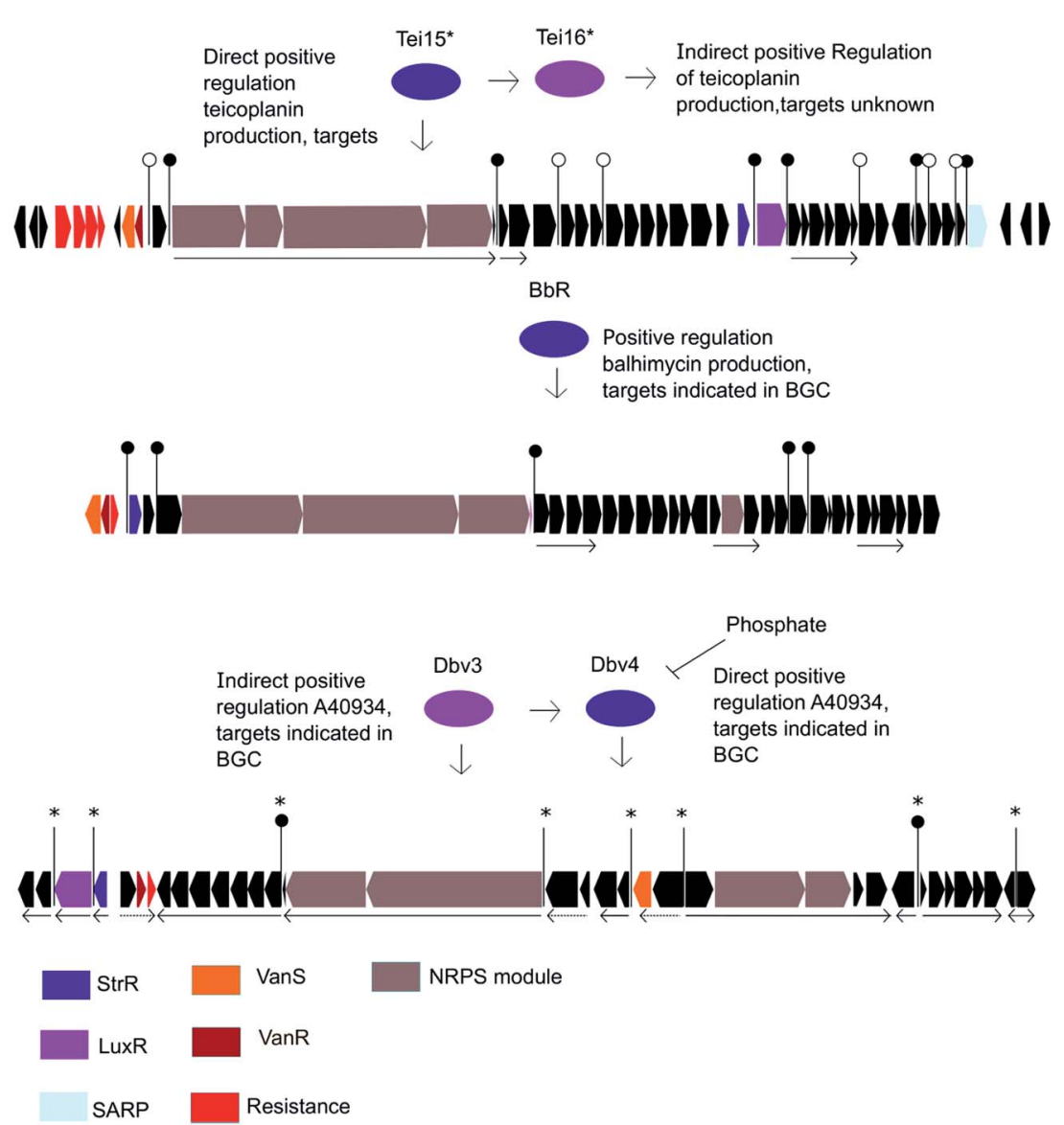

Fig. 6 Regulation of glycopeptide biosynthetic gene clusters. Shown are the BGCs for teicoplanin (tei), balhimycin (bal) and A40926 (dbv). Known and putative binding sites for StrR (purple) are indicated in the clusters with closed and open circles, respectively. The consensus sequence for the StrR binding sites GTCCAR(N)17TTGGAC is shared between all three BGCs. Genes regulated by LuxR (magenta) are indicated with an asterisk. Experimentally confirmed operons are indicated with an arrow. The primary CSR of the teicoplanin BGC is Tei15*, which positively regulates the expression of LuxR-family regulator Tei16* and of the SARP-family regulator Tei31*, with both regulators having unknown targets. The bal cluster is regulated by the CSR BbR, and lacks a gene for a LuxR regulator. The primary CSR of the $d b v$ cluster is the LuxR regulator Dbv3, which positively regulates the expression of StrR regulator Dbv4, most likely indirectly. For details see the text. BGCs adapted from the MiBIG database. ${ }^{412}$ 
The BGCs of these antibiotics are typically controlled by CSRs of the StrR and LuxR families. ${ }^{330-332}$ The teicoplanin BGC spans $89 \mathrm{~kb}$ and includes five regulatory genes, tei2, tei3, tei15*, tei16* and tei31*.324,325 Tei2 and Tei3 show high homology with the VanR/VanS system of $S$. coelicolor ${ }^{333,334}$ and are involved in the control of teicoplanin resistance. The genes tei15* and tei16* encode members of the StrR and LuxR family regulators, respectively. Overexpression of Tei15* results in 30-40-fold increase in teicoplanin biosynthesis. ${ }^{332,335}$ Tei15* is the primary $\mathrm{CSR}$, and directly controls the transcription of the regulatory genes teiA for the NRPS module, tei2* (which encodes a deacetylase), tei16*, tei17* involved in Dpg synthesis and tei27* (for an unknown protein). Tei15* also controls the expression of the LuxR family regulator Tei16* and the SARP family regulator Tei31*. The targets of Tei16* and Tei31* in the teicoplanin cluster remain unknown, although Tei16* does positively control teicoplanin production. ${ }^{332}$ Tei15* does not show autoregulation, in contrast to its orthologue $\mathrm{BbR}$ in the balhimycin BGC. ${ }^{331,332}$ See Fig. 6.

The dalbavancin BGC of Nonomuraea sp. ATCC39727 contains four regulatory genes, namely $d b v 3, d b v 4$, and the TCS $d b v 6$ and $d b v 22$ for the control of resistance (Fig. 6). Dbv4 (similar to StrR and Tei15*) is the likely CSR, and is expressed under phosphate-limiting conditions, while Dbv3 is a LuxR-type regulator similar to Tei16*. Both Dbv3 and Dbv4 are required for A40926 production. ${ }^{330}$ Dbv3 controls the transcription of $d b v 4$, as well as genes for the biosynthesis of 4-hydroxyphenylglycine, the heptapeptide backbone, and for glycosylation and export. However, similar to the situation for Tei16* in the teicoplanin BGC, no common regulatory elements were identified in the promoter regions of the Dbv3-controlled genes, and control could therefore be indirect. ${ }^{330}$ Dbv4 is directly involved in the regulation of genes involved in 3,5-dihydroxyphenylglycine, cross-linking, halogenation, glycosylation and acylation. ${ }^{330}$ The gene for Dbv4 and its regulon are repressed by phosphate, whereas Dbv3 and its regulon are not. No Pho-boxes were identified upstream of the $d b v 4$ genes, suggesting the phosphate repression is indirect. ${ }^{336}$

The glycopeptide balhimycin is produced by Amycolatopsis balhimycina (formerly Amycolatopsis mediterranei). The balhimycin BGC has a simpler control system with three regulatory genes, namely the VanR/VanS TCS for resistance and the StrRlike regulator Bbr (Fig. 6). Bbr binds to a consensus sequence (GTCCAR(N) ${ }_{17}$ TTGGAC) that is found within the promoter for its own transcription, the putative $\mathrm{ABC}$ transporter gene $t b a$, oxyA for a $\mathrm{P} 450$ monooxygenase, dvaA involved in dehydrovancosamine synthesis and the putative sodium proton antiporter gene orf7. ${ }^{331}$ In the three glycopeptide BGCs the StrR CSR binds to the consensus sequence that is conserved in the intergenic regions of the glycopeptide BGCs, although the target sequence may vary and deviate from the consensus. ${ }^{329,331,332,336}$ Although these three BGCs are organised in a similar manner and contain regulatory genes, the mechanism of regulation differs between them, and therefore making assumptions about the regulatory network based on bioinformatics alone is not sufficient. ${ }^{330}$ In $S$. griseus, StrR is positively controlled by the pleiotropic regulator AdpA. However, overexpression of the putative adpA gene of $A$. balhimycina did not induce antibiotic production, although heterologous expression of this regulator in $S$. coelicolor, S. ghanaensis and several soil Actinobacteria was successful. ${ }^{337}$ Vancomycin biosynthesis and its control are well understood, but the role of StrR regulator in the BGC (AORI_1475) has not been elucidated.

Since most glycopeptide BGCs contain a StrR-like positive regulator, over-expression of the corresponding gene is a logical generic strategy to induce the expression of (cryptic) glycopeptide BGCs. A good example is the production of ristomycin A in Amycolatopsis japonicum. This strain is known for the production of $(S, S)$-ethylenediamine disuccinic acid [ $(S, S)$-EDDS], the biodegradable isoform of EDTA (Section 7). Under standard laboratory conditions this strain does not produce antibiotics, but over-expression of the StrR orthologue in A. japonicum induced the production of ristomycin A, which is used for the diagnosis of von Willebrand disease and Bernard-Soulier syndrome. $^{338}$

\subsection{Control of glycopeptide resistance}

Bacteria that are resistant against glycopeptide antibiotics replace the $\mathrm{D}$-alanine for $\mathrm{D}$-lactate as the terminal residue of the peptide chain of the peptidoglycan. As the affinity of the glycopeptide for the latter is a lot lower than for D-ala-D-ala, binding of the glycopeptide is prevented. ${ }^{339,340}$ The glycopeptide BGCs contain genes that encode homologues of the VanR/VanS TCS that governs glycopeptide resistance.

$S$. coelicolor is resistant against vancomycin and this resistance is conferred by genes that are similar to the ones present in vancomycin resistant enterococci. ${ }^{333,334}$ The resistance cluster of $S$. coelicolor is organized in four transcription units, namely vanRS, vanJ, vanK and vanHAX. The latter encode the enzymes required for biosynthesis and incorporation of D-lac in the peptide moiety of the PG. All transcription units are regulated by VanRS. ${ }^{333}$ Binding of vancomycin by the N-terminal part of Vans leads to its autophosphorylation, and this phosphate is then transferred to the N-terminal receiver domain of VanR, thereby activating its C-terminal DNA binding effector domain. This results in expression of the resistance genes. In the absence of vancomycin VanS acts a phosphatase that dephosphorylates VanR, and hence vans mutants show constitutive expression of vancomycin resistance. ${ }^{334,341}$ In contrast, deletion of vanS in S. toyocaensis results in sensitivity to A47934, and it was suggested that VanR of $S$. coelicolor is phosphorylated by other proteins while that of $S$. toyocaensis is not. ${ }^{342}$ Interestingly, the VanRS TCS is an important determinant of the speciesspecific glycopeptide resistance profile. $S$. coelicolor is resistant against vancomycin and A47934, but sensitive to teicoplanin, while $S$. toyocaensis is only resistant against A47934. ${ }^{8}$ Exchanging the VanRS TCSs between the two Streptomyces strains is sufficient to switch the resistance profile. ${ }^{8}$ Surprisingly, expression of the VanR orthologue of A. balhimycina (VnlR) in $S$. coelicolor even governed resistance to teicoplanin, and led to increased actinorhodin biosynthesis. ${ }^{343}$ VnlR controls vanHAX in $S$. coelicolor, despite the fact that it does not control vanHAX in A. balhimycina itself. ${ }^{343}$ 


\section{3. $\sigma$-Factor/anti- $\sigma$-factor systems and the control of antibiotic biosynthesis}

An important new element of antibiotic control that was discovered in recent years is the control by $\sigma$-factors, the subunits of the RNA polymerase responsible for promoter recognition. An important example is that of the control of lantibiotics. Lantibiotics are ribosomally synthesized, post translationally modified peptide antibiotics (RiPPs ${ }^{344}$ ). The best known lantibiotic is the food-preservative nisin, produced by Lactococcus lactis and discovered as early as $1928 .^{345}$ Lantibiotics are synthesized as a prepropeptide encoded by a precursor gene generally referred to as lanA. This propeptide is post-translationally modified via intramolecular lanthionine bridges that are formed between unusual amino acids to yield the mature peptide. ${ }^{346}$ Nisin and several other lantibiotics target the pyrophosphate linkage component of the cell-wall precursor lipid II. As this target is different from that of the clinically used antibiotic vancomycin, there is no cross-resistance with glycopeptides, making them interesting new antibiotics for the treatment of methicillin resistant Staphylococcus aureus (MRSA) and vancomycin-resistant enterococci (VRE). ${ }^{347}$ Screening a library of 120000 chemical extracts derived from 40000 Actinobacteria for activity against cell-wall biosynthesis by Vicuron Pharmaceuticals identified five novel lantibiotics, including microbisporicin (also known and NAI-107) and planosporicin, produced by Microbispora corallina and Planobispora alba, respectively. ${ }^{348,349}$ The control of the BGCs for microbisporicin ( $m i b$ in $M$. corallina and $m l b$ in $M$. ATCC-PTA5024) and for planosporicin ( $p s p)$ have been studied in detail. $^{350-352}$ The BGCs have a gene for an extracytoplasmic function (ECF) $\sigma$-factor/anti- $\sigma$-factor complex (MibX/MibW for microbisporicin and PspX/PspW for planosporicin). ECF $\sigma$ factors mediate responses to extracellular signals and stress or steps in morphological differentiation, ${ }^{353,354}$ but their involvement in the control of antibiotic production was only recognized recently. The microbisporicin and planosporicin BGCs also contain a gene for a regulator with a LuxR-like C-terminal domain. Herein, we use microbisporicin biosynthesis as the example for both BGCs, see Fig. 7 for an overview of its control. The BGC is controlled by its own production by a feed-forward mechanism: deletion of mibA results in decreased transcription of the other mib genes, while growth of mibA mutant colonies adjacent to wild-type microbisporicin-producing colonies restored mib transcription. ${ }^{351,352,355}$ This effect is specific, since microbisporicin cannot induce the production of planosporicin by Planobispora alba. ${ }^{351}$ The mib cluster includes six transcription units, for synthesis, modification, proteolysis, export, immunity and regulation, and all except the mibA structural gene contain the ECF $\sigma$-factor promoter motif (GACC-N15-GCTAC) that is recognized by $\mathrm{MibX}^{350,352,355}$ (Fig. 7). The promoter of mibA is controlled by MibR; in turn, transcription of mibR depends on MibX and is enhanced by the stringent response. Indeed, deletion of relA in M. corallina abolishes microbisporicin production. Thus, a complex regulatory network ensures the correct timing of microbisporic biosynthesis, which is induced by both nitrogen starvation and the ensuing stringent response, which activates MibR expression and hence the expression of the (non-toxic)

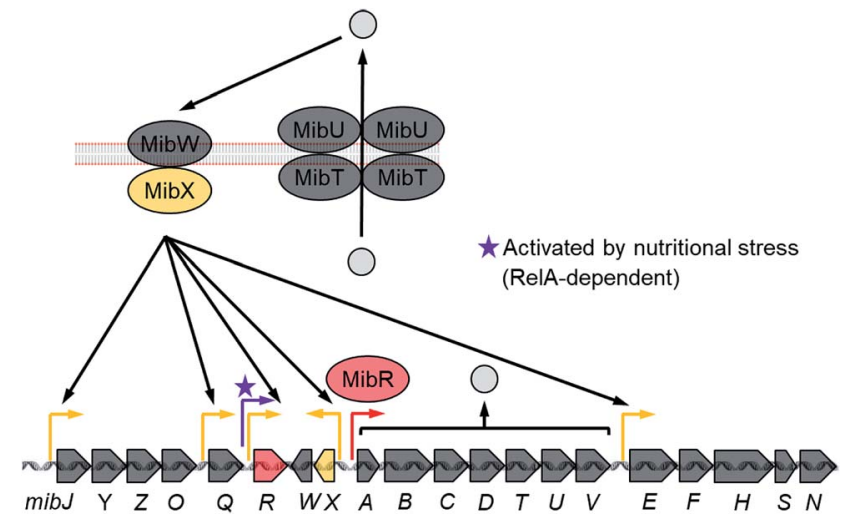

Fig. 7 The regulation of microbisporicin production by Microbispora corallina. Nutritional stress leads to the RelA-dependent production of ppGpp which results in the expression of the LuxR-family regulator MibR. MibR activates the expression of mibABCDTUV, which results in the production of an immature and less active form of microbisporicin (grey circle) and the means for its export. A basal level of expression of the genes encoding an ECF $\sigma$-factor (MibX)/anti- $\sigma$-factor (MibW) system enables a feed-forward regulatory mechanism. The immature compound itself or possibly interaction with its lipid II to be sensed by MibW, at which point the ECF $\sigma$-factor, MibX is released. MibX then in turn activates its own expression and that of mibR as well as the remaining genes in the $\mathrm{BGC}$.

precursor peptide. This precursor is then exported and processed to yield the active antibiotic. ${ }^{350}$ Under repressing conditions, MibX is recruited by the membrane bound anti sigma factor MibW, thereby shutting down the biosynthetic pathway. Microbisporicin production also directly depends on the developmental programme, with reduced expression in bld mutants, similarly to the biosynthesis of the morphogenic lantibiotic-like morphogen SapB in $S$. coelicolor. ${ }^{356}$ For a detailed overview on the regulation of RiPPs in Actinobacteria and other bacterial genera, we refer the reader a recent review. ${ }^{357}$

Involvement of $\sigma$ factors in the control of antibiotic production is not exclusive to lantibiotic BGCs. SigT regulates Act production in $S$. coelicolor via relA in response to nitrogen starvation, which links nitrogen stress to secondary metabolism. ${ }^{358}$ In $S$. albus, the ECF $\sigma^{\text {AntA }}$ controls the synthesis of the antimycin precursor, 3-formamidosalicylate, ${ }^{359,360}$ and $\sigma^{25}$ differentially controls the biosynthesis of oligomycin and of the important anti-helminthic drug avermectin in $S$. avermitilis. ${ }^{361}$ Antimycin is a mitochondrial cytochrome c reductase inhibitor produced by diverse Actinobacteria. $\sigma^{\text {AntA }}$ was the first example of regulation of antibiotic production by a cluster-situated ECF $\sigma$ factor in Streptomyces species and it was recently shown that this is likely to be a conserved strategy of regulation for more than 70 antimycin BGCs. ${ }^{362}$ Unlike other ECFs, which are controlled by an anti- $\sigma$ factor that is unable to maintain an inactive complex in the presence of cognate stimulus, $\sigma^{\mathrm{AntA}}$ is an orphan and is not controlled by such a factor. Instead, evidence to date suggests that $\sigma^{\text {AntA }}$ is controlled by Clp proteolysis. ${ }^{359}$ The involvement of $\sigma$-factor genes in the control of antibiotic production is a new concept, and in particular the presence of $\sigma$ factor genes within BGCs may function as beacons to identify BGCs in genome mining. 


\subsection{Regulation of antibiotic production in Salinispora}

Recently, studies have also been dedicated to the regulatory network of natural product biosynthesis in the marine actinomycete Salinispora. Salinispora is an obligate marine actinomycete and most of the isolates are derived from marine sediments. The genus knows three different species, under which S. pacifica, S. tropica and S. arenicola. ${ }^{363}$ The compounds that were discovered from this genus are predominantly new and therefore this genus is a good example of the concept that new genera derived from remote areas are a good source for the discovery of novel natural products. ${ }^{363}$ One of these studies reveals that in S. tropica CNB-440, a LuxR-type regulator positively regulates the biosynthesis of the important natural product salinisporamide A, a proteasome inhibitor that is in stage 1 of clinical trials of anti-cancer treatment. This regulator controls the genes involved in the biosynthesis of the salinisporamide A precursor chloroethylmaloyl-CoA, and thereby specifically regulates the production of salinisporamide A and not of other salinosporamides that are produced by $S$. tropica CNB-440. ${ }^{364}$

In the genus Salinispora an important concept for the study of cryptic gene clusters was revealed. ${ }^{365}$ Transcriptomic comparison of the Salinispora strains S. pacifica CNT-150, S. tropica CNB-440, S. arenicola CNS-205 and S. arenicola CNS991 revealed that BGCs common between different strains are not necessarily controlled in the same way and could be active in one while silent in another. Such strain-specific silencing of a BGC was explained by mutation of regulatory genes. Indeed, an orphan BGC in S. pacifica (STPKS1) was expressed normally, while its counterpart in $S$. tropica was silent due to the lack of the AraC-family CSR, which was replaced by a transposase. Interestingly, this silent gene cluster is conserved throughout the $S$. tropica clade, which suggests that either this BGC is permanently silenced or that another regulator is involved in the control of the BGC. The BGC for the enediyene PKS1A was silent in CNS-991 and expressed in CNS-205. Comparative genomics and transcriptomic data revealed that a $\sigma$ factor upstream of the BGC was expressed in S. arenicola CNS205, but not in CNS991. Differential expression of this $\sigma$ factor was proposed be a consequence of its different chromosomal location in the two strains. The BGC for the black spore pigment was present in all four Salinispora strains, but the full BGC was only expressed by S. tropica CNB-440 and S. pacifica CNT-150, whereas only a subset of the genes within the gene cluster was expressed in the two $S$. arenicola strains. The spore pigment BGCs that were entirely expressed contained one or two luxR genes, whereas the partially expressed BGC contained small genes encoding hypothetical proteins of unknown function. The sta gene cluster for staurosporine was also differentially expressed between the four Salinispora strains, but all strains contained the malT gene for the CSR. Finally, the fact that a BGC (NRPS4) was expressed in S. arenicola and S. pacifica, but not in $S$. tropica was explained by the lack of a xenobiotic response element in S. tropica. $^{365}$ Further genetic analysis of these interesting examples is required to fully understand the regulatory mechanisms for these BGCs. The differential expression of gene clusters between different species suggests that one feasible approach to the problem of silent gene clusters may be to look for the same (or highly similar) gene cluster in related Actinobacteria, and see if the cluster is expressed there. With the ever-growing genome sequence information, this approach is becoming increasingly feasible, and is particularly attractive in strains that are not genetically tractable.

\subsection{Regulation of rifamycin biosynthesis in Amycolatopsis mediterranei}

Recently, the molecular regulation of the rifamycin BGC was studied in Amycolatopsis mediterranei. Although rifamycin and its derivatives are the first-line anti-tuberculosis drugs, the regulation of the rifamycin BGC was only studied recently. Deletion of $g \ln R$ influences the biosynthesis of rifamycin, although this control is indirect. ${ }^{366}$ The LuxR-type regulator RifZ, encoded by the last gene in the gene cluster, positively controls all of the operons in the rifamycin BGC. ${ }^{367}$ The rifamycin BGC also encodes a TetR-family repressor (RifQ), which represses rifamycin biosynthesis and efflux. Deletion of rifQ resulted in increased production of rifamycin, while accumulation of rifamycin B lowered the affinity of RifQ for its target sequences. ${ }^{368}$ This system is consistent with what is known for other TetR-family regulators that control natural product biosynthesis.

\subsection{GBL-receptors and antibiotic production in Actinobacteria other than Streptomyces}

GBL-like molecules are produced by many Actinobacteria, including the industrial important strains A. teichomyceticus (producer of teicoplanin), A. mediterranei (produces rifamycin), and Micromonospora echinospora (produces gentamicin). ${ }^{369}$ The exact structures of the GBL molecules produced by these strains are unknown, but the type of GBL that is produced could be determined using binding assays with tritium-labeled GBL molecules as ligands. ${ }^{369,370}$ These binding assays confirmed that A. teichomyceticus produces a GBL similar to virginiae butenolide (VB) derived from $S$. viginiae. The strains A. mediterranei and M. echinospora produce a GBL similar to IM-2, derived from S. lavendulae (see Section 9.2). ${ }^{369}$ In the rifamycin producer A. mediterranei, four genes that encode GBL-receptor paralogues are present, namely bamA1-bamA4. ${ }^{371}$ All four receptor proteins can bind GBLs derived from Streptomyces, including VB from $S$. virginiae and SCB1 from S. coelicolor. Only BamA1 was shown to bind the IM-2 GBL, an autoregulator produced by A. mediterranei itself. ${ }^{369,371}$

Kitasatospora setae, a member of a genus closely related to Streptomyces, harbours several GBL-receptors. ${ }^{264,372} \mathrm{~K}$. setae produces bafilomycins A1 and B1. These macrolides specifically inhibit vacuolar $\mathrm{H}^{+}$-ATPases and are used in studies of molecular transport in eukaryotes. The genome of $K$. setae contains three genes that are similar to GBL-receptors, namely $k s b A, k s b B$ and $k s b C .{ }^{373} \mathrm{KsbA}$ binds ${ }^{3} \mathrm{H}$-labeled SCB1, and deletion of $k s b A$ increases bafilomycin biosynthesis. ${ }^{372}$ Conversely, KsbC indirectly represses bafilomycin biosynthesis, perhaps via the activation of the gene for the autoregulator KsbS4. ${ }^{373} \mathrm{KsbC}$ also 
indirectly activates the production of kitasetaline, a $\beta$-carboline alkaloid, and of the kitasetaline derivative JBIR-133. ${ }^{373}$

Interestingly, Rhodococcus jostii, a genus of the Nocardiaceae produces the GBL (called RJB) that is structurally identical to a precursor of SCB2 (6-dehydro SCB2) produced by $S$. coelicolor, and can bind to the $S$. coelicolor GBL receptor ScbR. ${ }^{374}$ This suggests cross-family communication mediated by GBLs in the natural environment. The gene for GBL biosynthesis, gblA, is located in a GBL BGC that is conserved between different Rhodoccocus species. This GBL BGC also encodes a GBL-receptor protein GblR and the biosynthesis enzyme GblE, which is an NAD-epimerase/dehydratase. Genome sequencing of $R$. jostii RHA1 indicated that the strain potentially has a rich NP biosynthetic repertoire. The precise role of GBLs in the regulation of natural product biosynthesis in Rhodococcus, and the value of the NPs these Actinobacteria can produce, merit further investigation.

\section{Outlook}

Over the last decade it has become increasingly clear that Streptomyces species and other antibiotic-producing Actinobacteria produce only a small percentage of their secondary metabolome under laboratory conditions. Accessing the chemistry specified by this 'silent majority' - also referred to as dark matter - without a doubt holds potential for drug discovery. This untapped resource can be harnessed by both genetic and non-genetic methods which been reviewed recently. ${ }^{375}$ The proverbial 'holy grail' in this respect is development of small molecules that can simply be added to culture media to elicit the production of all or ideally only a subset of compounds. Progress has been achieved in this area (i.e. sugarresponsive antibiotic repressors, REEs, GBLs and manipulation of $\mathrm{C}, \mathrm{N}$ and $\mathrm{P}$ concentrations, discussed above); the molecular insights that is reviewed above can be harnessed to develop strategies to activate antibiotic production. Clearly, more work is required with the identification of other small molecules. Reporter-based methods have therefore been developed to aid detection of activated or de-repressed gene clusters, ${ }^{376,377}$ and screening using small molecule libraries forms an attractive black box alternative to rational approaches that are based on molecular insights. ${ }^{378,379}$ For details on molecular, environmental and HT screening approaches to find elicitors we refer the reader to recent reviews. ${ }^{35,380}$ Elicitors are also instrumental in unsupervised metabolomics approaches, required to identify compounds in the complex metabolic matrix of microbial cultures. ${ }^{381}$ Here, significant fluctuation of the secondary metabolome needs to be achieved, allowing statistical correlation of a given bioactivity of interest to a specific metabolite and/or a BGC. NMR- or MS-based metabolomics then facilitate the identification of the sought-after bioactive molecules. ${ }^{382-385}$

Ultimately, the productivity of any given biosynthetic pathway is dictated by one or more CSRs. The examples provided by among others Salinispora show that BGCs may be silent in one species of a given genus, and active in another. Thus, with the growing wealth of genome sequence information, a promising strategy is to look for related bacteria that harbour a close relative of the gene cluster of interest. Indeed, it is not illogical to assume that over the hundreds of millions of years of evolution, the natural products specified by the BGCs have remained structurally the same or highly similar, but are expressed under different growth conditions or in response to different environmental stimuli. The functionality of most putative CSRs can be deduced bioinformatically (i.e. as a repressor or an activator). Therefore, an obvious strategy and one that is commonly employed for elicitation of poorly expressed BGCs is augmentation of endogenous regulatory system(s). For example, by deleting genes encoding repressors or over-expressing those encoding activators. ${ }^{232,386}$ This strategy depends upon the genetic tractability of the organism, but this is becoming less and less of a requirement as the cloning of large genomic fragments and their de novo synthesis becomes more feasible, which enables their tractability and heterologous expression in a panel of potential hosts. ${ }^{387-389}$ Indeed, it is now possible to completely refactor the regulation of a biosynthetic pathway by replacing native promoters with those that are constitutively expressed to increase production titres using CRISPR-Cas9 technology. ${ }^{390}$ Longer term, improved understanding of how secondary metabolism is controlled and the development of approaches to exploit this and/or efficient synthetic biology strategies to activate biosynthetic pathways are required in order to capitalise on the treasures beneath our feet.

\section{Conflicts of interest}

The authors have no conflicts to declare.

\section{Acknowledgements}

The work was supported by grants 731.014.206 and 14221 from the Netherlands Organization for Scientific Research to GPvW.

\section{References}

1 R. H. Baltz, Curr. Opin. Pharmacol., 2008, 8, 557-563.

2 E. A. Barka, P. Vatsa, L. Sanchez, N. Gavaut-Vaillant, C. Jacquard, J. Meier-Kolthoff, H. P. Klenk, C. Clément, Y. Oudouch and G. P. van Wezel, Microbiol. Mol. Biol. Rev., 2016, 80, 1-43.

3 P. Caffrey, J. F. Aparicio, F. Malpartida and S. B. Zotchev, Curr. Top. Med. Chem., 2008, 8, 639-653.

4 D. A. Hopwood, Streptomyces in nature and medicine: the antibiotic makers, Oxford University Press, New York, 2007.

5 C. Olano, C. Mendez and J. A. Salas, Nat. Prod. Rep., 2009, 26, 628-660.

6 A. L. Harvey, R. Edrada-Ebel and R. J. Quinn, Nat. Rev. Drug Discovery, 2015, 14, 111-129.

7 K. Lewis, Nat. Rev. Drug Discovery, 2013, 12, 371-387.

8 M. I. Abrudan, F. Smakman, A. J. Grimbergen, S. Westhoff, E. L. Miller, G. P. van Wezel and D. E. Rozen, Proc. Natl. Acad. Sci. U. S. A., 2015, 112, 11054-11059.

9 J. M. Raaijmakers and M. Mazzola, Annu. Rev. Phytopathol., 2012, 50, 403-424. 
10 W. C. Ratcliff and R. F. Denison, Science, 2011, 332, 547548.

11 J. Davies, G. B. Spiegelman and G. Yim, Curr. Opin. Microbiol., 2006, 9, 445-453.

12 J. F. Linares, I. Gustafsson, F. Baquero and J. L. Martinez, Proc. Natl. Acad. Sci. U. S. A., 2006, 103, 19484-19489.

13 D. Romero, M. F. Traxler, D. Lopez and R. Kolter, Chem. Rev., 2011, 111, 5492-5505.

14 D. I. Andersson and D. Hughes, Nat. Rev. Microbiol., 2014, 12, 465-478.

15 E. Gullberg, L. M. Albrecht, C. Karlsson, L. Sandegren and D. I. Andersson, mBio, 2014, 5(5), e01918-14.

16 S. Westhoff, T. M. van Leeuwe, O. Qachach, Z. Zhang, G. P. van Wezel and D. E. Rozen, ISME J., 2017, 11, 11681178.

17 D. P. Labeda, M. Goodfellow, R. Brown, A. C. Ward, B. Lanoot, M. Vanncanneyt, J. Swings, S. B. Kim, Z. Liu, J. Chun, T. Tamura, A. Oguchi, T. Kikuchi, H. Kikuchi, T. Nishii, K. Tsuji, Y. Yamaguchi, A. Tase, M. Takahashi, T. Sakane, K. I. Suzuki and K. Hatano, Antonie van Leeuwenhoek, 2012, 101, 73-104.

18 W. Ludwig, J. Euzeby, P. Schumann, H.-J. Busse, M. E. Trujillo, P. Kämpfer and W. B. Whitman, in Bergey's Manual of Systematic Bacteriology, ed. M. Goodfellow, P. Kämpfer, H.-J. Busse, M. E. Trujillo, K.-I. Suzuki, W. Ludwig and W. B. Whitman, Springer, New York, 2nd edn, 2012, vol. 5, pp. 1-28.

19 S. D. Bentley, K. F. Chater, A. M. Cerdeno-Tarraga, G. L. Challis, N. R. Thomson, K. D. James, D. E. Harris, M. A. Quail, H. Kieser, D. Harper, A. Bateman, S. Brown, G. Chandra, C. W. Chen, M. Collins, A. Cronin, A. Fraser, A. Goble, J. Hidalgo, T. Hornsby, S. Howarth, C. H. Huang, T. Kieser, L. Larke, L. Murphy, K. Oliver, S. O'Neil, E. Rabbinowitsch, M. A. Rajandream, K. Rutherford, S. Rutter, K. Seeger, D. Saunders, S. Sharp, R. Squares, S. Squares, K. Taylor, T. Warren, A. Wietzorrek, J. Woodward, B. G. Barrell, J. Parkhill and D. A. Hopwood, Nature, 2002, 417, 141-147.

20 K. F. Chater, in Streptomyces: Molecular Biology and Biotechnology, ed. P. Dyson, Caister Academic Press, Norfolk, UK, 2011, pp. 43-86.

21 K. F. Chater and R. Losick, in Bacteria as multicellular organisms, ed. J. A. Shapiro and M. Dworkin, Oxford University Press, New York, 1997, pp. 149-182.

22 D. Claessen, D. E. Rozen, O. P. Kuipers, L. SogaardAndersen and G. P. van Wezel, Nat. Rev. Microbiol., 2014, 12, 115-124.

23 K. Flärdh and M. J. Buttner, Nat. Rev. Microbiol., 2009, 7, 3649.

24 D. A. Hopwood, Microbiology, 1999, 145, 2183-2202.

25 M. J. Merrick, J. Gen. Microbiol., 1976, 96, 299-315.

26 K. F. Chater, J. Gen. Microbiol., 1972, 72, 9-28.

27 K. F. Chater, S. Biro, K. J. Lee, T. Palmer and H. Schrempf, FEMS Microbiol. Rev., 2010, 34, 171-198.

28 K. F. Chater and G. Chandra, FEMS Microbiol. Rev., 2006, 30, 651-672.

29 D. A. Hopwood, Annu. Rev. Genet., 2006, 40, 1-23.
30 G. H. Kelemen and M. J. Buttner, Curr. Opin. Microbiol., 1998, 1, 656-662.

31 M. J. Bibb, Curr. Opin. Microbiol., 2005, 8, 208-215.

32 G. Liu, K. F. Chater, G. Chandra, G. Niu and H. Tan, Microbiol. Mol. Biol. Rev., 2013, 77, 112-143.

33 G. P. van Wezel and K. J. McDowall, Nat. Prod. Rep., 2011, 28, 1311-1333.

34 R. F. Seipke, M. Kaltenpoth and M. I. Hutchings, FEMS Microbiol. Rev., 2012, 36, 862-876.

35 A. van der Meij, S. F. Worsley, M. I. Hutchings and G. P. van Wezel, FEMS Microbiol. Rev., 2017, 41, 392-416.

36 D. R. Bignell, R. F. Seipke, J. C. Huguet-Tapia, A. H. Chambers, R. J. Parry and R. Loria, Mol. PlantMicrobe Interact., 2010, 23, 161-175.

37 R. Loria, D. R. Bignell, S. Moll, J. C. Huguet-Tapia, M. V. Joshi, E. G. Johnson, R. F. Seipke and D. M. Gibson, Antonie van Leeuwenhoek, 2008, 94, 3-10.

38 B. A. Rudd and D. A. Hopwood, J. Gen. Microbiol., 1979, 114, 35-43.

39 J. S. Feitelson, F. Malpartida and D. A. Hopwood, J. Gen. Microbiol., 1985, 131, 2431-2441.

40 D. A. Hopwood and H. M. Wright, J. Gen. Microbiol., 1983, 129, 3575-3579.

41 L. F. Wright and D. A. Hopwood, J. Gen. Microbiol., 1976, 95, 96-106.

42 G. L. Challis and D. A. Hopwood, Proc. Natl. Acad. Sci. U. S. A., 2003, 100, 14555-14561.

43 G. van Keulen and P. J. Dyson, Adv. Appl. Microbiol., 2014, 89, 217-266.

44 J. P. Gomez-Escribano, L. Song, D. J. Fox, V. Yeo, M. J. Bibb and G. L. Challis, Chem. Sci., 2012, 3, 2716-2720.

45 K. Pawlik, M. Kotowska, K. F. Chater, K. Kuczek and E. Takano, Arch. Microbiol., 2007, 187, 87-99.

46 G. Cao, C. Zhong, G. Zong, J. Fu, Z. Liu, G. Zhang and R. Qin, Genome Announc., 2016, 4(5), e01020-16.

47 P. Cruz-Morales, E. Vijgenboom, F. Iruegas-Bocardo, G. Girard, L. A. Yanez-Guerra, H. E. Ramos-Aboites, J. L. Pernodet, J. Anne, G. P. van Wezel and F. BaronaGomez, Genome Biol. Evol., 2013, 5, 1165-1175.

48 H. Ikeda, J. Ishikawa, A. Hanamoto, M. Shinose, H. Kikuchi, T. Shiba, Y. Sakaki, M. Hattori and S. Omura, Nat. Biotechnol., 2003, 21, 526-531.

49 Y. Ohnishi, J. Ishikawa, H. Hara, H. Suzuki, M. Ikenoya, H. Ikeda, A. Yamashita, M. Hattori and S. Horinouchi, J. Bacteriol., 2008, 190, 4050-4060.

50 M. Oliynyk, M. Samborskyy, J. B. Lester, T. Mironenko, N. Scott, S. Dickens, S. F. Haydock and P. F. Leadlay, Nat. Biotechnol., 2007, 25, 447-453.

51 D. W. Udwary, L. Zeigler, R. N. Asolkar, V. Singan, A. Lapidus, W. Fenical, P. R. Jensen and B. S. Moore, Proc. Natl. Acad. Sci. U. S. A., 2007, 104, 10376-10381.

52 H. Gross, Curr. Opin. Drug Discovery Dev., 2009, 12, 207-219.

53 M. H. Medema, R. Breitling, R. Bovenberg and E. Takano, Nat. Rev. Microbiol., 2011, 9, 131-137.

54 M. Nett, H. Ikeda and B. S. Moore, Nat. Prod. Rep., 2009, 26, 1362-1384.

55 M. Zerikly and G. L. Challis, ChemBioChem, 2009, 10, 625-633. 
56 K. Ochi, Y. Tanaka and S. Tojo, J. Ind. Microbiol. Biotechnol., 2014, 41, 403-414.

57 P. J. Rutledge and G. L. Challis, Nat. Rev. Microbiol., 2015, 13, 509-523.

58 V. Yoon and J. R. Nodwell, J. Ind. Microbiol. Biotechnol., 2014, 41, 415-424.

59 H. Zhu, S. K. Sandiford and G. P. van Wezel, J. Ind. Microbiol. Biotechnol., 2014, 41, 371-386.

60 M. Medema, K. Blin, P. Cimermancic, V. de Jager, P. Zakrzewski, M. A. Fischbach, T. Weber, E. Takano and R. Breitling, Nucleic Acids Res., 2011, 39, W339-W346.

61 T. Weber, C. Rausch, P. Lopez, I. Hoof, V. Gaykova, D. H. Huson and W. Wohlleben, J. Bacteriol., 2009, 140, 13-17.

62 M. A. Skinnider, N. J. Merwin, C. W. Johnston and N. A. Magarvey, Nucleic Acids Res., 2017, 45, W49-W54.

63 M. Rottig, M. H. Medema, K. Blin, T. Weber, C. Rausch and O. Kohlbacher, Nucleic Acids Res., 2011, 39, W362-W367.

64 A. de Jong, A. J. van Heel, J. Kok and O. P. Kuipers, Nucleic Acids Res., 2010, 38, W647-W651.

65 G. Yadav, R. S. Gokhale and D. Mohanty, Nucleic Acids Res., 2003, 31, 3654-3658.

66 A. K. Chavali and S. Y. Rhee, Briefings Bioinf., 2017, bbx020. 67 N. Ziemert, M. Alanjary and T. Weber, Nat. Prod. Rep., 2016, 33, 988-1005.

68 A. Wietzorrek and M. Bibb, Mol. Microbiol., 1997, 25, 11811184.

69 S. Autret, R. Nair and J. Errington, Mol. Microbiol., 2001, 41, 743-755.

70 H. C. Gramajo, E. Takano and M. J. Bibb, Mol. Microbiol., 1993, 7, 837-845.

71 A. Tomono, Y. Tsai, H. Yamazaki, Y. Ohnishi and S. Horinouchi, J. Bacteriol., 2005, 187, 5595-5604.

72 G. P. van Wezel, J. White, G. Hoogvliet and M. J. Bibb, J. Mol. Microbiol. Biotechnol., 2000, 2, 551-556.

73 E. P. Guthrie, C. S. Flaxman, J. White, D. A. Hodgson, M. J. Bibb and K. F. Chater, Microbiology, 1998, 144, 727-738.

74 J. White and M. Bibb, J. Bacteriol., 1997, 179, 627-633.

75 M. I. Hutchings, Adv. Appl. Microbiol., 2007, 61, 1-26.

76 M. Carmody, B. Byrne, B. Murphy, C. Breen, S. Lynch, E. Flood, S. Finnan and P. Caffrey, Gene, 2004, 343, 107-115.

77 O. N. Sekurova, T. Brautaset, H. Sletta, S. E. F. Borgos, O. M. Jakobsen, T. E. Ellingsen, A. R. Strom, S. Valla and S. B. Zotchev, J. Bacteriol., 2004, 186, 1345-1354.

78 C. M. Vicente, J. Santos-Aberturas, T. D. Payero, E. G. Barreales, A. de Pedro and J. F. Aparicio, Appl. Microbiol. Biotechnol., 2014, 98, 9311-9324.

79 P. Zhang, Z. Zhao, H. Li, X. L. Chen, Z. Deng, L. Bai and X. Pang, Microbiology, 2015, 161, 539-552.

80 E. Takano, Curr. Opin. Microbiol., 2006, 9, 287-294.

81 J. M. Willey and A. A. Gaskell, Chem. Rev., 2011, 111, 174187.

82 K. Tahlan, S. K. Ahn, A. Sing, T. D. Bodnaruk, A. R. Willems, A. R. Davidson and J. R. Nodwell, Mol. Microbiol., 2007, 63, 951-961.

83 L. Wang, X. Tian, J. Wang, H. Yang, K. Fan, G. Xu, K. Yang and H. Tan, Proc. Natl. Acad. Sci. U. S. A., 2009, 106, 86178622.
84 A. R. Willems, K. Tahlan, T. Taguchi, K. Zhang, Z. Z. Lee, K. Ichinose, M. S. Junop and J. R. Nodwell, J. Mol. Biol., 2008, 376, 1377-1387.

85 S. Horinouchi, Biosci., Biotechnol., Biochem., 2007, 71, 283299.

86 Y. Ohnishi, S. Kameyama, H. Onaka and S. Horinouchi, Mol. Microbiol., 1999, 34, 102-111.

87 H. Onaka, N. Ando, T. Nihira, Y. Yamada, T. Beppu and S. Horinouchi, J. Bacteriol., 1995, 177, 6083-6092.

88 H. Onaka and S. Horinouchi, Mol. Microbiol., 1997, 24, 9911000.

89 Y. Ohnishi, H. Yamazaki, J. Y. Kato, A. Tomono and S. Horinouchi, Biosci., Biotechnol., Biochem., 2005, 69, 431-439.

90 G. Akanuma, H. Hara, Y. Ohnishi and S. Horinouchi, Mol. Microbiol., 2009, 73, 898-912.

91 J. Y. Kato, N. Funa, H. Watanabe, Y. Ohnishi and S. Horinouchi, Proc. Natl. Acad. Sci. U. S. A., 2007, 104, 2378-2383.

92 S. Hirano, K. Tanaka, Y. Ohnishi and S. Horinouchi, Microbiology, 2008, 154, 905-914.

93 B. Hong, S. Phornphisutthimas, E. Tilley, S. Baumberg and K. J. McDowall, Biotechnol. Lett., 2007, 29, 57-64.

94 G. C. Uguru, K. E. Stephens, J. A. Stead, J. E. Towle, S. Baumberg and K. J. McDowall, Mol. Microbiol., 2005, 58, 131-150.

95 M. A. Swiatek-Polatynska, G. Bucca, E. Laing, J. Gubbens, F. Titgemeyer, C. P. Smith, S. Rigali and G. P. van Wezel, PLoS One, 2015, 10, e0122479.

96 S. Colson, J. Stephan, T. Hertrich, A. Saito, G. P. van Wezel, F. Titgemeyer and S. Rigali, J. Mol. Microbiol. Biotechnol., 2007, 12, 60-66.

97 S. Rigali, H. Nothaft, E. E. Noens, M. Schlicht, S. Colson, M. Muller, B. Joris, H. K. Koerten, D. A. Hopwood, F. Titgemeyer and G. P. van Wezel, Mol. Microbiol., 2006, 61, 1237-1251.

98 N. L. McKenzie and J. R. Nodwell, J. Bacteriol., 2007, 189, 5284-5292.

99 P. Brian, P. J. Riggle, R. A. Santos and W. C. Champness, J. Bacteriol., 1996, 178, 3221-3231.

$100 \mathrm{~W}$. Champness, P. Riggle, T. Adamidis and P. Vandervere, Gene, 1992, 115, 55-60.

101 S. Rico, R. I. Santamaria, A. Yepes, H. Rodriguez, E. Laing, G. Bucca, C. P. Smith and M. Diaz, Appl. Environ. Microbiol., 2014, 80, 2417-2428.

102 A. Yepes, S. Rico, A. Rodriguez-Garcia, R. I. Santamaria and M. Diaz, PLoS One, 2011, 6, e19980.

103 C. Gao, H. Hindra, D. Mulder, C. Yin and M. A. Elliot, mBio, 2012, 3, 00407-00412.

104 B. Gorke and J. Stülke, Nat. Rev. Microbiol., 2008, 6, 613624.

105 H. Korner, H. J. Sofia and W. G. Zumft, FEMS Microbiol. Rev., 2003, 27, 559-592.

106 A. Piette, A. Derouaux, P. Gerkens, E. E. Noens, G. Mazzucchelli, S. Vion, H. K. Koerten, F. Titgemeyer, E. De Pauw, P. Leprince, G. P. van Wezel, M. Galleni and S. Rigali, J. Proteome Res., 2005, 4, 1699-1708. 
107 R. Chakraburtty and M. Bibb, J. Bacteriol., 1997, 179, 58545861.

108 S. G. Kang, W. Jin, M. Bibb and K. J. Lee, FEMS Microbiol. Lett., 1998, 168, 221-226.

109 J. H. Sun, A. Hesketh and M. Bibb, J. Bacteriol., 2001, 183, 3488-3498.

110 H. Rodriguez, S. Rico, M. Diaz and R. I. Santamaria, Microb. Cell Fact., 2013, 12, 127.

111 D. Shu, L. Chen, W. Wang, Z. Yu, C. Ren, W. Zhang, S. Yang, Y. Lu and W. Jiang, Appl. Microbiol. Biotechnol., 2009, 81, 1149-1160.

112 M. Urem, T. van Rossum, G. Bucca, G. F. Moolenaar, E. Laing, M. A. Świątek-Połatyńska, J. Willemse, E. Tenconi, S. Rigali, N. Goosen, C. P. Smith and G. P. van Wezel, mSystems, 2016, 1, e00014-00016.

113 Z. Yu, H. Zhu, F. Dang, W. Zhang, Z. Qin, S. Yang, H. Tan, Y. Lu and W. Jiang, Mol. Microbiol., 2012, 85, 535-556.

114 A. M. Stock, V. L. Robinson and P. N. Goudreau, Annu. Rev. Biochem., 2000, 69, 183-215.

115 D. E. Whitworth, in Two-component systems in bacteria, ed. R. Gross and D. Beier, Caister Academic Press, Poole, UK, 2012, ch. 1, pp. 1-20.

116 M. I. Hutchings, P. A. Hoskisson, G. Chandra and M. J. Buttner, Microbiology, 2004, 150, 2795-2806.

117 J. F. Martin and P. Liras, Subcell. Biochem., 2012, 64, 115138.

118 A. Sola-Landa, A. Rodriguez-Garcia, E. Franco-Dominguez and J. F. Martin, Mol. Microbiol., 2005, 56, 1373-1385.

119 A. Sola-Landa, R. S. Moura and J. F. Martin, Proc. Natl. Acad. Sci. U. S. A., 2003, 100, 6133-6138.

120 F. Daigle, S. Lerat, G. Bucca, E. Sanssouci, C. P. Smith, F. Malouin and C. Beaulieu, J. Bacteriol., 2015, 197, 913-923.

121 T. C. McLean, P. A. Hoskisson and R. F. Seipke, mSphere, 2016, 1(6), e00305-16.

122 C. M. Vicente, T. D. Payero, J. Santos-Aberturas, E. G. Barreales, A. de Pedro and J. F. Aparicio, Appl. Microbiol. Biotechnol., 2015, 99, 5123-5135.

123 J. Santos-Aberturas, T. D. Payero, C. M. Vicente, S. M. Guerra, C. Canibano, J. F. Martin and J. F. Aparicio, Metab. Eng., 2011, 13, 756-767.

124 K. J. McDowall, A. Thamchaipenet and I. S. Hunter, J. Bacteriol., 1999, 181, 3025-3032.

125 M. Martinez-Castro, Z. Salehi-Najafabadi, F. Romero, R. PerezSanchiz, R. I. Fernandez-Chimeno, J. F. Martin and C. Barreiro, Appl. Microbiol. Biotechnol., 2013, 97, 2139-2152.

126 J. L. Doull and L. C. Vining, Biotechnol. Adv., 1990, 8, 141158.

127 H. Chouayekh and M. J. Virolle, Mol. Microbiol., 2002, 43, 919-930.

128 C. Fabret, V. A. Feher and J. A. Hoch, J. Bacteriol., 1999, 181, 1975-1983.

129 F. Santos-Beneit, Front. Microbiol., 2015, 6, 402.

130 L. T. Fernandez-Martinez, F. Santos-Beneit and J. F. Martin, Mol. Gen. Genet., 2012, 287, 565-573.

131 M. Diaz, A. Esteban, J. M. Fernandez-Abalos and R. I. Santamaria, Microbiology, 2005, 151, 2583-2592.
132 F. Santos-Beneit, A. Rodriguez-Garcia, E. FrancoDominguez and J. F. Martin, Microbiology, 2008, 154, 2356-2370.

133 S. Horinouchi, J. Ind. Microbiol. Biotechnol., 2003, 30, 462467.

134 T. Umeyama, P.-C. Lee and S. Horinouchi, Appl. Microbiol. Biotechnol., 2002, 59, 419-425.

135 F. Santos-Beneit, A. Rodríguez-García, A. Sola-Landa and J. F. Martín, Mol. Microbiol., 2009, 72, 53-68.

136 S. K. Hong, M. Kito, T. Beppu and S. Horinouchi, J. Bacteriol., 1991, 173, 2311-2318.

137 A. Matsumoto, S. K. Hong, H. Ishizuka, S. Horinouchi and T. Beppu, Gene, 1994, 146, 47-56.

138 A. Tanaka, Y. Takano, Y. Ohnishi and S. Horinouchi, J. Mol. Biol., 2007, 369, 322-333.

139 F. Santos-Beneit, A. Rodriguez-Garcia and J. F. Martin, J. Bacteriol., 2011, 193, 2242-2251.

140 N. E. Allenby, E. Laing, G. Bucca, A. M. Kierzek and C. P. Smith, Nucleic Acids Res., 2012, 40, 9543-9556.

141 E. Takano, H. Kinoshita, V. Mersinias, G. Bucca, G. Hotchkiss, T. Nihira, C. P. Smith, M. Bibb, W. Wohlleben and K. Chater, Mol. Microbiol., 2005, 56, 465-479.

142 E. Takano, R. Chakraburtty, T. Nihira, Y. Yamada and M. J. Bibb, Mol. Microbiol., 2001, 41, 1015-1028.

143 R. Yang, X. Liu, Y. Wen, Y. Song, Z. Chen and J. Li, Appl. Microbiol. Biotechnol., 2015, 99, 10547-10557.

144 J. Reuther and W. Wohlleben, J. Mol. Microbiol. Biotechnol., 2007, 12, 139-146.

145 Y. Tiffert, P. Supra, R. Wurm, W. Wohlleben, R. Wagner and J. Reuther, Mol. Microbiol., 2008, 67, 861-880.

146 J. Wang and G.-P. Zhao, Biochem. Biophys. Res. Commun., 2009, 386, 77-81.

147 L. Reitzer and B. L. Schneider, Microbiol. Mol. Biol. Rev., 2001, 65, 422-444.

148 M. J. Merrick and R. A. Edwards, Microbiol. Rev., 1995, 59, 604-622.

149 S. Sanchez and A. L. Demain, Enzyme Microb. Technol., 2002, 31, 895-906.

150 L. V. Wray, M. R. Atkinson and S. H. Fisher, J. Bacteriol., 1991, 173, 7351-7360.

151 Y. Tiffert, M. Franz-Wachtel, C. Fladerer, A. Nordheim, J. Reuther, W. Wohlleben and Y. Mast, Appl. Microbiol. Biotechnol., 2011, 89, 1149-1159.

152 J. M. He, H. Zhu, G. S. Zheng, P. P. Liu, J. Wang, G. P. Zhao, G. Q. Zhu, W. H. Jiang and Y. H. Lu, J. Biol. Chem., 2016, 291, 26443-26454.

153 Z. Hostalek, Folia Microbiol., 1980, 25, 445-450.

154 S. Sanchez, A. Chavez, A. Forero, Y. Garcia-Huante, A. Romero, M. Sanchez, D. Rocha, B. Sanchez, M. Avalos, S. Guzman-Trampe, R. Rodriguez-Sanoja, E. Langley and B. Ruiz, J. Antibiot., 2010, 63, 442-459.

155 E. S. Kim, H. J. Hong, C. Y. Choi and S. N. Cohen, J. Bacteriol., 2001, 183, 2969.

156 H. N. Lee, J. H. Im, M. J. Lee, S. Y. Lee and E. S. Kim, Process Biochem., 2009, 44, 373-377. 
157 R. K. Bhatnagar, J. L. Doull and L. C. Vining, Can. J. Microbiol., 1988, 34, 1217-1223.

158 A. L. Demain and E. Inamine, Bacteriol. Rev., 1970, 34, 1-19.

159 L. Escalante, H. Lopez, R. D. Mateos, F. Lara and S. Sanchez, J. Gen. Microbiol., 1982, 128, 2011-2015.

160 O. Bermudez, P. Padilla, C. Huitron and M. E. Flores, FEMS Microbiol. Lett., 1998, 164, 77-82.

161 F. Titgemeyer and W. Hillen, Antonie van Leeuwenhoek, 2002, 82, 59-71.

162 J. Deutscher, C. Francke and P. W. Postma, Microbiol. Mol. Biol. Rev., 2006, 70, 939-1031.

163 J. B. Warner and J. S. Lolkema, Microbiol. Mol. Biol. Rev., 2003, 67, 475-490.

164 B. Goerke and J. Stulke, Nat. Rev. Microbiol., 2008, 6, 613624.

165 P. W. Postma, J. W. Lengeler and G. R. Jacobson, Microbiol. Rev., 1993, 57, 543-594.

166 M. H. Saier Jr. and J. Reizer, J. Bacteriol., 1992, 174, 14331438.

167 R. Brückner and F. Titgemeyer, FEMS Microbiol. Lett., 2002, 209, 141-148.

168 M. G. Gunnewijk, P. T. van den Bogaard, L. M. Veenhoff, E. H. Heuberger, W. M. de Vos, M. Kleerebezem, O. P. Kuipers and B. Poolman, J. Mol. Microbiol. Biotechnol., 2001, 3, 401-413.

169 H. Nothaft, D. Dresel, A. Willimek, K. Mahr, M. Niederweis and F. Titgemeyer, J. Bacteriol., 2003, 185, 7019-7023.

170 S. Lambert, M. F. Traxler, M. Craig, M. Maciejewska, M. Ongena, G. P. van Wezel, R. Kolter and S. Rigali, Metallomics, 2014, 6, 1390-1399.

171 M. F. Traxler, M. R. Seyedsayamdost, J. Clardy and R. Kolter, Mol. Microbiol., 2012, 86, 628-644.

172 K. Yamanaka, H. Oikawa, H. O. Ogawa, K. Hosono, F. Shinmachi, H. Takano, S. Sakuda, T. Beppu and K. Ueda, Microbiology, 2005, 151, 2899-2905.

173 R. Perez-Redondo, I. Santamarta, R. Bovenberg, J. F. Martin and P. Liras, Microbiology, 2010, 156, 1527-1537.

174 A. Romero, B. Ruiz, J. K. Sohng, N. Koirala, R. RodriguezSanoja and S. Sanchez, Appl. Biochem. Biotechnol., 2015, 175, 3207-3217.

175 G. P. van Wezel, K. Mahr, M. Konig, B. A. Traag, E. F. Pimentel-Schmitt, A. Willimek and F. Titgemeyer, Mol. Microbiol., 2005, 55, 624-636.

176 D. A. Hodgson, J. Gen. Microbiol., 1982, 128, 2417-2430.

177 E. T. Seno and K. F. Chater, J. Gen. Microbiol., 1983, 129, 1403-1413.

178 S. Angell, C. G. Lewis, M. J. Buttner and M. J. Bibb, Mol. Gen. Genet., 1994, 244, 135-143.

179 S. Angell, E. Schwarz and M. J. Bibb, Mol. Microbiol., 1992, 6, 2833-2844.

180 J. H. J. M. Kwakman and P. W. Postma, J. Bacteriol., 1994, 176, 2694-2698.

181 G. P. van Wezel, M. Konig, K. Mahr, H. Nothaft, A. W. Thomae, M. Bibb and F. Titgemeyer, J. Mol. Microbiol. Biotechnol., 2007, 12, 67-74.

182 A. Chavez, A. Forero, M. Sanchez, R. Rodriguez-Sanoja, G. Mendoza-Hernandez, L. Servin-Gonzalez, B. Sanchez,
Y. Garcia-Huante, D. Rocha, E. Langley, B. Ruiz and S. Sanchez, Appl. Microbiol. Biotechnol., 2011, 89, 799-806.

183 S. Guzman, A. Carmona, L. Escalante, I. Imriskova,

R. Lopez, R. Rodriguez-Sanoja, B. Ruiz, L. ServinGonzalez, S. Sanchez and E. Langley, Microbiology, 2005, 151, 1717-1723.

184 J. Gagnat, H. Chouayekh, C. Gerbaud, F. Francou and M. J. Virolle, Microbiology, 1999, 145(Pt 9), 2303-2312.

185 H. Chouayekh, H. Nothaft, S. Delaunay, M. Linder, B. Payrastre, N. Seghezzi, F. Titgemeyer and M. J. Virolle, J. Bacteriol., 2007, 189, 741-749.

186 I. Ramos, S. Guzman, L. Escalante, I. Imriskova, R. Rodriguez-Sanoja, S. Sanchez and E. Langley, Res. Microbiol., 2004, 155, 267-274.

187 M. K. Pope, B. Green and J. Westpheling, J. Bacteriol., 1998, 180, 1556-1562.

188 M. K. Pope, B. D. Green and J. Westpheling, Mol. Microbiol., 1996, 19, 747-756.

189 M. Eccleston, R. A. Ali, R. Seyler, J. Westpheling and J. Nodwell, J. Bacteriol., 2002, 184, 4270-4276.

190 M. Urem, M. A. Swiatek-Polatynska, S. Rigali and G. P. van Wezel, Mol. Microbiol., 2016, 102, 183-195.

191 S. Colson, G. P. van Wezel, M. Craig, E. E. Noens, H. Nothaft, A. M. Mommaas, F. Titgemeyer, B. Joris and S. Rigali, Microbiology, 2008, 154, 373-382.

192 J. W. Seo, Y. Ohnishi, A. Hirata and S. Horinouchi, J. Bacteriol., 2002, 184, 91-103.

193 B. Nazari, M. Kobayashi, A. Saito, A. Hassaninasab, K. Miyashita and T. Fujii, Appl. Environ. Microbiol., 2012, 79, 707-713.

194 S. Rigali, F. Titgemeyer, S. Barends, S. Mulder, A. W. Thomae, D. A. Hopwood and G. P. van Wezel, EMBO Rep., 2008, 9, 670-675.

195 M. Craig, S. Lambert, S. Jourdan, E. Tenconi, S. Colson, M. Maciejewska, M. Ongena, J. F. Martin, G. van Wezel and S. Rigali, Environ. Microbiol. Rep., 2012, 4, 512-521.

196 C. Liao, S. Rigali, C. L. Cassani, E. Marcellin, L. K. Nielsen and B. C. Ye, Microbiology, 2014, 160, 1914-1928.

197 C. H. Liao, Y. Xu, S. Rigali and B. C. Ye, Appl. Microbiol. Biotechnol., 2015, 99, 10215-10224.

198 S. B. Fillenberg, M. D. Friess, S. Korner, R. A. Bockmann and Y. A. Muller, PLoS One, 2016, 11, e0157691.

199 S. B. Fillenberg, F. C. Grau, G. Seidel and Y. A. Muller, Nucleic Acids Res., 2015, 43, 1283-1296.

200 G. P. van Wezel, N. L. McKenzie and J. R. Nodwell, Methods Enzymol., 2009, 458, 117-141.

201 E. Tenconi, M. Urem, M. A. Swiatek-Polatynska, F. Titgemeyer, Y. A. Muller, G. P. van Wezel and S. Rigali, Biochem. Biophys. Res. Commun., 2015, 464, 324-329.

202 S. Hiard, R. Maree, S. Colson, P. A. Hoskisson, F. Titgemeyer, G. P. van Wezel, B. Joris, L. Wehenkel and S. Rigali, Biochem. Biophys. Res. Commun., 2007, 357, 861864 .

203 Z. Hindle and C. P. Smith, Mol. Microbiol., 1994, 12, 737745.

204 G. P. van Wezel, J. White, P. Young, P. W. Postma and M. J. Bibb, Mol. Microbiol., 1997, 23, 537-549. 
205 H. Nothaft, S. Rigali, B. Boomsma, M. Swiatek, K. J. McDowall, G. P. van Wezel and F. Titgemeyer, Mol. Microbiol., 2010, 75, 1133-1144.

206 S. H. Kim, B. A. Traag, A. H. Hasan, K. J. McDowall, B. G. Kim and G. P. van Wezel, Antonie van Leeuwenhoek, 2015, 108, 201-213.

207 B. A. Traag, G. H. Kelemen and G. P. Van Wezel, Mol. Microbiol., 2004, 53, 985-1000.

208 B. A. Traag and G. P. van Wezel, Antonie van Leeuwenhoek, 2008, 94, 85-97.

209 M. A. Swiatek, J. Gubbens, G. Bucca, E. Song, Y. H. Yang, E. Laing, B. G. Kim, C. P. Smith and G. P. van Wezel, J. Bacteriol., 2013, 195, 1236-1248.

210 S. S. Park, Y. H. Yang, E. Song, E. J. Kim, W. S. Kim, J. K. Sohng, H. C. Lee, K. K. Liou and B. G. Kim, J. Ind. Microbiol. Biotechnol., 2009, 36, 1073-1083.

211 X. Li, T. Yu, Q. He, K. J. McDowall, B. Jiang, Z. Jiang, L. Wu, G. Li, Q. Li, S. Wang, Y. Shi, L. Wang and B. Hong, Mol. Microbiol., 2015, 96, 1257-1271.

212 S. K. Ahn, L. Cuthbertson and J. R. Nodwell, PLoS One, 2012, 7, e50562.

213 L. Cuthbertson and J. R. Nodwell, Microbiol. Mol. Biol. Rev., 2013, 77, 440-475.

214 J. Gubbens, M. Janus, B. I. Florea, H. S. Overkleeft and G. P. van Wezel, Mol. Microbiol., 2012, 86, 1490-1507.

215 A. Romero-Rodríguez, D. Rocha, B. Ruiz-Villafan, V. Tierrafría, R. Rodríguez-Sanoja, D. Segura-González and S. Sánchez, BMC Microbiol., 2016, 16, 1.

216 C.-H. Liao, L.-l. Yao and B.-C. Ye, Mol. Microbiol., 2014, 94, 1065-1084.

217 A. Derouaux, S. Halici, H. Nothaft, T. Neutelings, G. Moutzourelis, J. Dusart, F. Titgemeyer and S. Rigali, J. Bacteriol., 2004, 186, 1893-1897.

218 C. H. Liao, L. Yao, Y. Xu, W. B. Liu, Y. Zhou and B. C. Ye, Proc. Natl. Acad. Sci. U. S. A., 2015, 112, 15630-15635.

219 X. F. Cen, J. Z. Wang, G. P. Zhao, Y. Wang and J. Wang, Biochem. Biophys. Res. Commun., 2016, 471, 510-514.

220 F. Santos-Beneit, A. Rodríguez-García and J. F. Martín, Microbiol. Res., 2012, 167, 532-535.

221 A. Sola-Landa, A. Rodríguez-García, R. Amin, W. Wohlleben and J. F. Martín, Nucleic Acids Res., 2013, 41, 1767-1782.

222 S. Ghorbel, A. Smirnov, H. Chouayekh, B. Sperandio, C. Esnault, J. Kormanec and M. J. Virolle, J. Bacteriol., 2006, 188, 6269-6276.

223 P. Le Marechal, P. Decottignies, C. H. Marchand, J. Degrouard, D. Jaillard, T. Dulermo, M. Froissard, A. Smirnov, V. Chapuis and M. J. Virolle, Appl. Environ. Microbiol., 2013, 79, 5907-5917.

224 E. Tenconi, S. Jourdan, P. Motte, M. J. Virolle and S. Rigali, Antonie van Leeuwenhoek, 2012, 102, 425-433.

225 G. Robertson, M. Hirst, M. Bainbridge, M. Bilenky, Y. Zhao, T. Zeng, G. Euskirchen, B. Bernier, R. Varhol, A. Delaney, N. Thiessen, O. L. Griffith, A. He, M. Marra, M. Snyder and S. Jones, Nat. Methods, 2007, 4, 651-657.

226 T. van Opijnen, K. L. Bodi and A. Camilli, Nat. Methods, 2009, 6, 767-772.

227 M. L. Guerinot, Annu. Rev. Microbiol., 1994, 48, 743-772.
228 A. A. Arias, S. Lambert, L. Martinet, D. Adam, E. Tenconi, M.-P. Hayette, M. Ongena and S. Rigali, FEMS Microbiol. Ecol., 2015, 91, fiv080.

229 J. Galet, A. Deveau, L. Hotel, P. Frey-Klett, P. Leblond and B. Aigle, Appl. Environ. Microbiol., 2015, 81, 3132-3141.

230 R. F. Seipke, PLoS One, 2015, 10, e0116457.

231 S. Lautru, R. J. Deeth, L. M. Bailey and G. L. Challis, Nat. Chem. Biol., 2005, 1, 265-269.

232 R. F. Seipke, L. Song, J. Bicz, P. Laskaris, A. M. Yaxley, G. L. Challis and R. Loria, Microbiology, 2011, 157, 26812693.

233 F. J. Flores, C. Barreiro, J. J. R. Coque and J. F. Martín, FEBS J., 2005, 272, 725-735.

234 F. J. Flores and J. F. Martin, Biochem. J., 2004, 380, 197-503. 235 S. Tunca, C. Barreiro, A. Sola-Landa, J. J. R. Coque and J. F. Martín, FEBS J., 2007, 274, 1110-1122.

236 S. Tunca, C. Barreiro, J. J. R. Coque and J. F. Martín, FEBS J., 2009, 276, 4814-4827.

237 S. Rico, A. Yepes, H. Rodriguez, J. Santamaria, S. Antoraz, E. M. Krause, M. Diaz and R. I. Santamaria, PLoS One, 2014, 9, e109844.

238 L. A. Finney and T. V. O'Halloran, Science, 2003, 300, 931936.

239 H. Reyes-Caballero, G. C. Campanello and D. P. Giedroc, Biophys. Chem., 2011, 156, 103-114.

240 E. M. Panina, A. A. Mironov and M. S. Gelfand, Proc. Natl. Acad. Sci. U. S. A., 2003, 100, 9912-9917.

241 J. H. Shin, S. Y. Oh, S. J. Kim and J. H. Roe, J. Bacteriol., 2007, 189, 4070-4077.

242 A. Hesketh, H. Kock, S. Mootien and M. Bibb, Mol. Microbiol., 2009, 74, 1427-1444.

243 D. A. Romero, A. H. Hasan, Y. F. Lin, L. Kime, O. RuizLarrabeiti, M. Urem, G. Bucca, L. Mamanova, E. E. Laing, G. P. van Wezel, C. P. Smith, V. R. Kaberdin and K. J. McDowall, Mol. Microbiol., 2014, 94(5), 963-987.

244 M. Spohn, W. Wohlleben and E. Stegmann, Environ. Microbiol., 2016, 18, 1249-1263.

245 K. Kawai, G. Wang, S. Okamoto and K. Ochi, FEMS Microbiol. Lett., 2007, 274, 311-315.

246 Y. Tanaka, T. Hosaka and K. Ochi, J. Antibiot., 2010, 63, 477-481.

247 T. Inaoka and K. Ochi, Appl. Environ. Microbiol., 2011, 77, 8181-8183.

248 K. W. Bayles, Nat. Rev. Microbiol., 2014, 12, 63-69.

249 K. C. Rice and K. W. Bayles, Mol. Microbiol., 2003, 50, 729738.

250 S. M. Rosenberg, PLoS Genet., 2009, 5, e1000418.

251 A. Manteca, M. Fernandez and J. Sanchez, Microbiology, 2005, 151, 3689-3697.

252 E. M. Miguelez, C. Hardisson and M. B. Manzanal, Int. Microbiol., 2000, 3, 153-158.

253 S. Rigali, H. Nothaft, E. E. Noens, M. Schlicht, S. Colson, M. Muller, B. Joris, H. K. Koerten, D. A. Hopwood, F. Titgemeyer and G. P. van Wezel, Mol. Microbiol., 2006, 61, 1237-1251.

254 E. Tenconi, M. Traxler, C. Hoebreck, G. P. van Wezel and S. Rigali, BioRXiv, 2018, DOI: 10.1101/240689. 
255 M. Elliot, F. Damji, R. Passantino, K. Chater and B. Leskiw, J. Bacteriol., 1998, 180, 1549-1555.

256 N. K. Gaur, J. Oppenheim and I. Smith, J. Bacteriol., 1991, 173, 678-686.

257 D. B. Kearns, F. Chu, S. S. Branda, R. Kolter and R. Losick, Mol. Microbiol., 2005, 55, 739-749.

258 C. D. den Hengst, N. T. Tran, M. J. Bibb, G. Chandra, B. K. Leskiw and M. J. Buttner, Mol. Microbiol., 2010, 78, 361-379.

259 N. Tschowri, M. A. Schumacher, S. Schlimpert, N. B. Chinnam, K. C. Findlay, R. G. Brennan and M. J. Buttner, Cell, 2014, 158, 1136-1147.

260 E. J. Lawlor, H. A. Baylis and K. F. Chater, Genes Dev., 1987, 1, 1305-1310.

261 B. K. Leskiw, E. J. Lawlor, J. M. Fernandez-Abalos and K. F. Chater, Proc. Natl. Acad. Sci. U. S. A., 1991, 88, 2461-2465.

262 G. Chandra and K. F. Chater, Antonie van Leeuwenhoek, 2008, 94, 111-126.

263 J. Willemse, J. W. Borst, E. de Waal, T. Bisseling and G. P. van Wezel, Genes Dev., 2011, 25, 89-99.

264 G. Girard, B. A. Traag, V. Sangal, N. Mascini, P. A. Hoskisson, M. Goodfellow and G. P. van Wezel, Open Biol., 2013, 3, 130073.

265 E. E. Noens, V. Mersinias, J. Willemse, B. A. Traag, E. Laing, K. F. Chater, C. P. Smith, H. K. Koerten and G. P. van Wezel, Mol. Microbiol., 2007, 64, 1244-1259.

266 G. P. van Wezel, P. Krabben, B. A. Traag, B. J. Keijser, R. Kerste, E. Vijgenboom, J. J. Heijnen and B. Kraal, Appl. Environ. Microbiol., 2006, 72, 5283-5288.

267 G. P. van Wezel, J. van der Meulen, S. Kawamoto, R. G. Luiten, H. K. Koerten and B. Kraal, J. Bacteriol., 2000, 182, 5653-5662.

268 D. van Dissel, D. Claessen and G. P. Van Wezel, Adv. Appl. Microbiol., 2014, 89, 1-45.

269 K. Fowler-Goldsworthy, B. Gust, S. Mouz, G. Chandra, K. C. Findlay and K. F. Chater, Microbiology, 2011, 157, 1312-1328.

270 S. H. Kang, J. Q. Huang, H. N. Lee, Y. A. Hur, S. N. Cohen and E. S. Kim, J. Bacteriol., 2007, 189, 4315-4319.

271 H. Huang, L. Hou, H. Li, Y. Qiu, J. Ju and W. Li, Microb. Cell Fact., 2016, 15, 116.

272 X. Huang, T. Ma, J. Tian, L. Shen, H. Zuo, C. Hu and G. Liao, J. Appl. Microbiol., 2017, 123, 669-677.

273 H. J. Kim, M. K. Kim, Y. Y. Jin and E. S. Kim, J. Microbiol. Biotechnol., 2014, 24, 1226-1231.

274 J. H. Nah, S. H. Park, H. M. Yoon, S. S. Choi, C. H. Lee and E. S. Kim, Biotechnol. Adv., 2012, 30, 202-209.

275 J. H. Noh, S. H. Kim, H. N. Lee, S. Y. Lee and E. S. Kim, Appl. Microbiol. Biotechnol., 2010, 86, 1145-1153.

276 M. Rabyk, B. Ostash, Y. Rebets, S. Walker and V. Fedorenko, Biotechnol. Lett., 2011, 33, 2481-2486.

277 G. Niu, K. F. Chater, Y. Tian, J. Zhang and H. Tan, FEMS Microbiol. Rev., 2016, 40, 554-573.

278 G. Xu, J. Wang, L. Wang, X. Tian, H. Yang, K. Fan, K. Yang and H. Tan, J. Biol. Chem., 2010, 285, 27440-27448.

279 J. D. Sidda, V. Poon, L. Song, W. Wang, K. Yang and C. Corre, Org. Biomol. Chem., 2016, 14, 6390-6393.
280 D. D'Alia, D. Eggle, K. Nieselt, W. S. Hu, R. Breitling and E. Takano, Microb. Biotechnol., 2011, 4, 239-251.

281 M. Gottelt, S. Kol, J. P. Gomez-Escribano, M. Bibb and E. Takano, Microbiology, 2010, 156, 2343-2353.

282 J. Wang, W. Wang, L. Wang, G. Zhang, K. Fan, H. Tan and K. Yang, Mol. Microbiol., 2011, 82, 236-250.

283 W. Wang, J. Ji, X. Li, J. Wang, S. Li, G. Pan, K. Fan and K. Yang, Proc. Natl. Acad. Sci. U. S. A., 2014, 111, 5688-5693.

284 X. Li, J. Wang, S. Li, J. Ji, W. Wang and K. Yang, Sci. Rep., 2016, 6, 21574.

285 X. Li, J. Wang, M. Shi, W. Wang, C. Corre and K. Yang, Appl. Microbiol. Biotechnol., 2017, 101, 5333-5340.

286 S. O'Rourke, A. Wietzorrek, K. Fowler, C. Corre, G. L. Challis and K. F. Chater, Mol. Microbiol., 2009, 71, 763-778.

287 S. Kitani, K. T. Miyamoto, S. Takamatsu, E. Herawati, H. Iguchi, K. Nishitomi, M. Uchida, T. Nagamitsu, S. Omura, H. Ikeda and T. Nihira, Proc. Natl. Acad. Sci. U. S. A., 2011, 108, 16410-16415.

288 J. B. Wang, F. Zhang, J. Y. Pu, J. Zhao, Q. F. Zhao and G. L. Tang, Biotechnol. Lett., 2014, 36, 813-819.

289 S. P. Sultan, S. Kitani, K. T. Miyamoto, H. Iguchi, T. Atago, H. Ikeda and T. Nihira, Appl. Microbiol. Biotechnol., 2016, 100, 9581-9591.

290 J. Zhu, D. Sun, W. Liu, Z. Chen, J. Li and Y. Wen, Mol. Microbiol., 2016, 102, 562-578.

291 D. A. Suroto, S. Kitani, K. T. Miyamoto, Y. Sakihama, M. Arai, H. Ikeda and T. Nihira, J. Biosci. Bioeng., 2017, 124(6), 611-617.

292 K. T. Miyamoto, S. Kitani, M. Komatsu, H. Ikeda and T. Nihira, Microbiology, 2011, 157, 2266-2275.

293 E. Mingyar, L. Feckova, R. Novakova, C. Bekeova and J. Kormanec, Appl. Microbiol. Biotechnol., 2015, 99, 309-325.

294 Z. Zou, D. Du, Y. Zhang, J. Zhang, G. Niu and H. Tan, Mol. Microbiol., 2014, 94, 490-505.

295 L. Wang and L. C. Vining, Microbiology, 2003, 149, 19912004.

296 S. Kitani, M. Doi, T. Shimizu, A. Maeda and T. Nihira, Arch. Microbiol., 2010, 192, 211-220.

297 S. Kitani, Y. Yamada and T. Nihira, J. Bacteriol., 2001, 183, 4357-4363.

298 S. Kitani, A. Iida, T. A. Izumi, A. Maeda, Y. Yamada and T. Nihira, Gene, 2008, 425, 9-16.

299 Y. N. Kurniawan, S. Kitani, A. Maeda and T. Nihira, Appl. Microbiol. Biotechnol., 2014, 98, 9713-9721.

300 Y. N. Kurniawan, S. Kitani, A. Iida, A. Maeda, J. Lycklama a Nijeholt, Y. J. Lee and T. Nihira, J. Biosci. Bioeng., 2016, 121, 372-379.

301 I. G. U. Pait, S. Kitani, Y. N. Kurniawan, M. Asa, T. Iwai, H. Ikeda and T. Nihira, J. Biosci. Bioeng., 2017, 124, 369-375.

302 Y. Mast and W. Wohlleben, Int. J. Med. Microbiol., 2014, 304, 44-50.

303 Y. Mast, T. Weber, M. Golz, R. Ort-Winklbauer, A. Gondran, W. Wohlleben and E. Schinko, Microb. Biotechnol., 2011, 4, 192-206.

304 Y. Mast, J. Guezguez, F. Handel and E. Schinko, Appl. Environ. Microbiol., 2015, 81, 6621-6636. 
305 J. Dun, Y. Zhao, G. Zheng, H. Zhu, L. Ruan, W. Wang, M. Ge, W. Jiang and Y. Lu, J. Bacteriol., 2015, 197, 441-450. 306 O. Genilloud, I. Gonzalez, O. Salazar, J. Martin, J. R. Tormo and F. Vicente, J. Ind. Microbiol. Biotechnol., 2011, 38, 375389.

307 P. Monciardini, M. Iorio, S. Maffioli, M. Sosio and S. Donadio, Microb. Biotechnol., 2014, 7, 209-220.

308 X. Yan, H. Ge, T. Huang, H. Hindra, D. Yang, Q. Teng, I. Crnovcic, X. Li, J. D. Rudolf, J. R. Lohman, Y. Gansemans, X. Zhu, Y. Huang, L. X. Zhao, Y. Jiang, F. Van Nieuwerburgh, C. Rader, Y. Duan and B. Shen, mBio, 2016, 7(6), e02104-16.

309 W. Fenical and P. R. Jensen, Nat. Chem. Biol., 2006, 2, 666673.

310 K. C. Freel, A. Edlund and P. R. Jensen, Environ. Microbiol., 2012, 14, 480-493.

311 M. Kamjam, P. Sivalingam, Z. Deng and K. Hong, Front. Microbiol., 2017, 8, 760.

312 G. L. Marcone, L. Carrano, F. Marinelli and F. Beltrametti, J. Antibiot., 2010, 63, 83-88.

313 P. H. Anborgh and A. Parmeggiani, EMBO J., 1991, 10, 779784.

314 T. Dairi, Y. Hamano, T. Furumai and T. Oki, Appl. Environ. Microbiol., 1999, 65, 2703-2709.

315 H. Suzuki, S. Takahashi, H. Osada and K. Yoshida, J. Microbiol. Biotechnol., 2011, 21, 675-678.

316 F. Flett, V. Mersinias and C. P. Smith, FEMS Microbiol. Lett., 1997, 155, 223-229.

317 L. Horbal, A. Kobylyanskyy, O. Yushchuk, N. Zaburannyi, A. Luzhetskyy, B. Ostash, F. Marinelli and V. Fedorenko, J. Biotechnol., 2013, 168, 367-372.

318 C. Bai, Y. Zhang, X. Zhao, Y. Hu, S. Xiang, J. Miao, C. Lou and L. Zhang, Proc. Natl. Acad. Sci. U. S. A., 2015, 112, 12181-12186.

319 K. Flinspach, C. Kapitzke, A. Tocchetti, M. Sosio and A. K. Apel, PLoS One, 2014, 9, e90499.

320 K. Yamanaka, K. A. Reynolds, R. D. Kersten, K. S. Ryan, D. J. Gonzalez, V. Nizet, P. C. Dorrestein and B. S. Moore, Proc. Natl. Acad. Sci. U. S. A., 2014, 111, 1957-1962.

321 M. J. Wood, J. Antimicrob. Chemother., 1996, 37, 209-222.

322 M. Sosio and S. Donadio, J. Ind. Microbiol. Biotechnol., 2006, 33, 569-576.

323 J. C. Barna and D. H. Williams, Annu. Rev. Microbiol., 1984, 38, 339-357.

324 M. Sosio, H. Kloosterman, A. Bianchi, P. de Vreugd, L. Dijkhuizen and S. Donadio, Microbiology, 2004, 150, 95-102.

325 T. L. Li, F. Huang, S. F. Haydock, T. Mironenko, P. F. Leadlay and J. B. Spencer, Chem. Biol., 2004, 11, 107119.

326 M. Sosio, S. Stinchi, F. Beltrametti, A. Lazzarini and S. Donadio, Chem. Biol., 2003, 10, 541-549.

327 S. Pelzer, R. Sussmuth, D. Heckmann, J. Recktenwald, P. Huber, G. Jung and W. Wohlleben, Antimicrob. Agents Chemother., 1999, 43, 1565-1573.
328 J. Pootoolal, M. G. Thomas, C. G. Marshall, J. M. Neu, B. K. Hubbard, C. T. Walsh and G. D. Wright, Proc. Natl. Acad. Sci. U. S. A., 2002, 99, 8962-8967.

329 S. Donadio, M. Sosio, E. Stegmann, T. Weber and W. Wohlleben, Mol. Genet. Genomics, 2005, 274, 40-50.

330 L. Lo Grasso, S. Maffioli, M. Sosio, M. Bibb, A. M. Puglia and R. Alduina, J. Bacteriol., 2015, 197, 2536-2544.

331 R. M. Shawky, O. Puk, A. Wietzorrek, S. Pelzer, E. Takano, W. Wohlleben and E. Stegmann, J. Mol. Microbiol. Biotechnol., 2007, 13, 76-88.

332 L. Horbal, A. Kobylyanskyy, A. W. Truman, N. Zaburranyi, B. Ostash, A. Luzhetskyy, F. Marinelli and V. Fedorenko, Appl. Microbiol. Biotechnol., 2014, 98, 9295-9309.

333 H. J. Hong, M. I. Hutchings, J. M. Neu, G. D. Wright, M. S. Paget and M. J. Buttner, Mol. Microbiol., 2004, 52, 1107-1121.

334 M. I. Hutchings, H. J. Hong and M. J. Buttner, Mol. Microbiol., 2006, 59, 923-935.

335 L. Horbal, N. Zaburannyy, B. Ostash, S. Shulga and V. Fedorenko, World J. Microbiol. Biotechnol., 2012, 28, 2095-2100.

336 R. Alduina, L. Lo Piccolo, D. D'Alia, C. Ferraro, N. Gunnarsson, S. Donadio and A. M. Puglia, J. Bacteriol., 2007, 189, 8120-8129.

337 B. Ostash, O. Yushchuk, S. Tistechok, H. Mutenko, L. Horbal, A. Muryn, Y. Dacyuk, J. Kalinowski, A. Luzhetskyy and V. Fedorenko, World J. Microbiol. Biotechnol., 2015, 31, 1297-1301.

338 M. Spohn, N. Kirchner, A. Kulik, A. Jochim, F. Wolf, P. Muenzer, O. Borst, H. Gross, W. Wohlleben and E. Stegmann, Antimicrob. Agents Chemother., 2014, 58, 6185-6196.

339 M. Arthur, P. E. Reynolds, F. Depardieu, S. Evers, S. DutkaMalen, R. Quintiliani Jr and P. Courvalin, J. Infect., 1996, 32, 11-16.

340 T. D. Bugg, G. D. Wright, S. Dutka-Malen, M. Arthur, P. Courvalin and C. T. Walsh, Biochemistry, 1991, 30, 10408-10415.

341 L. T. van der Aart, N. Lemmens, W. J. van Wamel and G. P. van Wezel, Antimicrob. Agents Chemother., 2016, 60, 4930-4939.

342 G. B. Novotna, M. J. Kwun and H. J. Hong, Antimicrob. Agents Chemother., 2015, 60, 1627-1637.

343 R. Kilian, H. J. Frasch, A. Kulik, W. Wohlleben and E. Stegmann, Microb. Drug Resist., 2016, 22, 499-509.

344 P. G. Arnison, M. J. Bibb, G. Bierbaum, A. A. Bowers, T. S. Bugni, G. Bulaj, J. A. Camarero, D. J. Campopiano, G. L. Challis, J. Clardy, P. D. Cotter, D. J. Craik, M. Dawson, E. Dittmann, S. Donadio, P. C. Dorrestein, K. D. Entian, M. A. Fischbach, J. S. Garavelli, U. Goransson, C. W. Gruber, D. H. Haft, T. K. Hemscheidt, C. Hertweck, C. Hill, A. R. Horswill, M. Jaspars, W. L. Kelly, J. P. Klinman, O. P. Kuipers, A. J. Link, W. Liu, M. A. Marahiel, D. A. Mitchell, G. N. Moll, B. S. Moore, R. Muller, S. K. Nair, I. F. Nes, G. E. Norris, B. M. Olivera, H. Onaka, M. L. Patchett, J. Piel, M. J. Reaney, S. Rebuffat, R. P. Ross, H. G. Sahl, 
E. W. Schmidt, M. E. Selsted, K. Severinov, B. Shen, K. Sivonen, L. Smith, T. Stein, R. D. Sussmuth, J. R. Tagg, G. L. Tang, A. W. Truman, J. C. Vederas, C. T. Walsh, J. D. Walton, S. C. Wenzel, J. M. Willey and W. A. van der Donk, Nat. Prod. Rep., 2013, 30, 108-160.

345 L. A. Rogers and E. O. Whittier, J. Bacteriol., 1928, 16, 211229.

346 J. M. Willey and W. A. van der Donk, Annu. Rev. Microbiol., 2007, 61, 477-501.

347 D. Munch, A. Muller, T. Schneider, B. Kohl, M. Wenzel, J. E. Bandow, S. Maffioli, M. Sosio, S. Donadio, R. Wimmer and H. G. Sahl, J. Biol. Chem., 2014, 289, 12063-12076.

348 F. Castiglione, L. Cavaletti, D. Losi, A. Lazzarini, L. Carrano, M. Feroggio, I. Ciciliato, E. Corti, G. Candiani, F. Marinelli and E. Selva, Biochemistry, 2007, 46, 5884-5895.

349 F. Castiglione, A. Lazzarini, L. Carrano, E. Corti, I. Ciciliato, L. Gastaldo, P. Candiani, D. Losi, F. Marinelli, E. Selva and F. Parenti, Chem. Biol., 2008, 15, 22-31.

350 L. T. Fernandez-Martinez, J. P. Gomez-Escribano and M. J. Bibb, Mol. Microbiol., 2015, 97, 502-514.

351 E. J. Sherwood and M. J. Bibb, Proc. Natl. Acad. Sci. U. S. A., 2013, 110, E2500-E2509.

352 L. Foulston and M. Bibb, J. Bacteriol., 2011, 193, 3064-3071. 353 J. D. Helmann, Adv. Microb. Physiol., 2002, 46, 47-110.

354 M. S. B. Paget, H. J. Hong, M. J. Bibb and M. J. Buttner, in SGM symposium 61, ed. D. A. Hodgson and C. M. Thomas, Cambridge University Press, Cambridge, 2002, pp. 105125.

355 L. C. Foulston and M. J. Bibb, Proc. Natl. Acad. Sci. U. S. A., 2010, 107, 13461-13466.

356 G. Gallo, G. Renzone, E. Palazzotto, P. Monciardini, S. Arena, T. Faddetta, A. Giardina, R. Alduina, T. Weber, F. Sangiorgi, A. Russo, G. Spinelli, M. Sosio, A. Scaloni and A. M. Puglia, BMC Genomics, 2016, 17, 42.

357 M. Bartholomae, A. Buivydas, J. H. Viel, M. MontalbanLopez and O. P. Kuipers, Mol. Microbiol., 2017, 106, 186206.

358 W. H. Feng, X. M. Mao, Z. H. Liu and Y. Q. Li, Appl. Microbiol. Biotechnol., 2011, 92, 1009-1021.

359 R. F. Seipke, E. Patrick and M. I. Hutchings, PeerJ, 2014, 2, e253. 360 R. F. Seipke and M. I. Hutchings, Beilstein J. Org. Chem., 2013, 9, 2556-2563.

361 S. Luo, D. Sun, J. Zhu, Z. Chen, Y. Wen and J. Li, Appl. Microbiol. Biotechnol., 2014, 98, 7097-7112.

362 R. Joynt and R. F. Seipke, Microbiology, 2018, 164, 28-39.

363 P. R. Jensen, B. S. Moore and W. Fenical, Nat. Prod. Rep., 2015, 32, 738-751.

364 A. Lechner, A. S. Eustaquio, T. A. Gulder, M. Hafner and B. S. Moore, Chem. Biol., 2011, 18, 1527-1536.

365 G. C. A. Amos, T. Awakawa, R. N. Tuttle, A. C. Letzel, M. C. Kim, Y. Kudo, W. Fenical, B. S. Moore and P. R. Jensen, Proc. Natl. Acad. Sci. U. S. A., 2017, 114, E11121-E11130.

366 H. Yu, Y. Yao, Y. Liu, R. Jiao, W. Jiang and G. P. Zhao, Arch. Microbiol., 2007, 188, 89-96.
367 C. Li, X. Liu, C. Lei, H. Yan, Z. Shao, Y. Wang, G. Zhao, J. Wang and X. Ding, Appl. Environ. Microbiol., 2017, 83(8), e03201-16.

368 C. Lei, J. Wang, Y. Liu, X. Liu, G. Zhao and J. Wang, Microb. Cell Fact., 2018, 17, 14.

369 S. U. Choi, C. K. Lee, Y. I. Hwang, H. Kinosita and T. Nihira, Arch. Microbiol., 2003, 180, 303-307.

370 A. V. Polkade, S. S. Mantri, U. J. Patwekar and K. Jangid, Front. Microbiol., 2016, 7, 131.

371 A. Aroonsri, S. Kitani, S. U. Choi and T. Nihira, Biotechnol. Lett., 2008, 30, 2019-2024.

372 S. U. Choi, C. K. Lee, Y. I. Hwang, H. Kinoshita and T. Nihira, J. Bacteriol., 2004, 186, 3423-3430.

373 A. Aroonsri, S. Kitani, J. Hashimoto, I. Kosone, M. Izumikawa, M. Komatsu, N. Fujita, Y. Takahashi, K. Shin-ya, H. Ikeda and T. Nihira, Appl. Environ. Microbiol., 2012, 78, 8015-8024.

374 A. Ceniceros, L. Dijkhuizen and M. Petrusma, Sci. Rep., $2017,7,17743$.

375 J. S. Zarins-Tutt, T. T. Barberi, H. Gao, A. Mearns-Spragg, L. Zhang, D. J. Newman and R. J. Goss, Nat. Prod. Rep., 2016, 33, 54-72.

376 F. Guo, S. Xiang, L. Li, B. Wang, J. Rajasarkka, K. GrondahlYli-Hannuksela, G. Ai, M. Metsa-Ketela and K. Yang, Metab. Eng., 2015, 28, 134-142.

377 Y. Q. Sun, T. Busche, C. Ruckert, C. Paulus, Y. Rebets, R. Novakova, J. Kalinowski, A. Luzhetskyy, J. Kormanec, O. N. Sekurova and S. B. Zotchev, ACS Synth. Biol., 2017, 6, 1026-1033.

378 A. Craney, C. Ozimok, S. M. Pimentel-Elardo, A. Capretta and J. R. Nodwell, Chem. Biol., 2012, 19, 1020-1027.

379 F. Xu, B. Nazari, K. Moon, L. B. Bushin and M. R. Seyedsayamdost, J. Am. Chem. Soc., 2017, 139, 92039212.

380 B. K. Okada and M. R. Seyedsayamdost, FEMS Microbiol. Rev., 2017, 41, 19-33.

381 K. Bingol, L. Bruschweiler-Li, D. Li, B. Zhang, M. Xie and R. Bruschweiler, Bioanalysis, 2016, 8, 557-573.

382 S. P. Gaudencio and F. Pereira, Nat. Prod. Rep., 2015, 32, 779-810.

383 C. Wu, H. K. Kim, G. P. van Wezel and Y. H. Choi, Drug Discovery Today: Technol., 2015, 13, 11-17.

384 S. P. Gaudencio and F. Pereira, Nat. Prod. Rep., 2015, 32, 779-810.

385 C. Wu, H. K. Kim, G. P. van Wezel and Y. H. Choi, Drug Discovery Today: Technol., 2015, 13, 11-17.

386 C. Olano, I. Garcia, A. Gonzalez, M. Rodriguez, D. Rozas, J. Rubio, M. Sanchez-Hidalgo, A. F. Brana, C. Mendez and J. A. Salas, Microb. Biotechnol., 2014, 7, 242-256.

387 H. J. Nah, H. R. Pyeon, S. H. Kang, S. S. Choi and E. S. Kim, Front. Microbiol., 2017, 8, 394.

388 J. P. Gomez-Escribano and M. J. Bibb, Microb. Biotechnol., 2011, 4, 207-215.

389 M. Komatsu, K. Komatsu, H. Koiwai, Y. Yamada, I. Kozone, M. Izumikawa, J. Hashimoto, M. Takagi, S. Omura, K. Shinya, D. E. Cane and H. Ikeda, ACS Synth. Biol., 2013, 2, 384396. 
390 M. M. Zhang, F. T. Wong, Y. Wang, S. Luo, Y. H. Lim, E. Heng, W. L. Yeo, R. E. Cobb, B. Enghiad, E. L. Ang and H. Zhao, Nat. Chem. Biol., 2017, DOI: 10.1038/ nchembio. 2341 .

391 D. Vujaklija, S. Horinouchi and T. Beppu, J. Bacteriol., 1993, 175, 2652-2661.

392 J. Guo, J. Zhao, L. Li, Z. Chen, Y. Wen and J. Li, Mol. Genet. Genomics, 2010, 283, 123-133.

393 S. Hackl and A. Bechthold, Arch. Pharm., 2015, 348, 455462.

394 Q. Xu, G. P. van Wezel, H. J. Chiu, L. Jaroszewski, H. E. Klock, M. W. Knuth, M. D. Miller, S. A. Lesley, A. Godzik, M. A. Elsliger, A. M. Deacon and I. A. Wilson, PLoS One, 2012, 7, e41359.

395 S. H. Kang, J. Huang, H. N. Lee, Y. A. Hur, S. N. Cohen and E. S. Kim, J. Bacteriol., 2007, 189, 4315-4319.

396 T. Wolf, J. Droste, T. Gren, V. Ortseifen, S. Schneiker-Bekel, T. Zemke, A. Puhler and J. Kalinowski, BMC Genomics, 2017, 18, 562 .

397 B. Hou, Y. Lin, H. Wu, M. Guo, H. Petkovic, L. Tao, X. Zhu, J. Ye and H. Zhang, J. Bacteriol., 2018, 200, e00447-17.

398 K. S. Ju, X. Zhang and M. A. Elliot, J. Bacteriol., 2018, 200, e00559-17.

399 J. Liu, J. Li, H. Dong, Y. Chen, Y. Wang, H. Wu, C. Li, D. T. Weaver, L. Zhang and B. Zhang, Appl. Microbiol. Biotechnol., 2017, 101, 5773-5783.

400 W. Li, X. Ying, Y. Guo, Z. Yu, X. Zhou, Z. Deng, H. Kieser, K. F. Chater and M. Tao, J. Bacteriol., 2006, 188, 8368-8375.

401 Y. H. Yang, E. Song, E. J. Kim, K. Lee, W. S. Kim, S. S. Park, J. S. Hahn and B. G. Kim, Appl. Microbiol. Biotechnol., 2009, 82, 501-511.

402 Q. Zhang, Q. Chen, S. Zhuang, Z. Chen, Y. Wen and J. Li, Appl. Environ. Microbiol., 2015, 81, 3753-3765.

403 N. F. Som, D. Heine, N. Holmes, F. Knowles, G. Chandra, R. F. Seipke, P. A. Hoskisson, B. Wilkinson and M. I. Hutchings, Microbiology, 2017, 163, 1415-1419.

404 M. Iqbal, Y. Mast, R. Amin, D. A. Hodgson, S. Consortium, W. Wohlleben and N. J. Burroughs, Nucleic Acids Res., 2012, 40, 5227-5239.

405 L. Yu, W. Gao, S. Li, Y. Pan and G. Liu, Microbiology, 2016, $162,537-551$.

406 Y. Lu, J. He, H. Zhu, Z. Yu, R. Wang, Y. Chen, F. Dang, W. Zhang, S. Yang and W. Jiang, J. Bacteriol., 2011, 193, 3020-3032.

407 L. Yu, Y. Pan and G. Liu, Curr. Microbiol., 2016, 73, 196-201.
408 S. Antoraz, S. Rico, H. Rodriguez, L. Sevillano, J. F. Alzate, R. I. Santamaria and M. Diaz, Front. Microbiol., 2017, 8, 2444.

409 X. M. Mao, Z. H. Sun, B. R. Liang, Z. B. Wang, W. H. Feng, F. L. Huang and Y. Q. Li, J. Bacteriol., 2013, 195, 2072-2078. 410 P. Xie, A. Zeng and Z. Qin, BMC Microbiol., 2009, 9, 157.

411 S. Martin-Martin, A. Rodriguez-Garcia, F. Santos-Beneit, E. Franco-Dominguez, A. Sola-Landa and J. F. Martin, J. Antibiot., 2017, 71, 113-122.

412 M. H. Medema, R. Kottmann, P. Yilmaz, M. Cummings, J. B. Biggins, K. Blin, I. de Bruijn, Y. H. Chooi, J. Claesen, R. C. Coates, P. Cruz-Morales, S. Duddela, S. Dusterhus, D. J. Edwards, D. P. Fewer, N. Garg, C. Geiger, J. P. Gomez-Escribano, A. Greule, M. Hadjithomas, A. S. Haines, E. J. Helfrich, M. L. Hillwig, K. Ishida, A. C. Jones, C. S. Jones, K. Jungmann, C. Kegler, H. U. Kim, P. Kotter, D. Krug, J. Masschelein, A. V. Melnik, S. M. Mantovani, E. A. Monroe, M. Moore, N. Moss, H. W. Nutzmann, G. Pan, A. Pati, D. Petras, F. J. Reen, F. Rosconi, Z. Rui, Z. Tian, N. J. Tobias, Y. Tsunematsu, P. Wiemann, E. Wyckoff, X. Yan, G. Yim, F. Yu, Y. Xie, B. Aigle, A. K. Apel, C. J. Balibar, E. P. Balskus, F. Barona-Gomez, A. Bechthold, H. B. Bode, R. Borriss, S. F. Brady, A. A. Brakhage, P. Caffrey, Y. Q. Cheng, J. Clardy, R. J. Cox, R. De Mot, S. Donadio, M. S. Donia, W. A. van der Donk, P. C. Dorrestein, S. Doyle, A. J. Driessen, M. Ehling-Schulz, K. D. Entian, M. A. Fischbach, L. Gerwick, W. H. Gerwick, H. Gross, B. Gust, C. Hertweck, M. Hofte, S. E. Jensen, J. Ju, L. Katz, L. Kaysser, J. L. Klassen, N. P. Keller, J. Kormanec, O. P. Kuipers, T. Kuzuyama, N. C. Kyrpides, H. J. Kwon, S. Lautru, R. Lavigne, C. Y. Lee, B. Linquan, X. Liu, W. Liu, A. Luzhetskyy, T. Mahmud, Y. Mast, C. Mendez, M. Metsa-Ketela, J. Micklefield, D. A. Mitchell, B. S. Moore, L. M. Moreira, R. Muller, B. A. Neilan, M. Nett, J. Nielsen, F. O'Gara, H. Oikawa, A. Osbourn, M. S. Osburne, B. Ostash, S. M. Payne, J. L. Pernodet, M. Petricek, J. Piel, O. Ploux, J. M. Raaijmakers, J. A. Salas, E. K. Schmitt, B. Scott, R. F. Seipke, B. Shen, D. H. Sherman, K. Sivonen, M. J. Smanski, M. Sosio, E. Stegmann, R. D. Sussmuth, K. Tahlan, C. M. Thomas, Y. Tang, A. W. Truman, M. Viaud, J. D. Walton, C. T. Walsh, T. Weber, G. P. van Wezel, B. Wilkinson, J. M. Willey, W. Wohlleben, G. D. Wright, N. Ziemert, C. Zhang, S. B. Zotchev, R. Breitling, E. Takano and F. O. Glockner, Nat. Chem. Biol., 2015, 11, 625-631. 